Illinois State University

ISU ReD: Research and eData

Theses and Dissertations

7-9-2021

\title{
A Thematic Analysis of Parenting Experiences of Women in Prison
}

Pious Dananai Maedzenge

Illinois State University, pdanmae1@gmail.com

Follow this and additional works at: https://ir.library.illinoisstate.edu/etd

\section{Recommended Citation}

Maedzenge, Pious Dananai, "A Thematic Analysis of Parenting Experiences of Women in Prison" (2021). Theses and Dissertations. 1452.

https://ir.library.illinoisstate.edu/etd/1452

This Thesis is brought to you for free and open access by ISU ReD: Research and eData. It has been accepted for inclusion in Theses and Dissertations by an authorized administrator of ISU ReD: Research and eData. For more information, please contact ISUReD@ilstu.edu. 


\section{A THEMATIC ANALYSIS OF PARENTING EXPERIENCES OF WOMEN IN PRISON}

\section{PIOUS DANANAI MAEDZENGE}

\section{Pages}

Given the increased representation of women in prisons, several collateral consequences have followed One of such consequences includes, but is not limited to, the effect that incarceration has on incarcerated mothers given that, in most instances, they are the primary caregivers of their children. Using Braun and Clarke's (2006; 2019) reflexive thematic analysis approach and secondary analysis of qualitative data, this study examines parenting experiences of women incarcerated in a Midwestern correctional center. Additionally, the researcher is interested in knowing the ways in which background experiences (i.e. sexual and physical abuse, drug dependency, and broken homes) shape women's experiences of mothering, the effect of incarceration on their children, and plans for returning home. Although there is growing literature examining justice-involved mothers, little is known about their parenting experiences and coping mechanisms. Results from this study will contribute to the body of literature by enhancing understanding of how incarceration shapes parenting and facilitates or presents barriers to mother-child relationships.

KEYWORDS: mothering; incarceration; parenting; prison; children; drugs; intersectionality 
PIOUS DANANAI MAEDZENGE

A Thesis Submitted in Partial

Fulfillment of the Requirements

for the Degree of

MASTER OF SCIENCE

Department of Criminal Justice Sciences

ILLINOIS STATE UNIVERSITY

2021 
(C) 2021 Pious Dananai Maedzenge 


\section{A THEMATIC ANALYSIS OF PARENTING EXPERIENCES OF WOMEN IN PRISON}

PIOUS DANANAI MAEDZENGE

COMMITTEE MEMBERS:

Dawn Beichner, Chair

Jessie Krienert

Mijin Kim 


\section{ACKNOWLEDGMENTS}

As a devout believer, foremost I would like to thank God the Almighty for allowing me this opportunity to study in the United States. As the giver of life and health, it would not have been possible for me to successfully complete my study program without His blessing and Sovereign Will. On that note, I do not take that for granted.

To the Department of Criminal Justice Sciences (CJS) and its awesome staff, I greatly humbled by your splendid support which saw me through the entire process of writing my thesis. Through your support, I found strength to persevere - even during the scourge of COVID-19, coupled with my being far away from home - up to this point. For that, I am greatly indebted and appreciative of your support.

To the Chair of my Committee and the current CJS Graduate Advisor, Professor Dawn BEICHNER, all I can say is thank you for your commitment to my academic success. I appreciate your genuine care for students in the Department, particularly for us international students who may be trying to strike a balance between settling in and perform our best in class. Through your guidance and supervision - both as my assistantship and thesis supervisor - I have reached this greatest point in my academic journey. As such, I do not take this for granted and will not cease to pray for you.

To the Co-Chairs of my Committee, Dr. MIJIN KIM and Dr. JESSIE KRIENERT I am grateful for your willingness to serve on the committee to which you committed one of the most important resource given you busy schedules - TIME. Your feedback, challenge and support were great contributions and were invaluable in helping me to come up with the final version of this work. Again, I do not take this for granted. 
To my host parents, Kevin and Janet MOHRMAN, I would like to thank you for being there in my greatest moment of need. For that, I believe the good Lord will recompense you in due season. It was my host mom, Janet, who convinced me to pursue a thesis instead of a Culminated Research Experience (i.e., which I perceived to be an easy option), and it has greatly paid me at the end. For that, I thank her a lot. At this point, I do not forget the HEARTLAND COMMUNITY CHURCH, where my host parents fellowship, for their love and support which has seen me reach this milestone.

To my American friends, Jacob (Jake) FOSTER, Alena HARM, William FALTYN, Jacob COOK, and Brenda JUHNKE-STEELE, I would like to thank you for your support which included teaching me the American lingo and making me feel at home. For that, I am forever grateful. I would also like to thank my Nigerian friend Maina Ibn MOHAMMED and Sailey ROMERO for their love and support and meaningful insights into my thesis project. That is greatly appreciated. Also, I would like to thank my Zimbabwean friends, the Inner Circle Bothwell PIASON, Aleaster MASIYAKURIMA, Givemore FANA, Lisa MHARI-FANA, and Tinashe SHILLINE - who supported me through. Additionally, I would like to thank other three Zimbabwean friends domiciled in the United States and South Africa - Nigel JAMES, Praise MAPHOSA, Chris MAZIVANHANGA, and Sharlom DAMBENI - for their love and support, which I do not take for granted. Not forgetting Advocate Claudius NHEMWA, who supported and sponsored my travel.

To my beloved family, I could not go forth without your direction and blessings beginning at the early age. From mom, sisters, brothers, and others I learned the true meaning of life and, by extension, the importance of education. At this point, I would like to thank my beloved wife - Ileen CHISVO-MAEDZENGE - who stood with me through thick and thin to 
see me achieve this milestone. Not forgetting my lovely son - Vladimir Amani MAEDZENGE who thinks I am a superhero in everything, that kept me going.

P.D.M. 


\section{CONTENTS}

Page

ACKNOWLEDGMENTS

TABLES Vii

FIGURES Viii

CHAPTER I: INTRODUCTION 1

Overrepresentation of the Incarcerated Minorities 1

Women in Prison $\quad 3$

$\begin{array}{ll}\text { Incarcerated Mothers } & 5\end{array}$

$\begin{array}{ll}\text { Children of Incarcerated Women } & 7\end{array}$

$\begin{array}{ll}\text { Problem Statement } & 7\end{array}$

$\begin{array}{ll}\text { Research Question } & 10\end{array}$

CHAPTER II: LITERATURE REVIEW 12

$\begin{array}{ll}\text { Incarcerated Women Trends } & 15\end{array}$

$\begin{array}{ll}\text { Scope of the Problem } & 17\end{array}$

$\begin{array}{ll}\text { Past Trauma and Abuse } & 18\end{array}$

$\begin{array}{ll}\text { Substance Issues } & 21\end{array}$

$\begin{array}{ll}\text { Mental Health } & 23\end{array}$

The Human Rights Framework: Bangkok Rules 25

$\begin{array}{ll}\text { Parenting and Prison } & 29\end{array}$

$\begin{array}{ll}\text { Pregnancy and Prison } & 32\end{array}$

Coping Strategies of Justice-Involved Mothers and Pregnant Women 36

$\begin{array}{ll}\text { The Effects of Incarceration on Children } & 41\end{array}$ 
1. Intersectionality 49

2. Pathways $\quad 50$

3. Attachment theory 53

Relevance of the Theories to Current Study $\quad 54$

$\begin{array}{ll}\text { CHAPTER III: METHODS } & 56\end{array}$

$\begin{array}{ll}\text { Current Focus } & 56\end{array}$

$\begin{array}{ll}\text { Sample } & 57\end{array}$

$\begin{array}{ll}\text { Data } & 58\end{array}$

$\begin{array}{lr}\text { Analysis Strategy } & 59\end{array}$

$\begin{array}{ll}\text { Hypothesis } & 62\end{array}$

$\begin{array}{ll}\text { IRB Concerns } & 62\end{array}$

$\begin{array}{ll}\text { CHAPTER IV: FINDINGS } & 63\end{array}$

Description of Interview Sample $\quad 64$

$\begin{array}{ll}\text { Qualitative Analysis } & 67\end{array}$

$\begin{array}{ll}\text { Theme 1. Mothering } & 69\end{array}$

$\begin{array}{ll}\text { Expectations of Motherhood } & 70\end{array}$

$\begin{array}{ll}\text { Pain of Separation } & 72\end{array}$

$\begin{array}{ll}\text { Parenting Style } & 74\end{array}$

$\begin{array}{ll}\text { Theme 2. Visitations } & 75\end{array}$

$\begin{array}{ll}\text { Travelling Distance } & 76\end{array}$

$\begin{array}{ll}\text { Children as Proxies of Intimate Partner Battles } & 77\end{array}$ 
$\begin{array}{ll}\text { Theme 3. Fears } & 81\end{array}$

$\begin{array}{ll}\text { Child wellbeing } & 81\end{array}$

$\begin{array}{ll}\text { State Surveillance } & 83\end{array}$

$\begin{array}{ll}\text { Recovering Mothering } & 84\end{array}$

$\begin{array}{ll}\text { Theme 4. Resilience } & 85\end{array}$

$\begin{array}{ll}\text { Coping Strategies } & 86\end{array}$

$\begin{array}{ll}\text { Desire for Self-Improvement } & 87\end{array}$

Children as Motivation $\quad 89$

$\begin{array}{ll}\text { Summary of Findings } & 90\end{array}$

CHAPTER V: DISCUSSION

$\begin{array}{ll}\text { Overlaps with Prior Studies } & 92\end{array}$

$\begin{array}{ll}\text { Emerging Issues } & 95\end{array}$

Relevance to Theory $\quad 96$

$\begin{array}{ll}\text { Strengths and Limitations } & 98\end{array}$

$\begin{array}{ll}\text { A Call to Action } & 99\end{array}$

$\begin{array}{ll}\text { Recommendations for Future Research } & 100\end{array}$

$\begin{array}{ll}\text { REFERENCES } & 101\end{array}$

APPENDIX: ORIGINAL RESEARCH QUESTIONS FROM DR. BEICHNER'S STUDY 121 


\section{TABLES}

Table

Page

1. Demographic Data 65

2. Total Number of Children 66

3. Conviction Charges

66 


\section{FIGURES}

Figure $\quad$ Page

$\begin{array}{lr}\text { 1. Mind Map } & 69\end{array}$ 


\section{CHAPTER I: INTRODUCTION}

While the global prison population is slightly over 10 million, about half of all prisoners are from the United States of America (USA), Russia, or China (Lee, 2015). The United States holds only $5 \%$ of the world's population, but $25 \%$ (over two million) of the world's prisoners (Lee 2015; World Prison Brief, 2021). These carceral statistics point to a serious problem of mass incarceration in the U.S.A. Over the last forty years, due in large part to the war on drugs and a raft of other punitive policies like the three strikes law, mandatory minimum sentences, and other policing strategies that focused on smaller crimes, incarceration rates are surging (Beichner \& Hagemann, 2016; Todd \& Frost, 2014). This vindictive approach by the U.S. criminal justice system to those in conflict with the law has left a trail of collateral consequences in the lives of individuals, communities, and the nation at large. Todd and Frost (2014) referred to this era (dating back to the last 40 years), as the "grand social experiment" or more aptly as “the punishment imperative" - one of America's darkest periods in carceral history.

\section{Overrepresentation of the Incarcerated Minorities}

In the U.S.A., mass incarceration is further exacerbated by the overrepresentation of those from 'minoritized' communities, particularly those from Black ${ }^{1}$ neighborhoods.

Unfortunately, the war on drugs has combined with socio-economic disparities, such as poverty rates, to produce incarceration rates that are extraordinarily higher for black men in America (Statista Research Department, 2020). At year-end 2019, according to the Bureau of Justice Statistics, there were 1,096 black prisoners per 100,000 black residents, 525 Hispanic prisoners

\footnotetext{
${ }^{1}$ For this study, the term Black is used as an inclusive term to refer to people with brown or black skin who have faced discrimination for their skin color. The term African American was deliberately excluded to avoid the unintended exclusion of those Black people who may not necessarily be African American or have African origin, e.g. those from Haiti.
} 
per 100,000 Hispanic residents, and 214 white prisoners per 100,000 white residents in the United States (Carson, 2020). Compared to their White counterparts, Black men are six times as likely to be incarcerated while, on the other hand, Latinx men are almost three times as likely (The Sentencing Project, 2020). As of 2018, approximately $47 \%$ of the federal prison population was incarcerated for drug offenses (The Sentencing Project, 2020). Though women are less likely to be arrested in their lifetime compared to men (i.e., 1 in 9 men of all men vs. 1 in 56 women of all women) (The Sentencing Project, 2020), there has been a disproportionate racial impact on the relationship between gender and incarceration (Gurusami, 2019; Williams, Spencer \& Wilson, 2020). For instance, while White women have a lifetime likelihood of incarceration of 1 in 111 (and 1 in 45 for Latina women), Black women - on the other hand have a likelihood of 1 in 18 (The Sentencing Project, 2020). Given this, it is impossible to study parenting experiences of incarcerated mothers and exclude how intersectional forms of marginalization - race, gender, and class - impact mothering.

Intersectionality Theory was originally posited by Crenshaw (1989) as a framework to explain how social identities, at both the micro and macro levels, overlap and create unique experiences for women (Beichner \& Hagemann, 2016; Crenshaw, 1991). In short, the theory explains that these social identities are not stand-alone - they are often interdependent and not mutually exclusive. Crenshaw (1991) argues that identity categories such as gender and race (among many) are oftentimes the vestiges of bias and domination. Intrinsically, these are the negative frameworks through which social power justifies its exclusion or marginalization of those who are (perceived to be) different (Audi, Santiago \& Andrade, 2016; Crenshaw, 1991). To put this into the context of the current study, the effects of this notion of 'othering' are disproportionately felt across racial categories - with (incarcerated) black women receiving the 
worst effects. For example, Gurusami (2019) posits that because Black women are disproportionately incarcerated for drug charges (and often poor), oftentimes, their children enter foster care and Family Court under charges of abuse and neglect. This disproportionately impacts their retention of parental rights compared to other races, as the intersectionality amplifies the likelihood of the termination of parental rights (Williams et al., 2020). As a result, it holds for one to argue that the war on drugs has become a war on Black women by proxy (Williams et al., 2020).

Another intersectional factor to consider is education. As already established in the cited literature, Black women are likely to be poor and are overrepresented in the incarceration statistics compared to their counterparts. This means they are more likely to miss out on education opportunities in terms of resources (poor) and time (most of it is spent in incarceration). When examining the relationship between education and recidivism, research is consistent - the higher the education level, the less likely the person is to be rearrested or reimprisoned (Clark 2016; McGinnis, 2018). Bearing this in mind, Intersectionality Theory is the lens through which the researcher remains wary of the multiple forms of oppression that incarcerated mothers face and navigate. In short, this is a crucial consideration to the study's inquisition on the consequences of incarceration on women and their families.

\section{Women in Prison}

Nearly 700,000 women are incarcerated worldwide, accounting for $7 \%$ of the global prison population (Ranjit, Azbel, Krishnan, Altice \& Meyer, 2019). According to the World Prison Brief (2021), over 30\% (or 207,190 to be precise) of these female prisoners were from the United States as of 2016. At the national level, female prisoners account for $9.8 \%$ of the total 
prison population, translating to a female prison population rate of $64 / 100,000$ of the national population (World Prison Brief, 2021).

While mass incarceration has affected both men and women (Williams et al., 2020) over the past 40 years, growth trends in the U.S.A indicate that women are the most rapidly growing (Ramirez, 2016), yet least violent segment of the prison population (The Sentencing Project, 2020)). Nationally, women's rates of incarceration rose by more than 700\% from 1980 to 2014 (Arditti, 2015; Gurusami, 2019; Ramirez, 2016). Growth trends indicate that women are now being incarcerated at approximately 1.5 times the rate of men (Arditti, 2015), their recidivism rates are similarly troubling (Ramirez, 2016). Approximately, one-quarter of women released from prison fail within six months (i.e., have an arrest for a new crime), one-third fail within a year, and two-thirds fail (68.1\%) within five years of release (Durose et al., 2016). Albeit, women's conflict with the law is typically for less serious and nonviolent offenses like drug crimes (Beichner \& Hagemann, 2016; Gurusami, 2019; Williams et al., 2020). The concept of intersectionality (i.e. the interplay of race, gender, class, and age, etc.) translates into the notion of correctional overrepresentation of the minority. Studies are replete with findings substantiating the long-held view that racial minorities in general, are more harshly sentenced compared to White peers (Gurusami, 2019; Williams et al., 2020). For instance, two-thirds of women parolees are women of color, and nearly half are convicted of drug crimes (Ramirez, 2016). Hence, it holds to argue that 'minoritized' women of color (including incarcerated mothers) in conflict with the law will end up having multiple burdens of disadvantage. Overall, concerning race and ethnicity, Black and American Indian women are markedly overrepresented in the U.S.A. prisons and jails. Women inmates are 53\% White, 29\% Black, 14\% Hispanic, 2.5\% 
American Indian and Alaskan Native, 0.9\% Asian, and 0.4\% Native Hawaiian and Pacific Islander (Kajstura, 2019).

\section{Incarcerated Mothers}

As women's representation in prisons grows, so does the number of incarcerated mothers (Beichner \& Rabe-Hemp, 2014; Zhao, Cepeda, Chou \& Valdez, 2020). Nearly 80\% of incarcerated women are mothers (Kajstura, 2019; Williams et al., 2020; Zhao et al., 2020), with most having children who are minors (Schlafer, 2019). Most incarcerated mothers live with the threat of having their children placed in foster care (Williams et al., 2020; Zhao et al., 2020) with about 400,000 children in foster care (AdoptUSKids, 2021). Though more than half of the children in foster care will be reunified with their parents or primary caregivers, approximately 120,000 of the 400,000 children in foster care are waiting to be adopted, many of whom will be adopted by their foster parents (AdoptUSKids, 2021). Thus, as mentioned earlier, there are collateral consequences associated with mass incarceration, one of which is the effect incarceration has on family ties, particularly for mothers. Given that women are the primary caregivers (Beichner \& Rabe-Hemp, 2014; Ramirez, 2016; Williams et al., 2020), it is important “... to better understand the challenges that women face in achieving sustainable financial, emotional, and familial ties (before and) after release" (Hunter, 2011, p. 198). Family provides emotional support upon release, an immediate place to live, motivation to succeed, and financial assistance (Beichner \& Hagemann, 2016; Zhao et al., 2020). In addition, people with strong family support have lower levels of recidivism rates (Zhao et al., 2020). However, due to stress and stigma - mainly related to the perceived contradictions between criminal behavior and maternal role expectations - formerly incarcerated mothers may have higher recidivism rates 
compared to their nonmother counterparts. In short, incarceration shatters family ties (Ramirez, 2016).

As reported by the Statista Research Department (2020) Black women are overrepresented among (formerly) imprisoned women (Duffin, 2020), it follows that they are also disproportionately represented among the formerly incarcerated mothers. Thus, according to Gurusami (2019), they often face disproportionate challenges in resuming their parenting roles post-incarceration. While all formerly incarcerated mothers face these challenges, for Black women, these mothering difficulties are often amplified by structural challenges which includes the erosion of social support, the demands of post-release supervision, and contention with multiple sources of surveillance (Gurusami, 2019). Reiterating this point, Williams and others lamented that Black women face complex surveillance from the state that similarly situated counterparts can escape (Williams et al., 2020). According to Gurusami (2019), Black mothers are juxtaposed or framed through the binary 'good/bad mother' as a manifestation of controlling images whose roots can be traced to the slavery era. A controlling image can be understood as a series of contradicting, objectifying, one-dimensional master stereotypes that make "forms of social injustice appear to be natural, normal, and inevitable parts of everyday life" (Gurusami, 2019, p. 130). In short, these stereotypes serve as the justification for "othering" and the reference point by which a dominant normative group is constructed.

In the case of (formerly) incarcerated Black mothers, given that controlling images are relational, they require a normative group to be defined against (Gurusami, 2020). In this vein, Black motherhood stands in opposition to normative white femininity's "good mother" - to which the controlling image of "bad mother" (e.g. the Welfare Queen controlling image, i.e., lazy, drug-addicted, hypersexual, and careless parents) is subtly induced to justify Black 
women's maternal inadequacy (Gurusami, 2020). Given this, it holds to argue that Black incarcerated mothers are likely to lose parental rights compared to their White peers. Therefore, due to this intersectionality, the negative effects of parental incarceration are unevenly felt across racial categories.

\section{Children of Incarcerated Women}

About $75 \%$ of incarcerated women in the U.S.A have at least one child below the age of 18 that they separated from due to incarceration; while $4 \%$ of incarcerated women give birth in prison (ARRWIP, 2021). Though children of incarcerated men are likely to continue living with their mothers, children of incarcerated women are less likely to have stable living arrangements (Rossiter et al, 2015). Earlier on Beichner and Rabe-Hemp (2014) had noted the same, that when mothers are incarcerated, children are more likely to reside with relatives (i.e., grandparents, aunts) or foster parents. However, oftentimes mothers are incarcerated far from their children, which makes it difficult for the new caregivers to arrange regular visits to the prison - thus, further straining the mother-child bond (Beichner \& Rabe-Hemp, 2014). Since most of these women were primary caretakers of their children prior to incarceration, both the women and their children risk being disjointed forever - which can do irreversible damage to children who committed no crime (Williams et al., 2020). Thus, research has shown that children of incarcerated mothers face long-term traumas surpassing even that of their mothers (Beichner \& Hagemann, 2016; Gurusami, 2019; Williams et al., 2020).

\section{Problem Statement}

While it is unpleasant for anyone to be incarcerated, the burden multiplies when one is a mother. As mentioned above, children of incarcerated men often remain living with their mothers, which is different from children of incarcerated mothers who are likely to have unstable 
living arrangements. The effect is even worse when the inmate mother is from a 'minoritized' race, young, and of low socioeconomic class which may exacerbate impacts of their parenting experiences in terms of emotional and financial support to their children (Gurusami, 2019; Williams et al., 2020).

Apart from the negative effects of carcerality on family ties posed by creating physical barriers to mother-child bond, legislation has had its contribution in exacerbating this separation. An example of such legislation is the Adoption and Safe Families Act of 1997, which made it easy for parents to lose parental rights (Williams et al., 2020). Due to the intersectional identities discussed previously, since the introduction of this legislation, there has been a disproportionate distribution of the Act's detrimental impacts primarily in terms of gender and race (Williams, Spencer \& Wilson, 2020). For example, through this Act, nearly $70 \%$ of all incarcerated mothers - who are disproportionately African American - either had parental rights terminated, children detained, or reunification requirements imposed (Williams et al., 2020). This has impacted women's custody of their children.

The current secondary study sets out to examine the parenting experiences of incarcerated women who were participating in a family reunification program in a Midwestern prison. By virtue of program enrollment, they have maintained custody of their children throughout their incarceration - which then questions the relevance of the Adoption and Safe Families Act, cited above, to this program. Though this piece of legislation may not be directly connected to mothers under study (given that they had maintained custody of their children throughout their incarceration, as such, they obviously had not lost parental rights), the Act is important to this study in that it shows how criminalization of mothering has existed for some time now. Please note, given that through this legislation it is difficult to claim back parental rights once they are 
lost, this might as well shape or influence parenting experiences of incarcerated mothers as they try to circumvent such a possibility. That is how this piece of legislation relates to the current study.

Using Braun and Clarke's (2006; 2018) reflexive thematic analysis (TA) approach, this study examines the parenting experiences and coping mechanisms for women incarcerated in a Midwestern correctional center in the United States. Thematic analysis is a method for identifying themes and patterns of meaning across a dataset in relation to a research question (Braun \& Clarke, 2006, ). According to Clarke (2019a, 2019b), three broad approaches to TA predominate - coding reliability TA, codebook TA, and reflexive TA. For this study, reflexive TA was chosen because just like Grounded Theory (GT), it takes a data-driven approach and is theoretically flexible - meaning it can work well with any type of data and can be used within different frameworks, to answer quite different types of research questions (Clarke, 2017, 2018, 2019b). It suits questions related to people's experiences (e.g. What are the experiences of parenting from prison for women?); it suits questions related to understanding and representation (e.g. How do incarcerated mothers cope with the stress of separation from their children?) and; it also suits questions related to the construction of meaning (e.g. How is mothering conceptualized among different racial categories of incarcerated women?). Thus, reflexive TA differs from the other two approaches both in terms of underlying philosophy and procedures for theme development. For theme development, reflexive TA involves a six-phase process for conducting analysis - familiarisation phase, coding phase, generating initial themes, reviewing themes, defining and naming themes, and writing up (Clarke, 2018).

This study is a secondary analysis of qualitative data collected through in-depth interviews of 42 incarcerated mothers (who were participating in a family reunification program) 
in a Midwestern correctional center. The data were collected by Dr. Dawn Beichner, a Criminal Justice Sciences professor at Illinois State University. Using the stated reflexive TA approach, the researcher will be focusing the analysis on the women's responses to the section of the interview that focused on their parenting experiences. In this quest, the current study seeks to qualitatively understand three things about family ties - connectedness to family, role of family, and incarceration's effect on families. According to Clarke (2018), themes can either be the analytic input or output. If themes are developed early on and guide coding, they are the analytic input of the study; if they are developed later and represent the outcome of the coding, they are the analytic output. Relating to this study, the goal is to come up with themes being the analytic output of the following research question.

\section{Research Question}

Prior studies revealed a plethora of background experiences that each individual mother may encounter in her lifespan - some studies refer to them as "pathways to criminality (Beichner \& Hagemann, 2016; Beichner \& Rabe-Hemp, 2014; Ramirez, 2016). These experiences may include but are not limited to, sexual and physical abuse, drug dependency, and broken homes. In addition, these background experiences might be a precursor to or have a bearing on the relationship between mother and child. In short, the researcher hypothesizes that these experiences may provide some 'tell-tale' signs of how those who lived these experiences 'mothered' their children even prior to incarceration. Hence, from this standpoint, mothers may perceive relationship effects that were not covered in the existing literature. There is need for an in-depth narrative, through examination and secondary analysis (of qualitatively collected data), of 'mothering' experiences while incarcerated. Given this, using Braun and Clarke's (2006; 2018) reflexive thematic analysis approach stated above, the researcher seeks to analyze the data, 
and identify themes grounded in the data that explain (or at least relate to) these mothering experiences. Though other studies may have explored the concept of carceral mothering from a race perspective in particular, the current study looks at it in terms of parenting, mothering, and the experiences these entail in a restrictive environment.

The study examines parenting experiences before and during incarceration, to which the overarching research question is: What are the parenting experiences of incarcerated women? Guided by the interview guide, to capture both periods (i.e., pre- and post-incarceration experiences), this broad question is broken down into three objectives: (a) explore participants' parenting experiences pre-incarceration, (b) develop an understanding of respondents' perceptions of the quality of the relationships with their child(ren), and (c) understand the respondents' perceptions of the effects of incarceration on their child(ren). 


\section{CHAPTER II: LITERATURE REVIEW}

Three experiences - trauma, substance abuse, and mental health issues - shape females' pathway into offending, and these "triple threats"2 are often co-occurring (Arditti \& Few, 2008; Garcia-Hallett, 2019a; Garcia, 2017). Thus, justice-involved mothers often have histories of trauma (Garcia, 2017), and drug or alcohol abuse (Garcia-Hallett, 2019a, 2019b) - a combination of factors that weakens mother-child relationships (Garcia, 2017) even prior to incarceration. The 'triple threat' impacts mothers' involvement in a child's life both psychologically and physically (Arditti \& Few, 2008). In fact, Siegel (2011) argues, pre-incarceration maternal involvement shapes mother-child relationships both during and after a mothers' imprisonment. Typically, children with mothers who are battling a triple threat of life challenges may experience long periods away from their mothers (Siegel, 2011), thus with these sporadic disengagements, children may find themselves in the care of others (Garcia, 2017). However, the intersection of motherhood and prison contradicts perceptions of criminality and femininity (Garcia, 2017), which is often followed by the stigmatizing label of "bad mother" (Garcia-Hallett, 2019a) - a tag these women may perceive to be worse than being a "criminal" (Byrne \& Trew, 2008).

Given that parenting from behind bars is a completely unique experience from that of parenting from outside or in the community, the experience of doing so from prison is a crucial element to the inmate's wellbeing and the adjustment of the family to incarceration (CarreteroTrigo, Carcedo \& Fernandez-Rouco, 2021). Once in prison, financial, physical, and emotional

\footnotetext{
${ }^{2}$ Scholars use this phrase in relation to the three factors - trauma, substance abuse, and mental health issues typically explaining the pathways that women and girls follow into crime which are different from those followed by men and boys ((Arditti \& Few, 2008; Garcia-Hallett, 2019a; Garcia, 2017). Unlike men and boys, women and girls are likely to have histories of abuse and victimization, which may drive them into substance abuse as a copying mechanism. However, apart from drug abuse being a crime itself, these women are likely to engage economicrelated crimes to fund their addiction (Garcia-Hallett, 2019a, 2019b), something which heightens their chances of being incarcerated and separated from their children..
} 
changes occur, which affects the incarcerated person's family relationships and participation in their children's lives (Carretero-Trigo et al., 2021), even - at times - during the preliminary stages of child development (Fochi, 2020) which may forever shatter the mother-child bond in the case of maternal incarceration. Being outside the home and the self-redefining that happens in the carceral environment, oftentimes, make the incarcerated parent feel anxious and inadequate in their parenting role (Carretero-Trigo et al., 2021).

Due to their primary caregiver role, Scott (2019) argues that incarcerated women face a tripartite burden of carceral motherhood to which, despite the constricting environment, they should find strategies to navigate: (1) mothering from prison (to children outside prison), (2) mothering in prison (to children inside prison), and (3) mothering after prison (parole). Taking, for instance, the first classification of carceral motherhood - mothering from prison - this situation may require the incarcerated mother to find alternative caregivers (Scott, 2019) which, in most cases, are family members (Beichner \& Hageman, 2016) who are likely to be already poor for the extra-burden. Therefore, it holds for one to argue that women in this classification are to be concerned about their child(ren)'s wellbeing as compared to the other two classifications.

This chapter of the study aims to provide a comprehensive overview and synthesis of what prior research has found on the topic of carceral parenting experiences of women. However, the study's focus on incarcerated women is not to suggest that men are not possible primary caretakers for their children or to underestimate the effects of paternal deprivation to the child, rather, this is meant to reiterate the accepted societal norm. The social norm - as is supported by statistics (Glaze \& Maruschak, 2010; Ramirez, 2016) - being, women are more likely (or are expected to) to play a significant role in childcare than men (Granja, Cunha \& 
Machado, 2015). Having said this, several studies have been conducted on incarcerated parents, drawing from both qualitative and quantitative approaches, focusing on both women and men as parents (Arditti, 2015; Beichner \& Rabe-Hemp, 2014; Garcia-Hallett, 2019a, 2019b; Gurusami, 2019; Scott, 2019; Williams et al., 2020).

Organizationally, this chapter follows a deductive approach (from general to specific). It begins by providing the global trends of incarcerated women which are then narrowed down to the U.S.A., capturing both the carceral statistics and the ensuing racial disparities of incarcerated women, at the national level. This section is followed by the scope of the problem, a section that tries to highlight the magnitude of the problem in relation to children impacted by parental incarceration, particularly those with incarcerated mothers. Thus, in this section, emphasis is placed on the fact that children who are likely to experience parental incarceration, are the ones that were already vulnerable even long before their parents were incarcerated.

Given this, the subsequent three sections discuss the "triple threats" - past trauma and abuse, substance issues, and mental health - bedeviling incarcerated women. The reason these three threats are 'pooled' together and discussed successively is that they are interrelated and cooccurring, thus inseparable. In short, they are not mutually exclusive. After this, the researcher discusses the Bangkok Rules as a human rights framework that lays groundwork for the ensuing two overlapping sections - parenting from prison, and pregnancy and prison. These sections discuss the challenges that incarcerated (and expecting) mothers face in conducting 'motherwork' in a restricted carceral environment. Closely linked to these challenges are coping mechanisms that these (expecting) mothers invent to navigate these barriers. As such, after these two sections, the ensuing section explores the coping mechanisms these women employ to circumvent these challenges. 
Lastly, children are often at the receiving end of parental incarceration whether they are with their parents (i.e., mothering in prison) in prison or outside prison (i.e., mothering from prison). Collaterally, children of incarcerated parents suffer for crimes they know nothing of, which has led scholars to argue that this is some form penal extension. Thus, this section focuses on the effects of incarceration on children. A theoretical framework - attachment, intersectionality, pathways, and disability theories - that guides this study is also provided as the last section of this chapter.

\section{Incarcerated Women Trends}

Typically, justice-involved women - especially those in prisons and jails - are often neglected, unseen, and overlooked (Cobbina, 2021). Given that globally women and girls are being incarcerated at historic rates compared to men and boys, this is surprising. According to Walmsley (2018), more than 714, 000 women and girls are incarcerated worldwide. Even though this figure translates to only $7 \%$ of the world prison population, it should be noted that between 2000 and 2017 the number of women and girls increased by a whopping 53\% globally

(Walmsley, 2018). In contrast, during the same period, UN figures indicate that the global population rose by only $21 \%$ (Cobbina, 2021). Therefore, this trend can neither be explained by global population growth nor by the number of people in prison, as global male prison population rose by $20 \%$ during that period (Cobbina, 2021). Given this, it is plausible to argue that crime - and the ensuing responses to it - is gendered. It is a pattern that holds true, worldwide.

In the U.S.A. racial and/or ethnic disparities in incarceration remain substantial. Black Americans and Latinos represent nearly $60 \%$ of the prison population (Nellis, 2016), despite that these two racial groups constitute $13.4 \%$ and $18.5 \%$ of the U.S.A. population (U.S. Census 
Bureau, 2020), respectively. Compared to their White and Latina counterparts, Black women are incarcerated at dramatically higher rates (Cobbina, 2021; Nellis, 2016). To reiterate what was brought up in the introduction chapter, while White women have a lifetime likelihood of arrest of 1 in 111 (and 1 in 45 for Latina women), Black women - on the other hand - have a likelihood of 1 in 18 (The Sentencing Project, 2020). Given this, it holds to argue that crime - and the subsequent responses to it - apart from being gendered, may and can be racialized.

Compared to men, women are often incarcerated for nonviolent offenses, typically those involving drug and property-related charges (Cobbina, 2021). This is further exacerbated by the fact that incarcerated women are likely to have been victims of violence prior to their contact with the correctional system (Cobbina, 2021; Verona, Murphy \& Javdani, 2016). Typically, these women exhibit mental health problems (Beichner \& Hagemann, 2016; Beichner \& RabeHamp, 2014) (i.e., according to The Marshall Project (2021), 66\% of women in prison reported having a history of a mental health disorder, which is about twice that of their men counterparts), are drug or alcohol dependent (Cobbina, 2021), are unemployed or economically marginalized (Morash, Kashy, Northcutt Bohmert, Cobbina \& Smith, 2015), and are mothers to one or more children (The Sentencing Project, 2020). Given this, one can reasonably argue that crime - and the succeeding responses to it - is not only gendered or racialized, but socioeconomic status may also be a risk factor. In short, literature shows that women follow distinct pathways into crime. Hence, given the distinct pathways, the ensuing worldwide increase in imprisonment rates over the past several decades has resulted in a growing number of children facing parental incarceration. 


\section{Scope of the Problem}

The rapid increase in incarceration in the past half a century has seen an unprecedented increase in the number of children exposed to parental incarceration in the U.S.A. (Turney \& Goodsell, 2018). According to the Bureau of Justice Statistics (2010), as from 1991 to 2007, the number of incarcerated mothers more than doubled (131\%). For this period, this finding reveals the rapid increase of mothers held in state and federal carceral facilities (up 122\%), compared to the number of fathers (up 76\%) (BJS, 2010). In short, Harris (2017) reports that while men make up the largest segment of the prison population, of the incarcerated women, more than $60 \%$ are mothers to children under the age of 18 years. Currently, $4 \%$ - or 2.6 million - of the population of children under the age of 18 in the U.S.A., have either a mother or father behind bars (Turney \& Goodsell, 2018). In addition, estimates from the National Survey of Children's Health between 2011 and 2012 revealed that $7 \%$ of children under the age of 18 had, at some point in their life, experienced parental incarceration (Turner \& Goodsell, 2018).

Given this, Turner and Goodsell (2017) argue, since children that are likely to experience parental incarceration are the ones who were already vulnerable long before their parents' incarceration, these inclinations are likely to increase inequalities among children. On that note, it is not surprising that several scholars have increasingly examined the intergenerational effects of incarceration. To sum it up, children with incarcerated mothers - particularly those from disadvantaged groups of society - face adverse social, health, and emotional circumstances, which exacerbates their vulnerability and inequalities (Rossiter et al., 2015). On the other hand, mothers held in carceral facilities face significant challenges in parenting their children, the experiences of such challenges which Rossiter and others (2015) aptly describe as "mothering at a distance." The fact that so many women are primary caregivers to dependent children is an 
intergenerational problem, as studies show that when a mother is incarcerated, the odds that her children, especially her daughters, will experience arrest, conviction, and incarceration as adults significantly increases (Burgess-Proctor et al., 2016).

This is not a minor problem, it is enormous. Arditti (2015) reports 64\% of mothers held in state prisons and $80 \%$ of mothers in federal prisons reported living with at least one of their children prior to incarceration. In addition, half of those mothers were living in a single-parent household (Arditti, 2015). Conversely, less than one in five incarcerated men are single parents (Jbara, 2012). In short, most female prisoners are mothers (Ramirez, 2016), and the steep increase in incarceration has been projected to impact more than one million American children (Arditti, 2015). On that note, the "triple threat" is discussed in detail below.

\section{Past Trauma and Abuse}

To reiterate, it is typical for justice-involved mothers to have histories of trauma (Garcia, 2017). In fact, when highlighting females and offending trajectories, Garcia-Hallett (2019a) and Cobbina (2021) state that most existing research found a correlation between female offending and life experiences of victimization. Oftentimes, female offenders report physical, sexual, and psychological abuse both in their childhood and adulthood (Cobbina, 2021; Garcia-Hallett, 2019a; Payne, Gainey, \& Carey, 2005; Severson, Postmus, \& Berry, 2005). Statistically, compared with men and boys, justice-involved women and girls are two times more likely to experience physical abuse, three times more likely to live through emotional abuse, and eight times more likely to face sexual abuse (Garcia-Hallett, 2019a). Given this, Payne, and colleagues (2005) emphasized that these histories of maltreatment (physical, sexual, and emotional) experienced by women and girls, closely relates with their subsequent criminal histories. 
Using life history interviews, Gilfus (1992) concluded that females' childhood victimization led to running away, which then coincided with property crimes as they attempted to fend for themselves and substance use as a therapeutic remedy or coping mechanism. These findings are corroborated by Garcia-Hallett (2019a) almost three decades later when she reiterated that trauma (and abuse), as one factor of the "triple threat," shape females' pathway into offending. However, even so, these gendered individual risk factors underlying female offending need not be understood independent of the structural context like neoliberalism and patriarchy. Garcia-Hallett (2019a) argues that, in a society where neoliberalism ${ }^{3}$ and patriarchy converge, it is typical for women's offending trajectories to be uniquely shaped by criminalization of their very survival strategies to adverse life experiences and unfortunate circumstances.

For instance, in a neoliberal agenda, political strategies are influenced by market relations (e.g., prison privatization by corporations), thus there is a trade-off between welfare spending in favor of criminal justice spending (Garcia-Hallett, 2019a). As a result, Wacquant (2009) argues that neoliberalism profits from punishing the poor by housing them in carceral facilities to the benefit of private corporations. Given the patriarchal nature of society, neoliberal policies disproportionately affect women including women offenders, as women are placed on the lower rungs of both gender and society hierarchies. Inherent to these hierarchies, is the disproportionate burden of poverty, creating a "feminization of poverty" (Garcia-Hallett, 2019a) in which women are less likely to be employed full-time and, when employed, receive lower income (Roscigno \& Bobbitt-Zeher, 2007).

\footnotetext{
${ }^{3}$ Neoliberalism is "the extension of competitive markets into all areas of life, including the economy, politics, and society" (Springer, Birch, \& MacLeavy, 2016, p. 2).
} 
Yet, there is a correlation between women's financial independence and decreased victimization; conversely, women's vulnerability and marginalization are exacerbated when women's empowerment is dismantled (Mariachiara Di Cesare, 2014). Worldwide, physical and psychological violence against women is likely to be inflicted by an intimate partner, and up to $70 \%$ of women globally experience intimate partner violence (IPV) (WHO, 2013). Given that in a patriarchal society, women are more likely to rely on men for their upkeep, this puts them at greater risk of violence as leaving the toxic relationship might not be an option. If they manage to leave, given the systematic economic marginalization, they may lack resources for personal upkeep which may drive them into drug crimes (i.e., possession and sale) and money crimes (e.g., identity theft, shoplifting, burglary, and robbery) (Garcia-Hallett, 2019b). Please note, while patriarchy generates hierarchies that create vulnerabilities to physical and psychological violence for women, sexual abuse is another form of oppression embedded within power dynamics (Garcia-Hallett, 2019b).

While the preceding paragraphs used a generic approach to highlight the plight of women and trajectories into offending, those trajectories - like past trauma and abuse (Cobbina, 2021) can be disproportionately experienced across races (Garcia-Hallett, 2019a, 2019b). Women of color endure unique obstacles at the intersection of at least two marginalized labels - race and gender (Potter, 2013), as such, they are a double minority (Garcia-Hallett, 2019b). Given the social-structural context that continues to dehumanize women of color, particularly Black women, the carceral system is expected to tame them into "docile bodies" (Foucault, 1977) by imprisoning them (Garcia-Hallett, 2019b).

The dehumanization often extends to systemic economic marginalization, which leaves Black women (and other racial minorities) economically exposed and more vulnerable to 
violence (e.g., IPV) and trauma than their White counterparts (Garcia-Hallett, 2019b). In the U.S.A., while statistics indicate that 1 in 3 of all women (compared to 1 in 10 of all men) will experience domestic violence in their lifetime, Back women - more disturbingly - are 2.5 times more likely to be murdered by men than White women, with $56 \%$ of these homicides committed by a current or former intimate partner (Blackburn Center, 2020). Also, in the context of power dynamics, Black women are still portrayed as sexually available and are thus sexually objectified and subsequently victimized (Garcia-Hallett, 2019b) - an experience which might occur to them at stark numbers compared to women of other races. Overall, the literature shows that abuse, trauma, addiction, and lack of income often drive many women into crime, resulting in their contact with the criminal justice system (Cobbina, 2021). This leads us to the next sectionsubstance issues.

\section{Substance Issues}

In her chapter, "Motherhood and Social Exclusion: Narratives of Women in Prison in Ireland," Quinlan (2019) examined the varying degrees of social exclusion that incarcerated mothers experience based on several factors. These include substance abuse, social supports, and custody of their children (Byvelds, 2019; Quinlan, 2019). Drawing from thirty-three narratives, Quinlan (2019) found most of the women in prison, and consequently most of them mothers, were from poor and socially marginalized backgrounds. According to the 2018 St. Joseph Institute for Addiction report, though the relationship between poverty and addiction ought not to be misconstrued as causal, lower income people are slightly more likely to struggle with drug and alcohol abuse. Reiterating this point, Guinn (2020) argued that stressful conditions - like

poverty and cycles of oppression - that many socially marginalized families live in, are both 
direct and indirect contributors to family dynamics, substance use, incarcerations, as well as access to treatment options.

Apart from the relationship between poverty and addiction, studies have shown that there is also a relationship between victimization/traumatization and addiction. It is typical for victimizations and addiction to overlap and worsen (Beichner \& Rabe-Hemp, 2014), thereby impacting rehabilitation efforts of incarcerated women - most of whom are mothers. According to Rose and LeBel (2017), most incarcerated mothers of minor children (and women in general) share common pre-incarceration experiences like depression, anxiety, victimization, and trauma. Thus, starting from childhood through adulthood, most incarcerated women may have been exposed to trauma due to neglect, physical and/or sexual abuse, or intimate partner violence (Beichner \& Rabe-Hemp, 2014; Rose \& Lebel, 2017). As a result, to unconsciously deal with the original trauma, this early trauma manifests itself in repetitive adult behaviors (Beichner \& RabeHemp, 2014), which may include substance use. Therefore, given historical oppression and subsequent victimization of women, it is unsurprising that substance abuse is common among female offenders. According to Garcia-Hallett (2019a), approximately $60 \%$ of female inmates in state facilities report having drug abuse problems a month prior to their offense. In addition, about 50\% were using drugs, alcohol, or both at the time of their offense (Garcia-Hallett 2019a).

Reiterating the preceding point, Rodda and Beichner (2017) posited that due to their past or present experiences which - oftentimes - are marred with physical and sexual abuse, there is compelling evidence that women retreat to drugs as a coping mechanism for these lived traumas. As already mentioned, early victimization and traumatization not only shapes behaviors, but establishes habits that may be difficult to change in a lifetime (Rodda \& Beichner, 2017). Since most women in prison lacked protected, privileged, and insulated lives as children (Rodda \& 
Beichner, 2017), their carceral motherhood is likely to be impacted by these experiences as they are likely to face mental health issues in addition to substance use during their incarceration (Rose \& Lebel, 2017).

In short, both poverty and victimization may be construed as drivers of addiction in socially marginalized groups like women. Turning to substance use gives a temporal false bravado to face life situations to these victims of social structural exclusion and/or violence. One common theme among these two drivers is the notion of 'escapism,' primarily through substance use. However, the consequences are too much to bear as this may lead to incarceration and the ensuing stigmatized identities associated with both addiction and incarceration. In corroboration, Burch (2016) laments that, "against the current backdrop of extreme social and economic marginalization, stigma and discrimination, state surveillance and legal and bureaucratic barriers, it is not difficult to understand why "successful" (re)entry (of women coming home from prison) is the exception rather than the norm" (p. 15). Also, these consequences may have collateral effects beyond the immediate victim, to include loved ones who, in the case of incarcerated mothers, may be children.

\section{Mental Health}

Mental health issues are more common in women than men (Wilson, 2016). Yet, according to WHO (2015), the global percentage of maternal mental health prevention and promotion programs is only two percent. The effect is exacerbated by the fact that only one percent of the global health workforce works in mental health (WHO, 2015). Given the prevalence of mental health issues among women, it holds to argue that - compared to men women are the most affected by this global workforce shortage as it significantly diminishes their access to mental healthcare. As already established, the three experiences of trauma, 
substance abuse, and mental health issues are often co-occurring (Garcia-Hallett, 2019a) posing a "triple threat" that shape women and girls offending trajectories (Garcia, 2017). Justiceinvolved women and girls often have mental health issues with $36 \%$ of those in the U.S.A. reporting major bipolar, depressive, and posttraumatic stress disorders (Garcia-Hallett, 2019a).

However, even though the U.S.A. is the leading world incarcerator, with a per capita prison population of 639/100,000 compared to - for instance - Ghana (i.e., 43/100,000) (World Prison Brief, 2020), its number of psychiatrists and nurses working in the mental health sector is very little (WHO, 2020). As stated earlier, mental health issues are more common in women than men, particularly those women in prisons and jails. Yet, compared to Ghana whose female prison population constitutes only $1.3 \%$ of its national inmate population but has a mental health workforce rate of $7.7 / 100,000$; the U.S.A., on the other hand, with $9.8 \%$ of its prison population being female, has a paltry mental health workforce rate of 4.3/100,000 (WHO, 2020; World Prison Brief, 2020).

Given the above, Beichner and Rabe-Hemp (2014) note that rehabilitation efforts pay little to no attention to the gendered pathways by which women travel to prison. Thereby, creating a gap in ensuring the availability of affordable substance abuse and mental health treatment programs to incarcerated or re-entering women, most of whom are mothers (Beichner \& Rabe-Hemp, 2014). Noting the primary caregiving role of most women, their untreated addiction and mental illness may have collateral impacts in the lives of their loved ones like their children (Beichner \& Rabe-Hemp, 2014). Also, considering the historical economic marginalization of women, these mothers are less likely than fathers to be employed (Beichner \& Rabe-Hemp, 2014) - an intersection of poverty and gender leaves little room for access to treatment for women. For example, to emphasize this issue of access to treatment, Rodda and 
Beichner (2017) found that only $38 \%$ of the 278 women who participated in their study reported seeking treatment despite the prevalence of mental health issues in their study sample.

In summary, the bulk of crimes women commit are monetary and drug crimes. While the former is largely attributed to economic marginalization women experience, the latter - on the other hand - often represent adoptive coping mechanisms to life challenges or negative relationships (Garcia-Hallett, 2019a, 2019b; Garcia, 2017). Thus, studies have consistently demonstrated that women's criminal activity is either a means to get drugs or the money to get drugs (Garcia-Hallett, 2019a; Garcia, 2017; Mumola, 2000). Given the co-dependence and cooccurrence of the "triple threats" - victimization/trauma, substance abuse, and mental health issues - these factors can be conceived as a cycle (Quinlan, 2019). Although there is much overlap between these three pathways, each was discussed individually.

The following human rights section lays the groundwork for the discussion of incarcerated mothers and pregnant women as well as the affected children. This is organizationally structured after Reichel's (2015) approach. Reichel (2015), stating the importance of a descriptive approach when studying comparative criminal justice, said, "A description of how something should work or operate provides the necessary basis for analysis and repair." As such, it is necessary to understand how something is supposed to work before we can even begin to discern how it varies from the model (Reichel, 2015). On that note, this framework was given as a reference point in relation to the lived experience of incarcerated mothers and pregnant women vis-à-vis the internationally expected standards.

\section{The Human Rights Framework: Bangkok Rules}

According to Crewe (2020) the applicability of human rights to all individuals including babies - who live in prison, is unquestionable. Thus, the Universal Declaration of 
Human Rights (1948) states that the foundation of freedom, justice and peace is rooted in the recognition of the inherent dignity and inalienable rights of all individuals (Birgden \& Perlin, 2009; Crewe, 2020), including those of prisoners (UNODC, 2015). This position is further corroborated by the 1993 Vienna Declaration and Program of Action (Birgden \& Perlin, 2009). Internationally, human rights for all prisoners are safeguarded through the 1987 Convention Against Torture and Other Cruel Inhuman or Degrading Treatment or Punishment (Crewe, 2020), which gives freedom from torture or cruel, inhuman, or degrading treatment (UNODC. 2015). Therefore, this universal legislation - alongside regional and domestic legislative frameworks - ought to guide the efforts of activists, practitioners, and other stakeholders (Crewe, 2017).

Recognizing that crimes committed by women differ from male criminality, the 2010 Bangkok Rules are the most recent sets of standards in criminal justice addressing various gender-specific issues of women prisoners (Barzano, 2012). Compiled under one instrument United Nations Rules for the Treatment of Women Prisoners and Non-custodial Measures for Women Offenders - the Rules complement and supplement the United Nations Standard Minimum Rules for Non-custodial Measures (the Tokyo Rules) with a section covering the application of non-custodial measures and for women and juvenile female offenders (Barzano, 2012) and Rule 6 of the Tokyo Rules which limit the use of pre-trial detention (UNODC, 2015). To reiterate, compared to men, women are far less likely to commit crime - a pattern which holds true across the globe (Barzano, 2012; Penal Reform International, 2013). Because women and girls represent less than $10 \%$ of the prison population, their characteristics and needs remain largely unacknowledged and unmet by criminal justice systems (Penal Reform International, 2013). Hence, prisons and their administrations - from the architecture and security procedures 
to healthcare, family contact and training opportunities - are typically designed for men (Barzano, 2012; Crewe, 2020; Penal Reform International, 2013; UNODC, 2015).

Cognizant of this gap, three foundational facts underlie the conceptualization and subsequent adoption of the Bangkok Rules by the UN General Assembly. These are: (1) a significant number of women are in prison as a direct or indirect result of intersectional layers of discrimination and deprivation, (2) crimes committed by women are closely linked to poverty, such as theft, fraud, and drug offences, and (3) while a small minority of women are convicted for violent offences, of those convicted, a large majority of them have been victims of violence themselves (Penal Reform International, 2013). Thus, the Rules are crucial to protecting the rights of women offenders and prisoners, explicitly addressing the different needs that women have and the different situations they come from (Barzano, 2012; Crewe, 2020; Penal Reform International, 2013; UNODC, 2015).

On that note, the UN Bangkok Rules cover five important areas - admission procedures (i.e., presence of children, childcare arrangements); healthcare (i.e., reproductive healthcare, gender-specific responses, access to preventive services, e.g. screening); humane treatment (i.e., treated with dignity, contact with children); search procedures (i.e., alternative screening process, retrauma of abuse, complaints process); and, protection from violence (i.e., improper processes, dressing, showering, avoiding humiliation (Kapua, 2021; Penal Reform International, 2013; UNODC, 2015). Even though the Rules are largely gender-specific, men prisoners and offenders are also protected by some of the rules. For instance, in the case of children, the central role of both parents is recognized, thus some of the rules equally apply to men prisoners who are fathers (Penal Reform International, 2013). However, given the limits of the current study whose focus is on parenting experiences of incarcerated mothers - emphasis is only on Rules 
relevant to this topic. These include the Rules covering the presence of children in prison and the ensuing childcare arrangements, contact with children, as well as reproductive healthcare.

Several of the Bangkok Rules are relevant to both women and children who are held in carceral facilities. Relevant Rules include: Rule 48 (pregnant or breastfeeding women prisoners shall receive advice on their health and diet under a program drawn up and monitored by a qualified health practitioner); Rule 49 (decisions to allow children to stay with their incarcerated mothers shall be based on the best interest of the children, and these children shall never be treated as prisoners); Rule 50 (women prisoners whose children are in prison with them shall be provided with the maximum possible opportunities to spend time with their children); Rule 51 (the environment provided for such children's upbringing shall be as close as possible to that of a child outside prison); and, Rule 52 (decisions as to when a child is to be separated from its mother shall be based on individual assessments and the best interests of the child within the scope of relevant national laws) (Justice Action, n.d.; UNODC, 2015). Rule 52 of the Bangkok Rules further emphasize that after children are separated from their incarcerated mothers and placed in alternative care, women prisoners shall be given the best possible opportunities and facilities to meet with their children, if doing so is in the best interest of the child and public safety (Justice Action, n.d.). In short, though the human rights framework is complex, the addition of the Bangkok Rules brings clarity for the detention of mothers, pregnant women, and babies (Crewe, 2020). Even though the U.S.A. consistently violate international standards, the inclusion of the Bangkok Rules in a U.S.A. based study is to give context as to how far it deviates from the norm or set standards. 


\section{Parenting and Prison}

Parenting from prison can be very challenging, especially for women. As mentioned earlier, incarcerated women who are mothers face at least three situations - mothering from prison, in prison, and after prison. Additionally, it is also possible to have an intersection of the first two scenarios whereby incarcerated mothers have some of their children in prison with them and some outside prison, most likely with alternative caregivers. Drawing from Scott's (2019) conceptualization of "carceral motherhood'4 for the purpose of this study, the concept can be understood from the beginnings of incarceration to after incarceration by juxtaposing issues related to caretaking with the challenges presented by the constriction of incarceration. It is also important to acknowledge that studies are replete with numerous challenges that mothers face upon release or during the re-entry phase. These include but are not limited to, re-exercising parental authority, arranging custody, and dealing with demanding conditions of state surveillance or post-release supervision (e.g., parole) which, if not followed, could bar them from retrieving their children from foster care (Gurusami, 2019; Scott, 2019).

Thus, formerly incarcerated mothers - particularly those from disadvantaged communities like Black women - must navigate multiple and overlapping barriers to protect their children which, oftentimes, puts them at risk of conflicting with the state (Gurusami, 2019). Rossiter and others (2015) pointed out that, though carceral release presents a welcome opportunity for women to reunite with their children, the re-entry process every so often presents

\footnotetext{
${ }^{4}$ For this study, 'carceral motherhood' is conceptualized to refer to the practice of mothering under a sentence of incarceration (Scott, 2019, p.78). Thus, in this study, those serving community sentences or on probation are either excluded or simply mentioned in passing. Please note, while women in jail and on pretrial detention face various parenting challenges as those in prison, the focus of this study is on those women who are in a prison environment and are convicted and serving a sentence. However, this is not to say that whenever relevant literature whose findings overlaps with women in prison (like a study by Rodda and Beichner (2017) cited above), is identified, it is to be shunned simply because it focuses on women in jail environment.
} 
quite a lot of challenges for calm and sensitive parenting, especially for those women experiencing health, income, and housing challenges (see also Beichner \& Rabe-Hemp, 2014). Also, for mothers whose children were removed at or prior to their incarceration, these hurdles add to an already complex family environment which makes restoration of parental rights even more difficult (Rossiter et al., 2015; Williams et al., 2020).

In a study conducted by Rodda and Beichner (2017) in which the researchers sought to identify programming needs for women detained and incarcerated in a jail environment, mothers who were experiencing custody issues provided mixed responses or perceptions. While some believed they were "doing the right thing" by relinquishing their parental rights, some felt they were deceived by agents in the system (Rodda \& Beichner, 2017). In short, while being separated puts a strain on any relationship, the emotional impact is exacerbated if there is a physical barrier between parents and their children (Beichner \& Rabe-Hemp, 2014; Rodda \& Beichner, 2017), to which incarceration presents such separation. Given this, it holds to argue that the experiences of incarceration present parenting challenges to mothers both during and after imprisonment, and - in some worst-case scenarios - even prior to incarceration (Beichner \& Hagemann, 2016).

Beichner and Hagemann (2016) lament the visitation challenges that mothers incarcerated in U.S.A. correctional centers face, and how such experiences threaten the prospects of mother-child bonding. For instance, though the U.S.A. is the global leader in women's incarceration, only few carceral facilities offer intensive mother-child programs including those that permit mothers to have overnight visitations with their children (Beichner \& Hagemann, 2016) with only nine nursery programs currently operational countrywide (Johnson, 2021) . Contrasting mother-child programs offered in U.S.A. carceral environments with those of other 
countries, Beichner and Hagemann (2016) concluded that programs in other countries tend to foster more bonds between mothers and children. This shortfall in mother-child programming in U.S.A. correctional centers exacerbates the negative experiences and difficulties presented by parenting from prison - something which may haunt the incarcerated mothers and their children long after release. Thus, noting these challenges in their study of women in a jail environment, Rodda and Beichner (2017) proposed the extension of visitation hours on weekends and the creation of a soft room, where mothers and children can share contact during such visitations. In addition, Rodda and Beichner (2017) further recommended the introduction of supervised visitations as a way of reintroducing the parent and child prior to release.

Apart from the visitation challenges presented by prison regulations and its constricting environment for physical bonding, challenges may also exist in terms of resources to use for such visitations. As mentioned in the introduction chapter, compared to those of incarcerated fathers, children of incarcerated mothers are less likely to have stable living arrangements (Rossiter et al., 2015), as such, they are likely to end up living with relatives (e.g., grandparents) or in foster homes (Beichner \& Rabe-Hemp, 2014). Thus, $88 \%$ of incarcerated fathers rely on the mother of the children to provide daily care and two percent rely on foster care, $37 \%$ of incarcerated mothers rely on the father to provide primary care, $45 \%$ rely on the children's grandparents, $23 \%$ rely on other friends and relatives, and $11 \%$ rely on foster care (Prison Fellowship, 2021). If we are to couple this with what was earlier stated in this chapter (and in the introduction chapter) that those with high likelihood of incarceration are those from disadvantaged communities or racial groups, it follows that those alternative caregivers (Scott, 2019) are likely to be poor (Gurusami, 2019; Williams et al., 2020), which means they are less likely to coordinate regularly scheduled visits to the prison (Beichner \& Rabe-Hemp, 2014). This leads to further strain on the 
mother-child bond and re-establishing this bond after prison is a challenging task (Beichner \& Rabe-Hemp, 2014), if not an impossible task altogether.

Using a qualitative approach, Finney (2016) interviewed 56 women confined to a county jail, with a focus on parent-child separation and jail visitation. As such, the study described women's family characteristics and examined their parenting roles and responsibilities, plans for family reunification, and concerns about their children visiting them. Finney found mothers were concerned about the disruption they had caused in the lives of their children, which includes the changing of schools and the strain it brings on the relatives that were now taking care of their children (Finney, 2016). This ties into the findings of the 2016 Bureau of Justice Statistics [BJS] report which focused on understanding women's paths to crime, and re-entry considerations for justice-involved women (Glaze \& Maruschak, 2016). The report states that, prior to incarceration, women are more likely to have served as primary caretakers of their children and plan to return to that role upon release - something which is corroborated by Ramirez (2016). Incarcerated mothers are continually concerned with the welfare of their children and the potential loss of legal custody (Finney, 2016; Ramirez, 2016). Hence, their children are often a motivating factor for their desistance from crime (Ramirez, 2016).

\section{Pregnancy and Prison}

Just like incarcerated mothers, pregnant women face a raft of unique challenges related to their impending parental role, and the restrictions thereof, associated with doing so in a constricted carceral environment. Nationwide, $4 \%$ of women in state prisons and $3 \%$ of those in federal prisons are pregnant at sentencing (Child Welfare League of America, 2021). This begs the question: what should happen when a child is born in prison? About two decades ago, Wismont (2000) conducted a study which focused on the lived pregnancy experience of women 
in prison. The study involved the analysis of journal entries and interview data using Georgi's phenomenological method ${ }^{5}$, in which the purpose of the study was to describe the childbearing experience as reported by pregnant incarcerated women (Wismont, 2000). Emerging themes from this analysis related to the experiences of childbearing include apprehension, grief, subjugation, and relatedness (Wismont, 2000). These themes are so compelling that they need to be discussed comprehensively, apiece.

Apprehension, to start with, is tied to two main concerns - fetal well-being, and estrangement from the child. Expecting mothers are perceived to exert a negative influence on the wellbeing of their unborn children through inadequate prenatal care, the effects of their substance use during pregnancy, lack of choice about their healthcare provider, sexually transmitted diseases, and difficulties or delay in having their healthcare needs attended to (Wismont, 2000). Apprehension related to the baby extended beyond birth. While the foremost worry of these women was to find a caregiver, once the caregiver was found, the women would worry about the emotional and physical distancing created by such a separation, fearing the child may not recognize them upon release (Wismont, 2000). This fear of child estrangement because of a weakened mother-child relationship is corroborated by a number of scholars in several studies (see Garcia, 2017; Siegel, 2011), with Beichner and Rabe-Hemp (2014) emphasizing that re-establishing this mother-child bond after prison is a challenging, if not an impossible, task.

\footnotetext{
${ }^{5}$ Giorgi's phenomenology as a theoretical movement seeks to avoid certain reductionist tendencies approaches associated with contemporary psychology research. Hence, researchers are encouraged to "bracket" out their own assumptions pertaining to the phenomena in question by refraining from imposing objective reality on the participants whose phenomena is being studied. Thus, for her study, Wismont (2000, p. 293) conceptualized Georgi's Phenomenological method as follows, "the phenomenological method seeks to uncover the meaning of human-experienced phenomena through the analysis of subjects' descriptions." Through this process, one can achieve an awareness of the world with all subjective influences removed. To achieve this exactness, the researcher must first "bracket" or suspend commonly held beliefs (Wismont, 2000, p. 293).
} 
Closely linked to apprehension is the theme of grief which, just like the latter, is tied to two related elements - separation from newborn, and loss of mothering opportunities - that describe the experience of childbearing in prison (Wismont, 2000). With exception of a woman who was planning to place her child for adoption, participants in Wismont's study expressed intense sadness over the impending separation from their newborns (Wismont, 2000). This concern would, ultimately, deny them the opportunity of continued care of and/or contact with their child. The expressed profound sadness, brought by the anticipated mother-child separation, resembles Finney's (2016) study cited in the above section. Bearing in mind that only nine of the 50 states in the U.S.A. have prison nursery programs (Williams, 2021), the concerns of being separated from their children are reasonably expected and justified. This is not to mention that even in the event that a nursery is available in a given correctional center, a mother is only allowed to parent her child for a finite period of time, ranging between 30 days to 30 months (Child Welfare League of America, 2021). Even so, a mother is only allowed to participate in a nursery program if she is convicted of a nonviolent offense and has no history of child abuse or neglect (Child Welfare League of America, 2021). All these factors denote a situation in which mother-child separation is eventually inevitable.

Tying these findings into prior studies, "subjugation" - for instance - typifies two things. First, it exemplifies the physical and emotional distancing experienced by incarcerated women; second, it illustrates the powerlessness or lack of autonomy experienced by these women within the correctional system (Ramirez, 2016; Wismont, 2000). Thus, while physical separation from family and friends added to the sense of loneliness for incarcerated pregnant women, they expressed extreme emotional isolation experienced within the prison itself (Wismont, 2000). Central to their experience as pregnant women was the total lack of autonomy in relation to the 
correctional system - hence they perceived the system to be controlling and/or conspiring against them (Wismont, 2000). In short, they viewed the forced separation from their newborn babies as the ultimate form of lack of control given their current situation (Wismont, 2000). Given this, the three themes and their related elements discussed so far can be construed to relate closely with the mental health (i.e., either by creating them or by triggering the underlying ones) of incarcerated pregnant women. Thus, pooled together, these thematic findings tie into Mukherjee and colleague's (2014) systematic study on mental health issues among pregnant women in carceral institutions, which suggested the need to address mental health issues among pregnant inmates. Due to incarceration-induced stress, incarcerated pregnant women were found to be a high-risk group for mental health problems, which resulted in adverse maternal and fetal outcomes (Mukherjee et al., 2014) - a finding which justifies the concerns of pregnant women in Wismont's (2000) study.

The last theme that Wismont (2000) found in connection to pregnant women in correctional facilities is relatedness, and it expresses the positive energy that the women described regarding their childbearing experiences in prison. Like the other three themes, relatedness is tied to two elements - connectedness to the fetus, and connectedness to self. While the former evolved around the incarcerated women' statements concerning their involvement with the fetus, the latter referred to their ability to persevere in adversity by identifying personal resources (Wismont, 2000). On that note, the latter element - connectedness to self - can be said to be closely linked to the coping strategies these women employed to survive in a constricted carceral environment. Regarding the element "maternal connectedness to fetus," it expressed both affective and behavioral responses to the fetus as well as their description of the unborn child as a companion (Wismont, 2000). However, though most of these women described their 
feelings of connectedness to the fetus, they would - concurrently - express apprehension about this experience (Wismont, 2000). More recent studies have corroborated this finding by citing the financial and emotional costs of, say, placing a child in a foster care (Gurusami, 2019), to which mothers may likely lose custody battles thereby reinforcing the emotional pain of separation (Garcia, 2019), and shattering prospects of mother-child bond (Beichner \& RabeHemp, 2014).

\section{Coping Strategies of Justice-Involved Mothers and Pregnant Women}

Given the physical and emotional distancing created by the carceral environment regarding mother-child relationships, incarcerated mothers may devise strategies or coping mechanisms to navigate the restrictions or barriers, during or post-incarceration. Easterling and others (2019) argue that since there is a wide variation of impacts of incarceration on women's identities, they employ varying strategies to deal with the hardship and stigma that being an incarcerated woman entails. This argument is corroborated by Gurusami (2019) when she traced the disproportionate representation of formerly incarcerated Black mothers to the state's hypersurveillance of this 'minoritized' population - a fact which, according to Garcia-Hallett (2019), is made possible by the geographic marginalization of their racially and economically segregated communities. As a result, Gurusami (2019) stated that forces of these hardships and stigma are not only instigated at individual and community levels, but even at the state level through this unwarranted state surveillance. Such a situation - as corroborated by William and colleagues (2020) - may create grounds for 'pseudo-violations' of state laws and the subsequent justifications for the imposition of legislations that threaten parental rights of these women (Gurusami, 2019). 
Gurusami (2019) - in her study which focused on examining the raced, classed, and gendered parenting labor of formerly incarcerated Black women - introduced the concept 'motherwork' ${ }^{6}$ in summation of three context-specific strategies these women employ to anticipate, react to, and cope with state surveillance and interventions that threaten their mothering. These three strategies are collective motherwork, hypervigilant motherwork, and crisis motherwork (emphasis added) - and they constitute what she terms 'decarceral motherwork ${ }^{7}$ (emphasis added) (Gurusami, 2019). In her conceptualization, foremost, "collective motherwork" can be understood as a community-based negotiation of tenuous childcare conditions between formerly incarcerated women living in proximity. Thus, by citing the West African proverb "it takes a village to raise a child" as resonating with the way members of Black communities must work together to remain resilient among oppressive regimes, GarciaHallett (2019b) corroborates this concept of collective motherwork. Second, "hypervigilant motherwork" refers to the anticipated work of protecting children from the state and strangers; and, lastly, "crisis motherwork" refers to the act of confronting immediate threats that would remove the children from their custody or prevent reunification (Gurusami, 2019). Protecting their children includes teaching them how to evade police (Gurusami, 2019). This claim is corroborated by Alice Goffman's findings in her ethnographic study of a black neighborhood in West Philadelphia. Given the disproportionate nature of scale of imprisonment and the ensuing impacts on "minoritized" populations like Black communities (i.e., one in 15 Black males,

\footnotetext{
${ }^{6}$ Gurusami (2019) theorizes the concept 'motherwork' to show "how mothers on the margins support their families under carceral infrastructures of control" (p. 132). For example, she mentions how motherwork for drugaddicted women, formerly incarcerated women, and Black women may include teaching their children how to evade the police, engaging in civil disobedience to protest inequality, feeding a family on a severely restricted income, or protecting children while mothers are in violent relationships.

7 Gurusami (2019) defines 'decarceral motherwork' as a "concept that captures how formerly incarcerated Black women labor to care for their children under the confines of state surveillance and bondage - a process that is often concealed by continued carceral logics and practices" (p. 130).
} 
compared to one in 106 White males is incarcerated), Goffman (2014) argued that this translates to an intersection of mass incarceration and race. Due to this constant threat of having their children taken away, women in this Philadelphia Black neighborhood, would train their children who were as young as 11 years to evade police (Goffman, 2014). This approach to mothering employed by justice-involved mothers from minoritized communities' ties well into the concept of crisis motherwork described by Gurusami (2019) above.

Wismont (2000), highlights strategies that women employ concerning carceral motherhood. For example, a coping strategy some of the mothers would use was to find an alternative caregiver who (likely) would be a relative that they trust (e.g., a sister, mother, etc.) (Wismont, 2000). Although the women may still be stressed and grieved about the welfare of the child, it would not be equal to having given up the child for adoption to a total stranger or placing the child in a foster care - options which leave them vulnerable to easily lose parental rights. Consequently, one may argue, if the alternative caregiver is a close relative, resumption of parental rights upon release may not be difficult for the incarcerated mother - which is different from having the child in a foster home.

Under the theme of 'relatedness' - which contained the elements of "connectedness to the fetus" and "connectedness to self" - some expecting mothers who had plans for adoption would navigate the impact of this separation by a purposeful emotional distancing from the unborn child (Wismont, 2000). Nevertheless, even though these women's lack of connectedness or affection to the fetus may act as an emotional buffer they still acknowledged interest in the child's wellbeing (Wismont, 2000). In short, the literature reveals women's accounts of connectedness with their unborn baby (Chambers 2009; Wismont 2000) and anticipatory grief when pre-empting separation, compounded when separation actually occurs (Abbott et al., 2020; 
Gardiner et al. 2016). Thus, knowing the inevitability of separation from their child, some women - as a coping strategy - may start to emotionally distance themselves from the fetus early on during pregnancy.

In addition, incarcerated (expecting) mothers tended to turn to spirituality - thus, the strength to cope was identified as coming from three main sources: the self, the baby, and God (Wismont, 2000). Spirituality is broadly understood as a "personal quest ... [for] answers to ultimate questions about life, meaning and...relationships to the sacred ... (Stringer, p. 327).” Because of this, it is often emotion-oriented and inwardly directed - hence, invisible, and difficult to measure. Bearing in mind that spirituality or religion may be a theme (or can be an entire study) in its own right, its inclusion here is to showcase that it is one way incarcerated mothers and pregnant women help cope with their prison-induced stress concerning their lived or expected parental role. In a study conducted by Stringer (2009) which focused on the role of religion and spirituality on incarcerated African American mothers, 90\% reported to have a religious affiliation with $86 \%$ highlighting it to be either "important" or "very important" in their lives. Thus, many prison officials report that religious activities are widely popular and successful (Stringer, 2009) and, according to one prison chaplain, recidivism is reduced by half for persons who participate in a weekly faith-based activity (Rioux, 2007). On that note, religion can allow persons to cope with the loss of freedom and reconcile their guilt through personal responsibility or recognition of evil influences (Stringer, 2009). Thus, religious experiences may help to modify behavior, promote self-reflection (Wismont, 2000), and bring about a new sense of hope and direction (Stringer, 2009).

Apart from using the motherwork strategy (i.e., collective ["it takes a village to raise a child"], hypervigilant, and crisis mothering) (Garcia-Hallett, 2019b; Gurusami, 2019), the 
alternative "related" caregiver (e.g., sister, mother) strategy (Wismont, 2000), the "emotional buffer/distancing from the fetus" strategy (Wismont, 2000), the spiritual "keeping the faith" strategy (Stringer, 2009; Wismont, 2000), incarcerated women can also use prison pseudofamilies as a coping strategy (Collica, 2010). Even though both men and women adopt various roles to cope with the pain of imprisonment, it is assumed that such pain disproportionally affect women than men because of the difficulty of being separated from their family and children (Collica, 2010). Given this, to deal with this pain, incarcerated women recreate their lost family in prison (Kolb \& Palys, 2018), and this carceral family has come to be known as a "pseudofamily" (Collica, 2010). In a pseudo-family setup, as a reflection of the outside world, incarcerated women may play or attach themselves to the role of aunts, cousins, uncles, mothers, and children (Zaitzow, 2003). In short, the gendered nature of prison regimes is tied to the gendered character of prison cultures and the ensuing gendered response to the "pains of imprisonment" (Cunha, 2018), and one such gendered response being the creation of pseudofamilies by incarcerated women.

Nonetheless, given all the above-cited strategies employed by both justice-involved mothers and pregnant women, Beichner and Rabe-Hemp (2014) posited a crucial point related to coping. They argue that while victims tend to adopt coping strategies as a way of circumventing their pain, these experiences may result in unhealthy coping skills such as self-blame and numbing by substance abuse (Beichner \& Rabe-Hemp, 2014). This ties back to the first sections of this chapter, particularly the "triple threat," which - in the case of maternal substance use does not only threaten the immediate user, but its collateral consequences can extend to children. As mentioned by Garcia-Hallett (2019a, 2019b), children of substance abusing mothers are more likely to already have been physically and emotionally distanced from their mothers even prior to 
maternal incarceration. This is because, prior to incarceration, these women may likely spend considerable time either on the streets or in a rehab (Garcia, 2017), to which in this absence, their children are cared for by alternative caregivers. This leads us to the next section - effects of incarceration on children.

\section{The Effects of Incarceration on Children}

From the Family Process perspective, some studies have focused on the effects of maternal incarceration on child wellbeing. For example, Arditti (2015) focused on the heterogeneous effects of maternal incarceration on child wellbeing and concluded that it is linked to child psychopathology. The noted effects include school failure, antisocial behavior, and intergenerational incarceration (Arditti, 2015). In addition, Arditti (2015) argues that these detrimental effects are partly caused by risk and discontinuity in children's care arrangements, which is typical following a mother's incarceration. This ties well into Wismont's (2000) findings discussed above, since it justifies the fear the expectant mothers had for both their unborn babies and their children left under various care options upon incarceration. As mentioned earlier, compared to children experiencing paternal incarceration, children of incarcerated women are likely to have - for instance - unstable living arrangements (Rossiter et al., 2015), and may end up in foster homes or living with relatives who may be struggling even before this extra burden (Beichner \& Rabe-hemp, 2014). Also, once the children are placed in foster care, resumption of parental duties upon release may be tricky, given that parental rights may have been lost already before release (Garcia-Hallett, 2019a, 2019b; Gurusami, 2019; Williams et al., 2019).

As mentioned before, most female prisoners are mothers and had to leave their children in the custody of other caregivers upon their incarceration. Many incarcerated women have 
experienced abuse as children (Ramirez, 2016), and leaving their children in the care of others may make them vulnerable to abuse just as they were. Given the pathways that women follow into criminality, this possible cycle of abuse - as exacerbated by the mother's absence - may lead to intergenerational victimization and offending. Studies show that when a mother is incarcerated, the odds that her children, especially her daughters, will experience arrest, conviction, and incarceration as adults significantly increases (Burgess-Proctor et al., 2016; Cobbina, 2021). To reiterate, according to Ramirez (2016), women in jails and prisons report high rates of mental health problems such as depression, post-traumatic stress disorder (PTSD), and substance use. Consequently, given the vicious cycle of victimization, offending, and arrest - just like their mothers - this might mean mental health implications to these children, especially girls.

To strike a balance, apart from maternal incarceration, a couple of studies (some of them recent) have focused on the link between paternal incarceration and child behavior problems (see Antle, Gibson \& Krohn, 2020) and some on father-child involvement (Roy, 2005) during reentry from prison (see Charles, Muentner \& Kjellstrand, 2019). The latter study - informed by Arditti's Family Inequality Framework (i.e., a conceptual model of responsible fathering) examined the experiences of 19 fathers recently released (Charles et al., 2019). The objective of this qualitative study was to understand how incarceration shapes parenting and facilitates or presents barriers to father-child relationships (Charles et al., 2019). Findings from this study demonstrate that, despite the substantial challenges to parenting from prison, fathers remain deeply committed. As such, it concludes, these perspectives can inform the design and implementation of services to promote father-child involvement among fathers returning from prison (Charles et al., 2019). 
On the other hand, drawing data from the Fragile Families and Child wellbeing Study, Antle and colleagues focused on the effects of paternal incarceration on child behavior (Antle et al., 2020). Findings from this study demonstrate that paternal incarceration had a direct effect on child externalizing behaviors (i.e., aggression, rule-breaking), and an indirect effect on both internalizing and externalizing behaviors (i.e., withdrawal, anxiety, and somatic disorders) (Antle et al., 2020).

Tying these two studies into Ramirez (2016), just as it is for men, focusing on re-entry is critically important for women as the majority will return home after their sentence. Typically, women serve shorter sentences than men, hence, planning for re-entry early on during incarceration is more critical (Ramirez, 2016). As recommended by Charles and colleagues (2019) above, understanding of these facts and perspectives is critical in informing the design and implementation of services to promote parent-child involvement among parents returning from prison. In such planning, scholars implore those responsible to understand and take into consideration that female inmates (i.e., incarcerated mothers) have unique needs compared to their male counterparts (i.e., incarcerated fathers) (see Ramirez, 2016; and Schlager, 2018).

The identified literature covering the topic of (parental) incarceration in the last two decades can be grouped according to the following themes. First, there were those studies covering the theme of 'mental health' (Rose \& LeBel, 2017) and general 'health issues/outcomes' (Barkauskas, Low \& Pimlott, 2002; Mignon, 2016) of incarcerated mothers. Second, some studies focused on the needs and experiences of pregnant inmates (Barkauskas, Low \& Pimlott, 2002; Eliason, Michele \& Arndt, 2004; Fritz \& Whiteacre, 2016; Sufrin, 2019). Third, other studies focused on educational programs for incarcerated mothers (Shoemaker, 2017) and programming needs for women detainees (Rodda \& Beichner, 2017). Fourth, the other 
area of focus for other studies were issues to do with (women) 're-entry' (Beichner \& RabeHemp, 2014). Fifth, others paid attention to the coping mechanisms of incarcerated mothers from racial minorities but paying specific concentration on religion and spirituality (Stringer, 2009).

Apart from maternal incarceration, other studies focussed on paternal incarceration (Antle, Gibson \& Krohn, 2020; Charles, Muentner \& Kjellstrand, 2019), albeit from different approaches, but the common and overarching goal being its effects on child wellbeing. However, several studies fixated on effects of parental incarceration in general (Casey, Shlafer \& Masten, 2015; Stalans \& Lurigio, 2015; Muentner, Holder, Burnson, Runion, Weymouth \& PoehlmannTynan, 2018), without paying particular attention to the gender of the parent in question. Lastly, other studies focused on the application of theories (e.g., grounded theory) and frameworks/models (e.g., Arditti's Family Inequality Framework; Family Process perspective) to explain the collateral effects of parental incarceration (Arditti, 2015; Charles, Muentner \& Kjellstrand, 2019; Gunn, 2020). However, even though research on the differential effects of paternal versus maternal incarceration have been mixed, national data indicate that incarcerated mothers are more likely than fathers to have been living with their children prior to incarceration (Glaze \& Maruschak, 2010), signifying that children may experience more disturbance in living and caregiving arrangements (Schlafer, Duwe, \& Hindt, 2019) following maternal incarceration, compared to paternal incarceration (Murray \& Murray, 2010).

As the researcher narrows down to the present study, it is important to acknowledge the existence of two other studies that used the same dataset, albeit for different research questions, from whence the current study also draws. The first study, which applied a Vulnerability Conceptual Model, is dedicated to the re-entry of incarcerated rural mothers (i.e., plans for returning home, effect of incarceration on children, and the community context that shapes 
women's experiences of mothering) (Beichner \& Rabe-Hemp, 2011). The last study, conducted by Rodda and Beichner (2017), focused on identifying needs of women incarcerated in local jails as opposed to those in state and federal prisons. As such, six themes that emerged from the transcribed interviews were: relationships, religion, addiction, health care, parenting, and release/re-entry (Rodda \& Beichner, 2017). These themes may also emerge, or at least overlap, in the current study.

Although these studies make valuable contributions to the body of literature through a systematic focus on effects of incarceration on families and the ensuing needs, the present study seeks to employ the core tenets of Braun and Clarke's reflexive thematic analysis (TA) approach (Clarke, 2019a, 2019b) to examine the experiences of imprisoned mothers. Even though many scholars acknowledge the collateral consequence to mass incarceration, there remains a need to understand the nuanced way in which incarcerated mothers 'navigate' and cope with such situations. The aim of this study, therefore, is to examine how incarceration shapes parenting and facilitates or presents barriers to mother-child relationships. Given that it is typical for divergent life trajectories to emerge from shared contexts, a wary understanding of this relationship is warranted. As such, attention will be paid, not only to the individual's objective experiences and choices, but also to the meaning and symbolism they ascribe to their experiences.

From the introduction through the literature review sections, the researcher has synthesized findings from several studies related to parenting or mothering from prison. Using a deductive approach (from general to specific), the researcher has so far covered four topical areas - mass incarceration; minority overrepresentation in the United States criminal justice system; the growing female inmate population; and lastly, an unprecedented number of inmates who are mothers. On that note, before moving on to the last section of this chapter - the 
theoretical framework - the researcher will briefly discuss the impact of legislation on carceral and post-carceral motherwork.

\section{Legislation and Parental Rights of Justice-Involved Mothers}

"A termination of parental rights is the family law equivalent of the death penalty in a criminal case" (Rippey, 2020, p. 531). Between the period 2006 and 2016, about 32,000 parents incarcerated in U.S.A correctional centers permanently lost their parental rights even though they had never been accused of child abuse (Rippey, 2020). Approximately, 5,000 of these lost their parental rights solely because of their incarceration (Rippey, 2020). This "family separation crisis" is a brainchild of the Adoption and Safe Families Act (ASFA), a federal law which requires states to initiate proceedings of severing parental rights against parents whose children have been in foster care for 15 of the last 22 months (Garcia, 2017; Hanney, 2015; Rippey, 2020).

Going back into history, a piece of legislation that resembles the ASFA was passed in the state of Louisiana in 1848 during the era of slavery. This law declared that all children born in the penitentiary of African Americans serving life sentences would become property of the state (Bauer, 2019). The women were to only raise the child up to the age of 10, at which point the penitentiary would place an advert in the newspaper, and the child - as "cash on delivery" - will be auctioned within 30 days (Bauer, 2019). While the proceeds from this transaction were used to fund schools for white children, these children would have been taken away forever from their mothers (Bauer, 2019). In fact, these mothers had a triple fate - the devastation of losing one's child, the twisted hope of living as a slave, and imprisonment. On that note, strong parallels can be drawn between this piece of legislation and the ASFA given that the severing of parental rights of incarcerated parents has the same effect - lifetime separation. 
While there is a higher number of incarcerated women in the U.S.A. than anywhere in the world, most of these carceral facilities do not have prison nurseries (Warner, 2015). Due to this, most female inmates who give birth in prison are separated immediately from their newborn (Warner, 2015). As a result, incarcerated mothers have fewer choices - put up the child for adoption, place the child in a foster care, or give the child to relatives - which, when chosen, poses a substantial risk of terminating the mother's parental rights (Hanney, 2015; Warner, 2015). According to Hanney (2015), about $20 \%$ of children in foster care have mothers with criminal justice records, which exacerbates the ever-present threat of having their parental rights terminated (Warner, 2015; Williams et al., 2020). Apart from the threat posed by the listed choices to mothers, studies have shown that there is a potential association between foster care placement and criminal justice involvement among foster youth (Shared Justice, 2017; Zhao, 2020), which heightens the collateral consequences of maternal incarceration.

Most, if not all, of these limited three options presented to incarcerated mothers, draw their strength from the prior-stated ASFA of 1997 (Hanney, 2015; Warner, 2015; Williams et al., 2020). Since the Act directs that parental rights be suspended if the child has been in foster care for 15 of the last 22 months (Garcia, 2017; Hanney, 2015), this means even a short 18-month prison sentence, could create a lifetime separation between a biological mother and her child (Warner, 2015). In 2013, while the average sentence length for women convicted of a statute carrying mandatory minimum was 60 months; on the other hand, the average sentence length for women convicted of a statute not carrying a mandatory minimum was 17 months (United States Sentencing Commission, 2013). This means the threat of a lifetime separation from their biological children exists even for mothers who are serving the shortest of sentences. In short, prisoners are more likely to have their parental connection absolved or severed (Hanney, 2015), 
and that threat is ever-present (Vera Institute of Justice, 2004). Thus, removal of children from their homes is one way in which state power disrupts, restructures, and polices poor - primarily Black - families (Hanney, 2015).

Still, of the three choices incarcerated mothers have, two - adoption and foster care prove to be the most difficult. This is because sometimes adoption require biological parents to cede parental rights to adoptive parents, which means the former will have no parental rights upon release (Warner, 2015). On the other hand, placing a child in foster care while a woman serves her sentence is tricky due to the shortened timeline in which parental rights remain valid before forfeiture (Warner, 2015). This means incarcerated mothers who are serving longer sentences are more at risk of losing these parental rights compared to those with shorter sentences. Also, in 2013, for instance, the average age of women in federal offender population at sentencing was 38 years (United States Sentencing Commission, 2013). Given this relative youthful age coupled with the fact that most of these women are mothers, one may argue these women are likely to have had children less than the age of 18 prior to incarceration - and most of these children (i.e., 50\%) are below the age of 10 (The Sentencing Project, 2016).

In the current study, though the participants had their children with them in prison and were not directly affected by the legislation through forced separation, the researcher included this section to show that criminalization of mothering has existed for some time now. Also, given that the threat of losing parental rights is ever present as earlier stated, these women - though temporarily safe at the time of the original study - may not have been not an exception, eventually. Thus, being constantly conscious of this fact may shape the experiences of these women and how they responded to questions posed to them by the interviewer. On that note, this proves the relevance of the listed legislation to the current study. 


\section{Theoretical Framework}

Several theories can be used to explain, analyze, or discuss parenting experiences of incarcerated mothers (or fathers). Hence, it will be a mammoth task to try and discuss every theory that is relevant to parenting. Given this, guided by the questions asked by Dr. Dawn Beichner in the initial study (see Appendix A) and the literature review, the researcher identified three theories that may be relevant to the current study - intersectionality, pathways, and attachment theory.

\section{Intersectionality}

Developed by Crenshaw $(1989,1991)$, intersectionality is a framework conceptualizing that people are often disadvantaged by multiple sources of oppression such as gender, race, and class. Given the interconnected nature of these social categorizations, this creates overlapping and interdependent systems of discrimination or disadvantage (Crenshaw, 1991) - hence, “intersectionality.” In short, intersectionality as a theoretical framework, explains why social identities themselves do not stand-alone and are often complicated and intersecting (Beichner \& Hagemann, 2016; McDermott, 2019). To put this into perspective, in relation to incarcerated mothers, intersectionality can be used to explore how social identities - at both micro and macro levels - overlap and create unique mothering experiences for different racial, socioeconomic, and age groups.

When Crenshaw $(1989,1991)$ first developed this theory, her primary focus was on Black American women who largely experienced disenfranchisement through identity markers "woman" and "black". She argued that the problem with identity politics is not that it is oblivious of difference as some might believe, rather, it conflates or ignores both intragroup and intergroup differences (Crenshaw, 1991) which then hinders appropriate responses. For example, 
she argued that the violence that many women experience is often shaped by other dimensions of their identities, like race and class (Crenshaw, 1991), to which when such intersectionality is ignored, inadequate or improper responses are provided. This ties into what was stated earlier on in this chapter that compared to their White counterparts, Black women disproportionately experience physical and structural violence.

Tying this into the current study, literature through various studies has established that, women experience prison differently from men. For mothers, this relates to their oftenintersecting roles of gender and primary caregiving which - when coupled with the intersection of motherhood and prison - leaves them in a different position compared to incarcerated fathers. Women in carceral settings have different needs than men, something which the Bangkok Rules take into consideration. Apart from gender, the intersectionality of prison and motherhood can stretch to include race and class. As established in literature prior, incarcerated women from "minoritized" communities experience prison differently from those from "privileged" communities. This means the effects and collateral consequences of a mother's incarceration are disproportionally felt across racial and class categories. Thus, it exacerbates inequalities among children of incarcerated mothers.

\section{Pathways}

Through a series of qualitative studies (i.e., biographical narratives of women offenders) grounded in feminist criminology, three distinct pathways to crime were identified - a childhood victimization pathway (Covington, 1998; Daly, 1992), an extreme marginalization pathway (Richie, 2001), and a relational pathway (Covington, 1998; Gilligan, 1982). While the childhood victimization pathway is linked to the "triple threat" - child abuse, substance use, and mental illness (Brennan et al, 2012; Garcia, 2017); on the other hand, the extreme marginalization 
pathway is explained by poverty, homelessness, and educational and vocational problems which are usually a resultant factor of the intersection of gender, race, and class (Brennan et al., 2012). The relational pathway, on the other hand, is linked to dysfunctional relationships which, over time, culminate into victimization, depression and anxiety, and subsequently substance abuse (Brennan et al., 2012).

Of the qualitative studies culminating into pathways theory conducted, two of Kathleen Daly's $(1992,1994)$ studies stand out. In these influential studies, she identified five prototypical pathways as follows: (a) street women - escape and survival, which involves women or girls entering the street as a result of fleeing from abuse and violence and, typically, these engage in drugs, prostitution, or theft to survive; (b) drug-connected women, this relates to those women and girls who are involved in drug trafficking usually in cahoots with family members or intimate partners, typically, they are arrested for drug possession and sale; (c) harmed and harming women, refers to those women who experienced extreme physical and sexual childhood abuse and neglect, resulting in delinquency and hostile demeanor, and ultimate chronic adult criminality; (d) battered women, reflects women who experienced extreme victimization from violent partners, leading to criminal behavior that cannot be explained by anything else apart from the relationship; and (e) "other" women, these are women who partly followed an “economic pathway, typically involving fraud, embezzlement, and theft - motives which spell the "desire for money," survival, or economic gain (Brennan et al., 2012; Gehring, 2018).

In short, "Pathways Theory posits childhood abuse is important in the etiology of offending behavior and its influence is via a "pathway" that is mediated by mental health issues and substance abuse" (Gehring, 2018, p. 121). Thus, Cobbina (2009) argues that prior to discussing women's reentry, it is of necessity to understand women's initiation into crime, since 
such experiences shape their transition out of crime. Studies have consistently shown the distinct differences between men and women experiences which shape their paths to offending (Belknap et al., 2016; DeHart, 2005, 2018; Cobbina, 2009; Ramirez, 2016). Hence, pathways theory is a feminist-informed research approach that documents the excessively elevated risk of experiencing (or having experienced) adverse life events among the offending women and girls, compared to nonoffending women and girls or nonoffending men and boys (Belknap et al., 2016; DeHart, 2018). Recurring factors like abuse victimization, addiction, poverty, marginalization, mental health disorders, and dysfunctional relationships (Belknap et al., 2016; DeHart, 2005, 2018; Ramirez, 2016; Quinlan, 2019), disproportionately affect women and play unique roles in shaping female criminality (Cobbina, 2009), and these factors can be conceived as the prison cycle of a vulnerable woman (Quinlan, 2019).

However, it should be noted that while abuse is a common theme explaining the etiology of female criminality in most pathways, not all women who have been abused commit crimes (Daly, 1994; Gehring, 2018), and not all incarcerated women have been abused. On that note, it should not be assumed that abuse and victimization are the only explanations of female trajectories into offending (Gehring, 2018). Nevertheless, given the evident intersection of extensive histories of abuse and prison among justice-involved women, scholars have wondered what lies in the "black box" between childhood victimization and adult criminal behavior (Daly, 1994; Gehring, 2018). To this end, one can note the similarity and interrelatedness of the two theories - intersectionality and pathways. Please note, for this study, intersectionality theory is primarily used for contextual background on how women arrived in prison. On that note, it may not directly explain their parenting experiences once incarcerated. 


\section{Attachment theory}

Attachment Theory was originally developed by a British psychoanalyst John Bowlby (1907-1990), who sought to understand the intense distress experienced by infants who have been separated from their parents (Bowlby, 1982; Fraley, 2021). Though psychoanalytic writers of Bowlby's time interpreted, as immature defense mechanisms, the extraordinary lengths (e.g., crying, clinging, and frantically searching) that infants would go to prevent separation from their parents or to re-establish proximity to a missing parent; Bowlby, on the other hand, noted that such expressions are typical among mammalian species and explanations to these behaviors may go beyond the explanation posited by his contemporaries (Fraley, 2021; Johnson, 2019). Thus, Bowlby explained that these attachment behaviors (like crying and searching), were adaptive responses to separation from a primary attachment figure (Fraley, 2021). Hence, he argued that over the course of evolutionary history, infants that maintained proximity to an attachment figure, were more likely to survive to a reproductive age (Fraley, 2021).

On that note, the theory has seven basic principles that are now being supported by many studies (Johnson, 2019) on child-parent and adult-partner bonding (Coan, 2016), which spells out the task of parenting and the emotional needs of children (Fraley, 2021). Central to the seven core tenets is that seeking and maintaining contact with the primary attachment figure (Fraley, 2021) or significant others is an innate and chief motivating factor in human beings at all lifespan phases (Johnson, 2019). Hence, dependency is an innate part of being human and, conversely, rejection and isolation are inherently traumatizing and coded as danger cues by the nervous system (Fraley, 2021; Johnson, 2019). Therefore, research on neuroscience notes that this connection is the basic requirement for coping and survival (Coan, 2016) assumed by the mammalian brain (Fraley, 2021) - thus, human beings are indeed bonding animals (Johnson, 
2019). Though connection is readily on the cognitive level like hearing a reassuring voice of the primary attachment figure (i.e., picture a mother calling her children from prison), Johnson (2019) argued that contact is still a primary need. In short, the bonds of love can be understood as an ancient innate survival code designed to keep those one depends on close to them, especially in times of vulnerability (e.g., in infancy) and perceived danger (Johnson, 2019).

Accordingly, this theory's focus is on the relationships and bonds between people, particularly long-term relationships, including those between a parent and child (Cassidy, Poehlmann \& Shaver, 2010; Poehlmann, 2005). Consequently, attachment, as a facet of the theoretical framework for this project, focuses on the quality or impact of attachment on caregiving relationships (i.e., as relating to mother-child relationships when the mother is incarcerated). Typically, children of incarcerated parents experience consequential disturbances in their family relationships because of changes in caregivers and separation from imprisoned parents. In short, this theory ties well into the first question asked in the initial study in which the researcher inquired about the nature of the relationship of the participant mother prior to incarceration. In the same question, the primary researcher sought to understand whether the incarcerated mothers were primary caregivers prior to their incarceration, an approach which can be linked back to attachment theory.

\section{Relevance of the Theories to Current Study}

The researcher identified the above theories to emphasise that women in carceral facilities have unique needs compared to men. Nevertheless, it should be noted that these theories are not mutually exclusive, they interrelate. For example, one may argue that both pathways and intersectionality theories are complimentary. Therefore, it holds to theorize that the experiences that define one's path to criminality (i.e., pathways) are likely to be overrepresented 
in certain groups of the vulnerable woman based on at least three intersectional factors - gender, class, and race - which then makes pathways theory an integral part of this intersectionality. Also, attachment theory compliments both pathways and intersectionality theories by emphasising the importance of the mother-child bond which would have been severed by the interaction of factors from the two theories. 


\section{CHAPTER III: METHODS}

\section{Current Focus}

Through an exploratory secondary analysis of (primarily) qualitative data, the purpose of this study is to carry out a thematic examination of parenting experiences of mothers incarcerated in a Midwestern prison. Therefore, while other studies may have explored the experiences of carceral motherhood mainly from the standpoint of race in particular, the current study takes a generic approach by looking at it, broadly, in terms of parenting, mothering, and the experiences or challenges these entail given the restrictive environment in which these mothers will have to carry out these responsibilities. On that note, to get both a holistic view and comparative advantage, the study will be looking at parenting experiences of these women from two periods before and during incarceration.

Hence, this project can be broken down into three objectives, which are to: (a) explore participants' parenting experiences pre-incarceration, (b) develop an understanding of respondents perceptions of the quality of relationships with their child(ren), and (c) understand the respondents' perceptions of the effects of incarceration on their child(ren). The current researcher came up with this line of inquiry after reading, several times, the interview guide of the initial study conducted by Dr. Dawn Beichner. For more information and the full list of original questions asked during the initial study, please refer to the Appendix A. As a strategy to carry out the prior-mentioned objectives, this chapter - under the following subsections provide an overview of the procedures to be followed, these subsections being: sample, data, analysis strategy (i.e., statistical, and qualitative analysis), a hypothesis, and, lastly, IRB concerns. 


\section{Sample}

The secondary data this study utilises is drawn from Dr. Dawn Beichner's longitudinal study, The Challenges of Mothering from Prison: An Examination of a Family Reunification Program. The original study was approved by the IRB, and all personal identifiers from the data set (i.e., there are no women's names or other identifiers associated with the data set) were removed by the original researcher. This study was conducted in a Midwestern correctional facility, and data were drawn from a population of incarcerated women that participated in family reunification programs at that carceral facility. Additionally, the prime condition for participation in those programs required one to have been incarcerated for a nonviolent offense (see Jbara, 2012). Embedded in this overall reunification program is a prison nursery program for pregnant nonviolent offenders serving two years or less. This program affords these (expecting) mothers a chance to remain with their newborn children for the duration of their carceral time. One notable aspect about the family reunification program is that it allows children visitations of up to eight hours a day, including weekends. Moreover, these two programs are situated in a special wing of the facility, separate from the main inmate population.

Given several concerns that were raised prior in the literature review, the family reunification program is designed in such a way that possibly addresses many of the problems encountered by incarcerated mothers. The program minimizes or possibly eliminates the negative effects of a mother's incarceration on children. Thus, from a reentry perspective, the family reunification program strengthens the mother-child bond - a foundational requirement for a strong family structure post-release. In the original study, from whence the present study draws its data, the researcher interviewed a total of 46 convenient-sampled women - 13 of whom were African American, 31 Caucasian, and two Asian (Beichner \& Rabe-Hemp, 2014). The 
interviews, which yielded a $100 \%$ compliance rate, were conducted in a private space in the correctional facility and ranged between 30 to 90 minutes in length (Beichner \& Rabe-Hemp, 2014).

By including all the women who were interviewed in the original study, the current researcher is interested in knowing what intersectionalities, including race, will shape women's parenting experiences. The current study appreciates that it is typical for divergent life trajectories to emerge from shared context. One such 'divergent trajectory' for the incarcerated mothers might be the racial factor even though there is a 'shared context' (i.e. the carceral environment and its restrictive nature). Given the concept of intersectionality, the current researcher believes that the experiences (i.e. meaning and symbolism) of parenting from prison will be well-pronounced if the three races involved (i.e., Caucasian, African American, and Asian) are included and juxtaposed.

\section{Data}

This study will use a mixed approach by employing both the quantitative and qualitative data collected in the original study. Quantitative data, mainly descriptive, will be from two focal areas - offender information (i.e. race, offense, and sentence length), and family information (i.e. number of children, temporary care provider) drawn from institutional records. Qualitative data will be from transcripts of interviews conducted with women who were enrolled in a family

reunification program. While quantitative data will be analyzed using SPSS; qualitative data, on the other hand, will be analyzed through thematic organization and coding using MAXQDA software and Braun and Clark’s $(2006 ; 2018)$ six-phase process for doing analysis familiarisation phase, coding phase, generating initial themes, reviewing themes, defining and 
naming themes, and writing up. A detailed description of this analysis strategy is provided in the next section.

\section{Analysis Strategy}

Statistical Analysis: To provide the demographic outline (i.e. race, offense leading to conviction, and sentence length) of the participants, information from institutional records will be analyzed using descriptive statistics. The researcher will also examine family information as gathered from the institutional records (i.e. information on temporary care provider, and number of children). The statistical analysis program (SPSS) will be utilized to provide descriptive quantitative data. For both offender and family information analysis, frequencies, means, ranges, and modes will be used.

Qualitative Analysis: The primary question for the current study examines the parenting experiences of mothers incarcerated in a Midwestern correctional facility. The current study will be a secondary analysis of (primarily) qualitative data. To ensure analytical rigor, the researcher will draw on the principles and heuristic devices of Braun and Clarke's $(2006,2018)$ Reflexive Thematic Analysis (TA) approach, which includes the above-stated six steps for conducting analysis. This strategy, just like Grounded Theory (GT) (Charmaz, 2006; DiPietro, 2019; Glaser $\&$ Strauss, 1967), enables unanticipated themes and avenues for inquiry to come to light (Braun \& Clarke, 2006; 2018; 2019a; 2019b). In fact, according to Clarke (2020), similarities exist between TA and GT because they are both believed to have evolved from Content Analysis. As stated in the introduction chapter, three broad approaches to TA predominate - coding reliability TA, codebook TA, and reflexive TA (Clarke, 2019a, 2019b). Therefore, for this study, reflexive TA was chosen over the other two because just like GT, it takes a data-driven approach and is theoretically-flexible - meaning it can work well with any type of data and can be used within 
different frameworks, to answer quite different types of research questions (Clarke, 2017, 2018, 2019b), and is based on 'organic' coding (Clarke, 2020).

Thematic analysis is a method for identifying themes and patterns of meaning across a dataset in relation to a research question (Braun \& Clarke, 2012, 2013, 2017, 2018, 2019a), “...and interprets various aspects of the research topic" (2006, p. 79). According to Clarke (2018), themes can either be the analytic input or output. If themes are developed early on and guide coding, they are the analytic input of the study; if they are developed later and represent the outcome of the coding, they are the analytic output (Clarke, 2020). Relating to this study, the goal is to have themes as the analytic output or end product of the project. Given this, what is a theme then? According to Clarke (2020), there are two main conceptualizations of a theme themes as 'domain summaries' or themes as 'fully realised' (shared meaning). While the former can be pictured as a 'bucket' theme in which summaries of a particular area or domain of data are captured without thinking about how they are related, 'fully realised' themes - on the other hand - look for a shared meaning underpinned by a central concept (Clarke, 2020). Hence, for analytic rigor, this study adopts the latter conceptualization - themes as 'fully realised.'

There are three elemental methods that serve as the foundational approaches to coding: (1) Descriptive, (2) In Vivo, and (3) Process coding (Miles et al., 2014). For this study, using MAXQDA software, the researcher will utilize the first two approaches - descriptive and in vivo coding. A descriptive code assigns labels to data to summarize in a word or short phrase, the basic topic of a passage of qualitative data (Miles et al., 2014), and is helpful for ethnographies and studies with a wide variety of data forms (field notes, interview transcripts, documents, etc.). On the other hand, when a code is taken directly from what the participant says and is placed in quotation marks - this is an In Vivo Code (Saldana, 2016), and it helps to prioritize and honor 
the participant's voice (Miles et al., 2014). In Vivo coding is appropriate for virtually all qualitative studies but particularly for beginning qualitative researchers learning how to code data (Miles et al., 2014). Given that the current researcher is a novice in qualitative coding, this will be adopted.

The initial line-by-line coding of the data will only occur after re-reading the interview transcripts several times. Following this, the tagged themes will be reorganized into overarching themes that are common across the individual responses provided by the interviewees. In short, after initial coding, data will be synthesized and sorted through more focused coding. As such, several quotations will be provided in the findings and discussion sections to illustrate the relativeness of the identified theme(s). After identifying the overarching themes, in the process of the analysis, attention will be paid to the factors of intersectionality (i.e. race, socioeconomic class, age) to determine what, if any, salient themes exist. Attention will not only be paid to the individual's objective experiences and choices, but also to the meaning and symbolism they ascribe to their experiences.

Throughout each phase of the analysis, the researcher will utilize the constant comparative method, whereby segments of data were compared with others to determine variation within and properties of particular categories, to identify patterns and gaps, and to develop new conceptual categories (Charmaz, 2006; DiPietro, 2019; Silverman, 2011). Additionally, inductive analysis of the data (DiPietro, 2019) will begin by examining the ways in which the incarcerated mothers described their pre and post-incarceration 'mothering' experiences, with particular emphasis on perceptions of trauma, family relationships (i.e. family ties: connectedness, role of family, and effect of incarceration on families), and self-identified sources of risk and resilience in their lives. 


\section{Hypothesis}

The researcher of this study expects to see an interplay of factors like race, age, and socioeconomic class playing a critical role in differentiating and defining parenting experiences in each individual mother. In addition, those single-parent mothers are likely to report more negative parenting experiences because their children will have limited care options following the incarceration of their 'only' parent. Such a scenario is likely to affect single parents more than those mothers that were living with their partners prior to incarceration. Like McDermott (2019), the current researcher believes that while the intricacies of intersectionality can be imperceptible to researchers and their subjects, these intricacies exude multiple positions of oppression for incarcerated mothers.

\section{IRB Concerns}

Since the present study is a secondary analysis in which there will be no personal identifiers in the data set, the study will not require IRB. Therefore, given this prior deidentification, anonymity and confidentiality are not a concern. But, if future studies (in which primary data is collected) are conducted, then IRB information will need to be more fully covered. For example, future researchers may want to conduct primary studies on the effects on children with mothers in prison, this could become a very sensitive study with this protected group - which warrants careful ethical considerations and IRB clearance. 


\section{CHAPTER IV: FINDINGS}

Women's annual prison population growth in the U.S.A. is almost double that of their men counterparts (Arditti, 2015). Literature has established that most of these women in prisons and jails are mothers to children below the age of 18 , with approximately $50 \%$ of those children being below the age of 10 (Gurusami, 2019; Ramirez, 2016; The Sentencing Project, 2016). While some of these children may be in prison with their mothers, given that studies have noted that approximately $4 \%$ of these women will be pregnant at sentencing (Child Welfare League of America, 2021), the majority of these women's children are outside prison under alternative caregiving arrangements (Beichner \& Rabe-Hemp, 2014).

However, studies have consistently highlighted that concerning the social expectations and family setups in the U.S.A., women are likely to be the primary caregivers to their children (Garcia-Hallett, 2019a, 2019b; Ramirez, 2016; Williams et al., 2019). Thus, compared to the incarceration of fathers, this caregiving role makes women's incarceration have weighted impacts on the lives of their children (Schlafer, Duwe, \& Hindt, 2019). As mentioned earlier, these incarcerated mothers can either be parenting from prison (i.e., if their children are outside prison) or in prison (i.e., if their children are in prison with them) or doing both (i.e., have some children outside prison and some in prison with them) (Scott, 2019). All these scenarios, as established by prior studies, have a tendency of creating both physical and emotional distancing between the mother and the child.

This study sought to explore the parenting experiences of women in prison by asking a broad question - what are the parenting experiences of women in a Midwestern correctional center? The question was answered by breaking it down into three objectives: (1) explore participants' parenting experiences pre-incarceration, (2) develop an understanding of 
respondents' perceptions of the quality of relationships with their child or children, and (3)

understand the respondents' perceptions of the effects of incarceration on their child or children.

This chapter will present results of the analysis. The chapter is split into two sections; descriptive statistics followed by qualitative results.

\section{Description of Interview Sample}

A total of 46 women (i.e., who were $100 \%$ of the program's participants) who participated or were participating in a family reunification program at a Midwestern correctional center were interviewed. In terms of race, most of these women identified as either White $(\mathrm{N}=$ 31) or Black $(\mathrm{N}=13)$, with two participants identifying as Asian (see Table 1). Although there was no minimum age requirement for participants, the mothers ranged in age from 20 to 50 years old $(\mathrm{SD}=6$ years $)$, with an average age of 30 years. In terms of education, most of the women $(\mathrm{N}=28$ or $65 \%$ ) had reached high school level (i.e., ranging from grade 10 to 12 ). Given the focus of the original study on the family reunification program ${ }^{8}$, all the women, save for two who were pregnant at the time of the interview, were mothers.

\footnotetext{
${ }^{8}$ The family reunification program allowed eight hours of visitation time per day, two to three times a month, in which incarcerated mothers would spend time with their children in a separate wing of the prison. For them to qualify for the program, these women had to satisfy the following requirements: (1) had to be serving time for a nonviolent offense, (2) must not have child-abuse or neglect issues logged with the Department of Children and Family Services, and (3) must have someone in their family (the alternative caregiver) who would bring their children for prison visit. On this note, it can be argued that these women were quite 'privileged' among their prison peers, and the sample is not representative of all women parenting from prison.
} 
Table 1: Demographic Data

\begin{tabular}{cccccc}
\hline & Frequency & Percent & Valid Percent & $\begin{array}{c}\text { Cumulative } \\
\text { Percent }\end{array}$ \\
\hline Race & Black & 13 & 28.3 & 28.3 & 28.3 \\
& White & 31 & 67.4 & 67.4 & 95.7 \\
& Asian & 2 & 4.3 & 4.3 & 100 \\
& Total & 46 & 100 & 100 & \\
\hline
\end{tabular}

On average, many of these women $(83 \%)$ had one to three children, with the mean number of children being two (see Table 2). Respondents' children's age ranged from zero to 24 years, with a mean of eight years and a standard deviation of approximately five years. Of these mothers, $24(53 \%)$ and $10(22 \%)$ were either single or divorced, respectively - with only nine $(19.6 \%)$ reporting to be married. During the time of their incarceration, alternative caregivers for most of the incarcerated women's children were either their maternal grandmother (49\%) or father $(23 \%)$, with the remaining percentage staying with their aunts or paternal grandmothers. Approximately, $57 \%$ of these children were reported to be male, while $43 \%$ were reported to be female. 
Table 2: Total Number of Children

\begin{tabular}{lccccc}
\hline & Frequency & Percent & Valid Percent & $\begin{array}{c}\text { Cumulative } \\
\text { Percent }\end{array}$ \\
\hline $\begin{array}{l}\text { Number of } \\
\text { children }\end{array}$ & 0 & 2 & 4.3 & 4.3 & 4.3 \\
& 1 & 14 & 30.4 & 30.4 & 34.8 \\
& 2 & 13 & 28.3 & 28.3 & 63 \\
& 4 & 11 & 23.9 & 23.9 & 87 \\
& 5 & 1 & 8.7 & 8.7 & 95.7 \\
& 6 & 1 & 2.2 & 2.2 & 97.8 \\
& Total & 46 & 2.2 & 2.2 & 100 \\
\hline
\end{tabular}

Almost half of the women $(\mathrm{N}=22)$ were unemployed at the time of arrest and subsequent incarceration. These women were most frequently incarcerated for drug crimes (i.e., manufacturing, possession, and sale) $(\mathrm{N}=17$ or $37 \%)$ and money crimes (e.g., identity theft, shoplifting, burglary, and robbery) $(\mathrm{N}=19$ or $41 \%)$ (see Table 3), common among women offenders (see Beichner \& Rabe-Hemp, 2014; Garcia-Hallett, 2019a; 2019b). Sentence length ranged from two to 15 years, with a mean sentence of six years.

Table 3: Conviction Charges

\begin{tabular}{llcccc}
\hline & Frequency & Percent & Valid Percent & $\begin{array}{c}\text { Cumulative } \\
\text { Percent }\end{array}$ \\
\hline Crime & Substance-related & 17 & 37 & 37 & 37 \\
& Traffic-related & 5 & 10.9 & 10.9 & 47.9 \\
& Theft-related & 19 & 41.3 & 41.3 & 89.2 \\
Miscellaneous & 5 & 10.9 & 10.9 & 100 \\
Total & 46 & 100 & 100 & \\
\hline
\end{tabular}


All the participants had prior offenses ranging from one to six, with the majority, 53\% (N $=24)$, having one prior offense. In addition, 15 (34\%) of the participants had a prior conviction. About $32 \%$ of all the women in the study had an incarcerated family member or members with the Illinois Department of Corrections (IDOC), most of them (86\%) being close family members like parents, siblings, and spouses.

\section{Qualitative Analysis}

For this part of the analysis, the 46 interview transcripts were coded using Braun and Clarke's (2006) thematic analysis techniques within MAXQDA software. The researcher's focus was on repetitions within and across interviews as indicative of thematic patterns arising from the data. This was done without a predetermined list of categories to attribute participants narratives, save for the background knowledge attained from the literature review. As mentioned earlier in Chapter 3 (i.e., Methods), according to Braun and Clarke (2018), thematic analysis can have themes as either a research input or output. For this study, themes were used as a research output summarizing the parenting experiences of incarcerated women. This means themes were the end product of the analysis not part of the process of analysis (i.e., input).

Four themes - which are tied to the study participants' pre-carceral, carceral, and postcarceral parenting experiences - were identified. These themes, which were developed by combining parent codes or nodes which in turn had been developed by combining examples from the data, are given here in their order of appearance: (1) mothering, (2) visitations, (3) fears, and (4) resilience. To summarize the theme development process and to highlight their interrelatedness, a visual or mind map (see Fig. 1) was developed. This mind map consists of three parts - emerging themes, manifestations, and examples. To avoid confusion, while 'emerging themes' refer to the end product of the analysis, 'manifestations' refer to the parent 
codes or nodes from which the themes were developed, and 'examples' refer to some instances in the data from whence the codes were developed or are perceived to mean.

As alluded earlier, the four themes cannot be understood in isolation because they do intersect and overlap. To highlight that one cannot exclude these overlaps from the analysis, the four themes are connected by a broken line in the visual. For example, the mothering experiences of these incarcerated women cannot be understood outside of the visitations they receive from their children, and the visitations may not be understood independent of the fears that they develop upon seeing their children during these visits. In short, how these visitations are structured has a bearing on mothering and, in turn, that can either infuse or diffuse their parenting fears. Consequently, all three themes shape the adaptation and survival strategies these mothers employ, which, in short, can be understood as the fourth theme - resilience. One last thing to note about this visual is the use of the phrase 'emerging themes' as opposed to Braun and Clarke's (2018) advice. They argue that themes do not 'emerge' or 'mushroom' from the data, rather, the researcher creates them. While conscious of this argument, the researcher used this phrase to indicate what was coming out as the data was being weaved, not necessarily to imply that themes were lying dormant in the data waiting to be discovered. 
Fig. 1: Mind Map

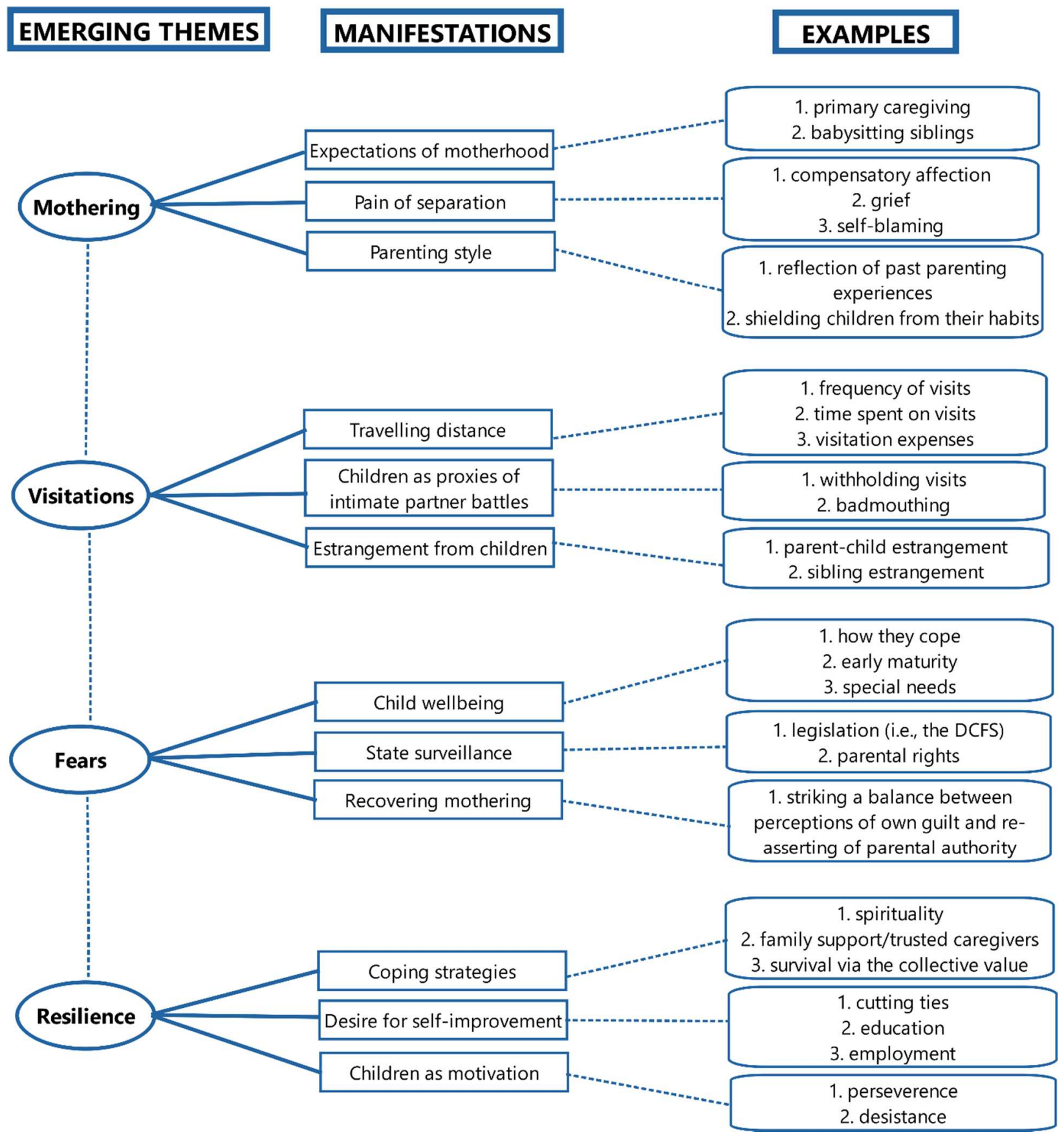

Theme 1. Mothering

Given that motherhood is deeply rooted in traditional historical notions of female identity, this theme was derived from the guilt, anxiety, and depression that incarcerated mothers go through as a result of being separated from their children. For this study, mothering is defined 
as the challenges, perceptions of their children's attitudes about their incarceration, and the adaptation strategies that participants in this study face and adopt to maintain their caregiver role even from a carceral distance. Even though several issues were raised by the mothers in question pertaining to this overarching theme, three areas were more evident in their narratives, which act as 'manifestations' or sub-themes of their mothering experiences. These are (1) expectations of motherhood, (2) pain of separation, and (3) parenting style.

\section{Expectations of Motherhood}

Typically, motherhood is perceived as the fulfillment of womanhood. Hence the belief that having a baby is a woman's most important achievement. Tied to this belief, is the naturalization of the caregiving role that comes with it as women, compared to their men counterparts, are in most instances the primary caregivers to their children. Women in this study were no exception, as their narratives indicated that they were their children's primary caregivers prior to incarceration or at least up to a point where they may have turned to substance use. The naturalization of these expectations' points to the amount of time mothers spend with their children, and the level of affection they give them, to which a mother-child bond is created. Given this, direct quotes below emphasize the belief that mothers have a particular role in children's lives that they only are supposed to play. This borders around the perception of gender roles. On this note, talking about suggestions for improvement to the family reunification program, motherhood expectations in terms of the primary caregiving role and the importance of mother-child bond is perfectly captured in Jordin's ${ }^{9}$ (a mother of six) words below:

It becomes a...as a mom, for me especially, 'cause I'm always the type of mom that has all the kids at my house 'cause I like to know where my kids are at all times...so I'm very

\footnotetext{
${ }^{9}$ Jordin is not her real name, including the names of all the participants in this study. Pseudonyms were used as a way of protecting the identity of participants, in respect to IRB requirements.
} 
kid-friendly. I love kids, ya know. These girls, when they're havin' their babies here [in the family reunification area of the prison], you bond with these little kids here. [Jordin]

In addition, Maya, an incarcerated mother of three who grew up in a dysfunctional home,

when she was asked to clarify her fears about what life is like for her son said:

Yea, I mean, yea, 'cause we have a joint custody. It's just that ya know, one parent is different than the other parent, ya know, especially bein' a father He's not gonna be, some fathers aren't that 'mother figure' loving, like, ya know, we do, hugs, kisses and all that. So that's a part that worries me 'cause, ya know, I lived with my parents when I had Mason, so I'm a very family-oriented person. And Bill, he's kinda, ya know, his mother passed away, so all he has is his dad, and his sisters all live in Chicago, so Mason don't see none of his relatives, and at my house, there's always somebody comin' over, so he sees all them. So, it's kinda, that's what kinda bothers me, but... [Maya]

Substantiating Maya's understanding of these expectations of motherhood, Evelyn - a mother of one, who was convicted for retail theft - when asked whether she would still prepare her daughter for school, narrates:

Yes. I wouldn't do it like I was supposed to, like a mother should, but I would have days where I would be running late but where I didn't keep up, my mom did. So, she was a big help, and she's there for them now since I've been incarcerated. And when I got locked up, my baby-daddy had my baby, and he ended up going back to jail, and he actually just got out yesterday, so I don't know what the outcome of that is going to be. [Evelyn]

To juxtapose the preceding narrations, talking about how life will be different for her children (i.e., in terms of attending to their needs) had she not been incarcerated, Elizabeth, a mother of three who was serving a sentence for drug-related charges, highlighted that:

Mmm hmm, that's why I talk to tell my kids now, like, now they gettin' into the mode of not bein' able to get what they want when they want it because I'm not there. And, like, my husband had to tell 'em like, they always want a pair of tennis shoes, 'Ya'll just, ya'll just got some tennis shoes, you can't just get another pair right now.' 'Well, if my momma were here... 'Your momma not here right now.' So, we not feelin' to be doin' that. So, I've had to tell 'em, 'Ya'll know when I get home, it's not gonna be the same.' They like, 'We know, mom, we don't care.' I'm like, 'I'm just lettin' ya 'll know, you know, when I get home, ain't gon' be just whenever we wanna go here 'n there, we can just go- 'Well, let's go to Disney World.' 'Okay, let's go.' 'Let's go to the Ozarks.' 'Okay, 
let's go.' We not just gonna be able to jump up ' $n$ do that. We have to plan like regular people do. [Elizabeth]

Lastly, even though some of the respondents were first-time mothers who indicated that they did not have pre-incarceration parenting experiences, expectations of motherhood were evident in how they would assume the role of babysitting their siblings. Avery, who grew up witnessing parental addiction, when asked why she would sometimes miss school indicated how she would take care of her mom's youngest children:

She would say that you need to do this. Because she was sick, throwing up, the baby had to be changed, fed, you know. they needed to be taken care of. And they were only 10 months apart, so it was like having twins. I was 13 doing that, taking care of them like that. Starting a new one and a 10-month-old. [Avery]

\section{Pain of Separation}

Given the key role that mothers play in the lives of their children - and, in most cases, the bond that comes with it as established above - by extension, the pain of separation that comes with incarceration is substantial and is often reciprocal between the mother and the child or children. The most telling factor in this, however, is the incarcerated women's loss of mothering opportunities. Thus, in the narratives given by participants in the current study, this pain was most evident in these women's grief, self-blaming, and the subsequent compensatory affection they would give to their children during visitations. In telling their stories, grief was manifest through how the women would be crying during the interview (or in private) as in how Aria, a mother of four, noted "I cries all the time (sic)." Similarly, Emma, a mother of five, when narrating how being around other people's children during carceral visitations bring mixed emotions in her, said:

Like the kids, they run up to me, like a few of 'em that I'm really, I got close with, um... you know, they come up, they give you a hug, gave me a hug 'n stuff like that, and...and when they do that, I hug 'em back ' $n$ stuff, but it, I tell 'em don't do it, but when 
they do it, I go in my room and cry because I wish it was my kids that I was holdin'. [Emma]

On account of the physical and emotional distancing from their children brought by their incarceration, women in this study would use phrases like, "I'm a worthless piece of shit" [Aurora] or “... it's my fault you know I take responsibility for what I did ...” [Penelope], to describe their blameworthiness in the circumstances that saw them being separated from their children. In short, the interviewed would self-blame. For example, Brooklyn, in spite of her sexual victimization as a child, took full responsibility of her actions when asked whether her childhood experiences may have had some impacts on her trajectory into crime:

I think that I could have been a much better parent because my parents were wonderful. They didn't do anything, I mean they didn't do anything wrong per se, in raising me. They did everything right, so I don't put any of the blame on them. My addiction is what took me away from being a parent. Otherwise, I think I would have been a really good parent because I was parented right. [Brooklyn]

Because they blamed themselves for their conspicuous absence from their children's lives, these women would then attempt to balance their perceptions of guilt and loss of mothering opportunities with some level of compensatory affection during visits. This compensatory love was informed from two perspectives, that is, compensating the affection they may not have gotten as children, or the one they did not give their children be it pre- or during incarceration. The following two quotes from some of the participants captures these two scenarios vividly first, the emotional gap and, second, the reaction to it like being "too affectionate":

Well when I was 12, my mom had a baby, and then 10 months later had another baby, so you can imagine them two, because at the time she was still struggling with her alcoholism. And so, I went straight from that to being pregnant, so I never had a chance to be a teenager. She would be hung over, and I wouldn't go to school, well my sisters would. I think I matured fast, and I became sexually active when I was 14. I was filling the emotional hole that my mom left [Avery] 
I don't know...just yeah, the...cause my daughter if you didn't talk to my daughter right now she'll tell ya that I am too affectionate with them you know I think I do that because I didn't get it as a kid myself. She's always like mom quit touching me so much you know cause I am always especially now since I don't see them as much when they come I am expecting their whole body I dint know you had a mole here or I dint know you had a mole there and I am just touchy lovey I'm always wanting to kiss and hug on them to her it's almost too much cause she wasn't used to it either y a know because I was in my addiction so much, but now that I am clean I know I took a lot of times for granted that I had with my kids. And I just want to be all over them now I just... [Kathrine]

\section{Parenting Style}

As demonstrated by Avery and Kathrine's quotes above, the reference point of parenting styles women in this study employed is somewhat tied to their past parenting experiences as children - ultimately, either positively or negatively impacting their present experiences. That means, these women may either consciously seek to change or uphold the way they were parented in relation to how they now parent their children, or subconsciously enact in their present parenting what they perceived as inappropriate in how they were parented. For example, while the majority of participants raised concern about how they were raised by absentee parents - either due their parents' work commitments, addiction issues, or incarceration - because they were also incarcerated, the same script was playing out in their children's lives. The desire to change parenting style is visibly noted in Chloe's words:

For me, I don't want to be like my parents. In a way, I do-just not in the way they were physically abusive. But other than that, I think they were good parents. I want to be strict and compromising. So, if they want to have fun, let them have fun. But still do schoolwork and still be doing things you should be doing.

In addition, given what they may have deemed inappropriate parenting as either emanating from their childhood experiences or their own perceptions of guilt. Several women in this study hinted at how, even during their pre-incarceration parenting, they would 'shield' their children from inappropriate habits they themselves were either victims (i.e., intimate partner 
violence) or partaking in (i.e., substance use). However, the 'shielding' may have had unintended consequences in that sometimes to achieve this, the women would have to take their children to alternative caregivers like grandparents for them not to be in proximity to these bad habits. On that note, the unintended consequences may be the separation that came with it, meaning these children were already experiencing parental absence in their lives even before their mothers' incarceration. Ultimately, doubly affecting the mother-child. The following remarks points out to this:

So, I didn't...I don't want my kids to... my son to grow up thinking men should treat women like this. And I don't want my daughter to think it's okay for a man to treat her like the way daddy treats his mom [Claire]

Once in a while, yea, her father was pretty leery of me at the time, and for good reason. I was using and, with very good reason he didn't want her around me like that [Brooklyn]

I bartended every weekend, I was makin' a lotta money where I was workin' at. So, I had, I had my kids all through the week, but on the weekend, you know, I worked nights or whatever, so my mom had my kids on the weeks, on the weeknights, or the weekends. And then it just went into... I started datin' a guy who was making meth, and when I, I was gettin' ready to move in with him, and I was like, I knew I couldn't take my kids into that environment, you know [Leah]

... but yeah I wouldn't let them see me use or anything you know either I He would stay out in the front room with them or in the bedroom and make sure he was okay while I would go do mine and then I would go do mine. And then we would take turns. We would never let them see us getting high [Aurora]

\section{Theme 2. Visitations}

Once incarcerated, visitations play a central role in maintaining the family bond that would have been threatened by the physical and emotional distancing that comes with imprisonment. In addition, it is a show of family support which is a dire need for these mothers in dealing with carceral trauma. Hence, the second theme that emerged from the analysis pertains to visitations. It can be understood as the challenges that the study participants faced in, foremost, getting a visit and, second, how they related to their children during these visits. Like 
mothering, this theme manifested in three areas of concern: (1) traveling distance, (2) children as proxies of intimate partner battles, and (3) estrangement from children.

\section{Travelling Distance}

Women in this study faced several challenges in staying connected to their children, once incarcerated. When mothers are imprisoned, it is likely that their children would stay with relatives (i.e., grandparents, aunts) or foster parents, as alternative caregivers. Given that those likely to be incarcerated are from struggling families who were already vulnerable prior to this unfortunate separation, it may be challenging for the new caregivers to coordinate regularly scheduled prison visits. One of the most telling impediments to visitation raised by participants in this study is traveling distance. A majority of the women indicated that their families stay at least three hours from where they are incarcerated which translates to a roundtrip of at least six hours. Coupled with the age and compromised health of some of these alternative caregivers, it further impedes the coordination of regular visits given the driving distance. Ultimately, this impediment would generate three other concerns - frequency of visits, time spent on visits, and visitation expenses - which further hampered the bonding effect that the reunification program was trying to achieve. Captured below are some of the remarks from the interviewed mothers:

Um we're supposed to have three visits a month, but I get two. They drive down once a month and they stay for two nights and then they drive back. So... It's work, and then it's gas, then it's hotels, then it's the food, then it's the driving back and it's me eating in the visiting room and you know me and my two kids eating in the visiting room [Claire]

Um, my mom. Yea, my mom brings 'im once a month. But he's still...he does let her, let him go to my mom's house every other weekend. So, he still gets to see, like, my other three kids every other weekend he's with 'em. Which is good [Leah]

Usually every week I see my kids 4-5 times a week [Aurora]

About an hour. But then, you know, he has to go and get them. He'll like go get them, if school is going on, he'll go get them on a Friday night and then come here on Saturday and take them back on a Sunday. So, it's a lot of driving. [Penelope] 


\section{Children as Proxies of Intimate Partner Battles}

The second impediment to visitations highlighted by the participants relates to how children were used as battle proxies by their estranged partners, who may either have assumed the caregiver's role or would have acquired custody rights upon the mother's incarceration. As a way of 'getting back' at them, the women noted two things - withholding visits or badmouthing - their estranged partners would do to frustrate the visits and, ultimately, the mother-child relationship. Thus, even though the children may eventually visit their incarcerated mother, the bond and relationship may already have been preemptively ruined. Quoted below are some of the concerns:

I had evens, he had odds [years]- he still never took it upon himself to come and get 'im. Maybe once a year, when it was convenient for him, when he had a new girlfriend he wanted to show off, 'Hey, I have a kid.' Kinda thing, you know, 'And I take care of 'em.' No, you don't. But, you know, but I still, I never, never did that, you know, like, in front of Braden, I never harassed 'im or talked down to 'im or made smart comments or nothin' like that, I just never did it because my parents didn't do it in front of me, you know, whatever their issues were. So, I knew better than to do it in front of him. However, his dad is not that way, and his dad takes every little thing that he's ever thought about me and throws it at him [Leah]

Um my ah husband, I still don't see him. He once in a blue moon will pick up his kids. Um it hurts when I talk to my children on the phone because my son's like, 'Daddy called and said he was coming to get us, but he ain't gonna show up.' And one time he sat... my parents got a big bay window and he sat in front of it for two hours waiting for daddy to come and he never came. So, you know I... I write him and tell him, 'don't do that to our children. You can do it to me', cause he does it to me all the time. 'You can hurt me but don't hurt our kids'. So now they already don't believe in promises. They're already startin' to learn that. [Claire]

You know. If he did not love me and wanna be with me, a baby would not mean crap 'cause he knows that he could get visitation, you know, he could pay child support, he could get visitation. He does not have to be with me to be part of his son's life. [Violet] 


\section{Estrangement from Children}

As would be evident by now given the above-stated, visitation challenges these incarcerated mothers face affects the amount and quality of time they spent with their children which, on its own, is a recipe for parent-child estrangement. Estrangement in this context can be defined as the likelihood that a child's attachment to the mother might be compromised as a result of long periods of separation. To which, in this case, the separation would not only have been caused by incarceration but is exacerbated by intimate partner battles. In that way encumbering further, the already compromised available carceral avenues of staying connected to children. Narratives from the women in this study voiced two relational areas in which this estrangement can happen - parent-child estrangement or sibling estrangement - and these two may happen concurrently. This may even see the mothers struggling to reassert parental authority during visitations. The following statements capture the remarks of the women:

Umm yeah, I mean even when she comes here sometimes, I have to remind her you know I'm mom and what I say goes. I know I am not there but I ma still your mom because I told her to do something when she's here and shell snatch something away from me or make a funny sound at me or something [Audrey]

I have a ten year sentence, so had he not been here with me, it would have been four years and three months before I finally got home, so...by the time I'd have got home, he would've known me as 'mom,' but I wouldn't have been mom [Layla]

No. No, 'cause he's my mama baby. Haha. So, I'm nobody to him it seem like, you know [Aria]

While parent-child estrangement is what has just been highlighted above, sibling estrangement, on the other hand, is when sibling attachment is threatened as a result of the separation induced when siblings are assigned to different caregivers upon their mother's incarceration. As the women in this study would note, this sibling separation creates emotional distancing among children as they are now raised under different living environments and parenting styles. The following remarks highlight this concern: 
I think they put him on medication at one time, I'm not sure if he's on it now. But he's more calm now, but you just can't like... my oldest son, when they do actually see each other, 'cause they have different dads, he'll try to joke with him, and my son will just try or he'll get real angry [Chantel]

Well the biggest one with all of them is that they are all separated. They're not only separated from me, but now they're separated from each other. So that played a big impact. But like my oldest son, he's... he used to be so confident and, he was a momma's boy but he didn't really need anyone to do anything for him, he was independent early on, and now he just kind of... it's like when he's around he wants me to do everything. I don't know if it's because he misses having me around all the time, or what it is, but I know he's been... he doesn't want to go to school, he's always trying to play sick, and that's not my son, you know. But, he's kind of got a temper. He's into this big kick of like... Carrie, my daughter, is too young to have a boyfriend, so he starts bumping chests with the little boy in school. (laughing). So, he's become very protective of her, though. [Camilla]

To this point, it is clear that the whole theme of children's prison visits affects a particular group of women, those who are mothering from prison (i.e., women with children outside prison), as opposed to those mothering in prison (i.e., women with children in prison with them). The former group of women includes mothers who are caught at the nexus of concurrent parenting from prison and in prison. As is emanating from the interview data, such women do have different mothering experiences compared to their latter counterparts, as their narratives tend to point to higher levels of grief and subjugation as far as carceral motherhood is concerned.

In the context of this study, the term subjugation illustrates two things: first, the physical and emotional distancing experienced by incarcerated mothers, and second, it suggests the powerlessness these women experience with the correctional system. In short, they experience both isolation and lack autonomy or control. This is not the case with women mothering only in prison as they are neither affected by isolation nor lack of autonomy, at least as far as being with their children is concerned. Thus, while almost all women in this study appreciated how the family reunification was "...a good program to have time to be bonding..." and staying 
connected with their children, still their experiences differed between the said groups. Below are two remarks that speaks to these varied experiences. While the first remark is coming from a woman caught at the intersection of mothering both from and in prison, the second quote is of a first-time mother of one, who gave birth whilst already enrolled in the prison reunification program. The two remarks juxtapose a completely different experience of how these two mothers perceive the intersection of incarceration and motherhood.

Um, it's nice. It's just, it's just harder for me because this isn't my first kid like a lot of the people here-it's their first baby. So, of course, they're just happy all the time, you know. But it's hard for me because I'm not with my other kids, and they're-... they don't get to be with her ' $n$ stuff like that. But I mean, as far as bein' a mom here in the program, it's been really great. But I just have my days where I'm just, I don't wanna get outta bed because I'm just depressed, you know, because of my other kids. But other than that, everything is, it's, it's really nice here. Everything's-...she's taken care of really, really well [Zoey].

So, it's, it's been...it's been good being here considering that I am in prison. I've learned a lot of things since I've been here. I've had a lot of help since I've been here. Um...it's... an experience that's hard to explain. Unless you've been in the situation of being here. I don't have other kids, so I hear the other moms talk about, you know, it's hard for them to go to doctor's appointments, and blah... It doesn't bother me because I've never had an experience of takin' a child to the doctor without bein' incarcerated. So, for me, it's, it's, I guess, maybe, like, another, just another day. I don't feel like I'm in prison. I don't feel like I would have really done anything different, had I been at home- I still parent him the way that I would've parented him, had I been at home. So, its...[Layla]

Whilst the two mothers, like the majority of women in the study, agree that the program is unparalleled as far as parenting behind bars is concerned, their tales also tell an opposite story. To which the experiences of prison visitations, apart from visits of other family members, are more relevant to the first mother than the second one. Evidently, whilst Zoey notes anxiety and lack of control concerning the wellbeing of her other children outside prison, Layla, on the other hand, sees prison as home. 


\section{Theme 3. Fears}

Due to factors related to their pre-incarceration, carceral, and post-incarceration traumasome of which are already highlighted in the above themes - women in this study experienced various fears related to their primary caregiving role vis-à-vis their conspicuous absence from their children's lives. On this note, fears - which refers to the women's perceptions of threats or dangers that incarceration posed to either their mothering role or their children or both - was identified as the third theme arising from the data. This fear was visible in three areas of manifestation: (1) child wellbeing, (2) state surveillance, and (3) recovering mothering.

\section{Child wellbeing}

Even though the majority, if not all, of women in this study commended the family reunification program with words such as "great," "perfect," or "good" being used to describe it, some women - the majority of whom with children outside prison - were concerned about the wellbeing of their children. This included women who may have given custody of their children to 'trusted caregivers' (like their biological parents), as they still felt they may still have parented their children differently had they been in their lives. Most of their concerns centered on the effects parental incarceration had on their children with the most recurring being anger issues, withdrawal, poor school performance, rebellion, and a host of other behavioral issues. Statements like, "he or she is always angry," "acting out," "sad," "she cries all the time," “...she gets pretty upset when she has to go," and "they don't wanna leave" (i.e., after visiting), were common in the narratives, thereby bearing witness to the unprecedented effects incarceration has on families. Several quotes below bear witness to this:

Yea, and they went through, um, like the first six months of me bein' locked up, my two year old, he just, I got locked up April 19 $9^{\text {th }}$, and he turned two the $23^{\text {rd }}$ of April, so...you know, he was a year when I got locked up, but, um... He would wake up in the middle of 
the night, my mom said, screamin' for me for, like, six months, he would do that. He did it for a while. [Zoey]

Yea, and his behavior, up in the lobby, and you can ask the guards that work up there, he is totally out of control. But when he gets back here with me, he's fine. I think that the more they come and the more they go and the more you have to tell them.... Just recently every time he comes, and he's not wanting to come now because I think, it's because I'm telling him no mommy can't come home tomorrow but I'll be home soon. So somedays, like I was supposed to have him Friday, but he wouldn't come. So, it does affect the kids, and nobody is going to tell me that it don't, because it does [Aurora]

Right, he, um...he's angry at his dad a lot and he tell me all the time, you know, like, my dad does this, and you never did that, 'n so, he, like, he bases everything that his dad does on how he was growin' up, you know. 'Cause, like I said, his dad was never around. Um, I took it upon myself to hire a lawyer and get visitations set 'n all that, you know, when I, when he was growin' up, or whatever, but he still never, he had every other weekend visitation, every other, like, odd, even, you know, we had, like, even and odd holidays or whatever [Leah]

Apart from the above, fears about children's wellbeing were also prompted by the child's age (and gender to some extent) upon separation, and special needs some of these children might have. While in the former concern, mothers perceived their children to have "matured too fast" due to their absence, and in the latter part, the concern was on children with special needs who may need parental care more than that of an alternative caregiver. Thus, the women emphasized the impact of parental presence in children's lives. A couple of quotes below highlight these fears:

He's very mature for his age. Um...he kinda had to be I guess there, but, um, he's, he understands, you know, that, like, it's not that I don't wanna see 'im. But, you know, and he understands that, I know I messed up, and that it's my fault that I don't get to see him right now. It's, more than what I should, you know, and it's my fault that I'm not at home. [Leah]

Well, I just felt that my husband keeps an eye on where she's at, who she's with, 'cause I know, I mean kids are curious. I know she talks about boys, and you know, I mean that's my main concern. I don't worry about her with drugs and alcohol and any of those kinds of things, she's good with her schoolwork, but I think that her and boys - oh boy! [Lucy] Absolutely, I think that um the only thing that bothers me at Braden's age now is because I read one of them baby's books you know on baby's first year and I am reading from a baby being 10 months older your supposed to sit down and eat and stuff a meal and like 
its family time and that's the only thing that I really don't do, but everything else like he's in my room. I don't think he's to the point to where he even knows he understands that where this is and why are all these people are around us and all that's important to me is my baby is getting the attention he needs, the love that he needs, and the food and nutrition that he needs because um I really honestly don't believe that if I was a mom and raising my son for the first year of his life I don't think we would have this strong bond [Isabella]

\section{State Surveillance}

Carceral mothering included fears related to state surveillance, especially through the Department of Children and Family Services (DCFS). Given that most of the interviewed mothers in this study had a history of substance use, they felt that were under constant threat, not only of being separated from their children through incarceration as several of them were recidivists, but also through losing parental rights or custody. As the mothers would cringe at the thought of losing parental rights, they would devise ways to circumvent state surveillance and the separation that typically follows it. These ways, dating back to pre-incarceration parenting, included shielding children from observing their addiction habits or signing-off children to 'trusted caregivers' once they know the inevitability of their incarceration. Examples of these fears and circumvention strategies are captured in the remarks below:

I didn't know-... I figured the state was gonna take my baby once I had her. I didn't know that my mom could come get here, or if I didn't come here, I didn't know any of that, so...um...I got called up to the office of family services, and they interviewed-...they told me it and interviewed me, um [Zoey]

So, you know, the first thing I thought, it was great, I'm pregnant, and the first thing I'm thinkin' is, I'm gonna go to prison, have my baby, and they're gonna take it from me, ya know. My first kid, and I'm gonna lose my first kid. I'm gonna lose that experience, that bond, everything, you know. You can't get that back. That was my first thought, so, therefore I was not happy about it. [Violet]

I had gotten into trouble, and I knew I was comin' to prison, so I, um, temporarily signed, or temporarily signed over guardianship of my kids to my mom [Leah]

Some of time yeah, I mean it's not a big secret. I mean I had DCFS in my life. They knew what was going on, but they're not in my life anymore, but yeah I wouldn't let them see me use or anything you know either I He would stay out in the front room with them or in 
the bedroom and make sure he was okay while I would go do mine and then I would go

do mine. And then we would take turns. We would never let them see us getting high

[Aurora]

\section{Recovering Mothering}

Even after tackling and circumventing threats to motherhood from the state, narratives from mothers in this study point towards a dilemma in striking a balance between perceptions of own guilt and the need to reaffirm parental authority on their children. Perceptions of own guilt included narratives that would question their lack of moral standing to either advise or be role models to their children. This was true, especially for mothers who were parenting from prison as opposed to those parenting in prison. Thus, reaffirming parental authority during visitations included the “...I am still your mom..." instances, as an indication of a mother's attempt to stamp authority and claim back the mothering role in her children's lives. This attempt, of course, was to be neutralized by the mother's concurrent pings of guilt, like Emily's - "but it's like who am I to tell him" - words. The indicated, already is a red flag to (or at least the possibility of) a threatened mother-child bond or relationship.

In addition, since the majority of women in this study indicated their commitment to return to their primary caregiving role upon release, by extension, they anticipated the challenges that may stand in their way to achieve this. One such challenge, equivalent to fear, is the burden of regaining trust from their children. This is vividly captured in the words of Lucy's daughter"You're never going to drink again, are you mom? You're never going to touch alcohol?" - on one of her visits. On that note, for the purposes of this study, recovering mothering ought to be understood not as just a mother's struggle to gain the physical custody or physical motherhood of her children, but also as inclusive of an expressed commitment to restoring relationships with her children. Hence, in regard to this theme, the fear is on whether or not the custody would be 
eventually gained (provided it had been lost), and the mother-child relationship subsequently

restored. Below are some remarks by these incarcerated women expressing their fear associated

with the process of recovering mothering and the joy they experience upon recovering

motherhood, be it during or post-incarceration:

It would have been a lot worse for me having to go home and trying to parent them now without having seeing them every weekend on the unit here, and being able to lay in bed with her, watch TV with her, eat dinner with her, and all the things that I get to do here in this program [Brooklyn]

I think with my kids, I'll probably have problems with my kids when I first get home. Like, they already test the boundaries when they come here, so I know that when I go home, they're gonna test and test. And it might be hard for me, like, first getting out. Getting 'em back to the way things are, I guess. Back used to me bein' around. [Maya]

But he needs to be interacting with his sisters, and he needs to know that those are his sisters, and he needs to know that I'm his mother at the same time. I just want visitation with him, I want to slowly transition him back just him being back into the family unit. Not so much him just living with me on an everyday basis, but if that comes later on down the road, I would of course embrace that option. But I don't want to do anything that would hard him. And at the same time, I need to be involved with him, and he needs to be involved with me. [Avery]

You know, so they hear things, or they may see things, or... and you know, I tried to explain to him that it's not his fault that I'm here, and I'm sorry, and I know-... it's okay for him to be mad at me, you know, but I'll be home soon. And, you know, I try to-... I let him share his feelings with me. You know, I don't say, 'Stop talkin' like that,' or, 'Don't say stuff like that.' You know, I don't shun him. [Juliet]

I'm hoping, he's not [her son], like you know, out on his own, or trying to go out on his own. But by then, I hope he wants to stick around. [Serenity]

It was great. It was different, back to my life. First couple of months; I spent a lot of time with my son. It's just different. It is exciting. [Ruby]

\section{Theme 4. Resilience}

Although study participants would face various parenting obstacles and the subsequent

fear at all three stages (i.e., before, during, and after incarceration), the women emphasized the importance of surviving these negative circumstances. Therefore, in the context of this analysis, 
resilience is understood to mean the incarcerated mothers' quest for survival, the motivation behind this quest, and the ensuing strategies that they employed to realize this quest. This last theme was expressed in three ways in the respondents' narratives - (1) coping strategies, (2) desire for self-improvement, and (3) children as motivation.

\section{Coping Strategies}

Generally, most women in this study reported a notable shift from a blissful preincarceration relationship with their children to an estranged carceral one, which they sought and commit to correct post-incarceration. In-between the pre- and post-carceral periods, these women had to survive and circumvent the threats posed to their motherhood by various factors, chief of which was the separation brought by incarceration. This quest for survival and the strategies employed therein in anticipation of an eventual return to their mothering role, are what is referred to in this study as 'coping strategies.' The 'faith' these mothers had in returning to their mothering role upon release included giving temporary custody to 'trusted caregivers' like their biological moms. This is vividly captured in the following words of Leah: "I had gotten into trouble, and I knew I was comin' to prison, so I, um, temporarily signed, or temporarily signed over guardianship of my kids to my mom." Notably, from the narratives of these mothers, three things seemed to be the most common in keeping them going as strategies of keeping them resilient. These are spirituality, family support, and survival via the collective value.

Remarkably, while turning to God was more of a form of escapism, family support which was usually expressed through visits - was crucial in assuring the women that they 'still matter' and 'someone cares.' Which, in turn, would give them peace of mind. On the other hand, the importance of surviving these carceral-related negative circumstances required some form of collective value which goes beyond spirituality and family support. This collective value 
included passing of crucial information to other incarcerated mothers, teaching less experienced mothers the dynamics of mothering, sharing experiences, praying for others, and collective mothering of other women's children. For example, a lot of women reported that they learned about the family reunification program through other incarcerated mothers, and first-time mothers would report that they were taught parenting skills by fellow women in prison. Below are some remarks from these women which highlight their coping strategies in terms of spirituality, family support, and collective survival:

Yea. I don't stress over it too much because I know God has my back. He's gonna take care of me, you know, and I truly, truly believe that because he's taken care of me through this whole thing. We all go through trials, and, uh, today was a very stressful day, but, ha, I got over it, you know, it's just, you have to stop and think where you are, who you're around, and that we have no control. Over nothing. [Janet]

Yea, I just gotta stay focused, um, I read a lot, and, um, readin' the Bible and tryin' to, today I'm tryin' to forgive people. You know, tryin' to forgive people that wronged me I'm askin' for forgiveness for things I've caused. You know, uh, it's really not too many people that really know the situation, as far as in here. [Emma]

And a lot of the times, a lot of 'em, see, a lot of 'em that comes here and stuff, they don't really acknowledge it as a blessing. It's just so bad... and it hurts me to my heart. But who am I? I'm here tryin' to get my life together, so I can 't say nothin' or do nothin' about it, you know. I don't do nothin' but go pray for 'em. I go in my room; I literally do pray for 'em. Because they don't know no better 'cause they're young. You know. And... I just, I just say, 'Lord, just keep me, just keep me strong 'cause I...it's too much, you know [Aria]

It was suggested to me when I first got here, when you first come in to the prison they explain it to you and let you know that there's this program - but whenever I was in Little Prairie, I had a friend that had been to Chihuahua before that had told my parents and had told me about the program [Brooklyn]

My dad is doing beautifully, he has his own trucking company. So, he knows what it's like to walk in my shoes, cause he's walked in them himself. He paved the way before I came along. That's what he tells me, and he's behind me 100\% [Avery]

\section{Desire for Self-Improvement}

In spite of the challenges of carceral motherhood and the threat these challenges posed to their mental health, several participants in this study showed an intense desire to improve their 
situations, both during and after incarceration. This desire for self-improvement was evident mainly in three areas, i.e., cutting ties, education, and employment. By cutting ties, the women sought to dissociate themselves from or shun certain individuals or groups of people that they perceived to have pressured them into crime mainly through peer pressure. Shunning these individuals included even the possibility of relocating or changing towns upon release to avoid staying in proximity to something that may drive them back into crime or addiction habits. Additionally, most participants expressed interest in upgrading themselves through education. Thus, several of the mothers had either acquired GED while incarcerated or intended to do so upon release, so as to expand their prospects of securing employment. As a way of showing this commitment to change, several women in this study emphasized the desire to find employment and recover their mothering role. However, even so, concerns were raised about the effect stigma of incarceration history would have on their chances of getting hired. Captured below are some of the remarks highlighting these issues:

Um...well, like, as far, like, the smoking habit...as long as I stay away from, like, you know, certain people. But that's what I'm sayin'- I know if I go stay at my foster mom's house, or my sister's house, I'll be alright when it comes to that. [Naomi]

Yea, no. Because he, he did nothin' but pull me down [her boyfriend], and, like, now, it took me a lot to see that, you know. But now, this is a big wakeup call, and in a way I'm very blessed for my prison sentence because it, it, it helped me a lot, you know. It made me quit. [Leah]

Yes ma'am. I plan to study as much as I can so that I am able to go home with a GED so in November, once I'm released, I can take some kind of classes to hopefully get a better job. I do have my job to go back home to. He is going to let me come back to my job, and that's gonna be real helpful. But I would like to expand my education, like go to school and get a better job. [Audrey]

[relating to a job preparedness class she was taking] Well, how to explain what kind of felony you have, it consists of, instead of making excuses for yourself, they teach to explain to them where you went wrong, you're willing to change it. You're becoming a productive member of society, trying to get a job, you know. And actually, making a positive out of it by telling them your abilities and your skills, instead of bringing out the negativity, it's a really good class. [Madison] 
Um...I think my biggest one is just employment right now. I guess housing's gonna be one, too. 'Cause if I rent from somebody-are they gonna be like-.... they're obviously gonna do a background check on me. Are they-... is it gonna be hard for me to rent a place? Is it-...I'm obviously not gonna have money to just go put a down payment on a house. I'm gonna have to rent from somewhere. So, is it gonna be easier for me to go back home and live rent-free? That's gonna be what's easier, but I have to think about what's good for Skyler-where he's gonna go to school at. [Layla]

\section{Children as Motivation}

Interestingly, in all these circumstances threatening motherhood noted above, the main motivation of these women to survive the ordeals and be able to withstand the pain that came with the separation, was their children. Thus, certain statements - such as, "I just think that my kids miss their mother" and "They want their moms, and they want you to come home" - which showed the intensity and reciprocity of the pain of separation, were not uncommon in the narratives of these mothers. In all this, children remained the main motivation to 'pull through' or persevere even to the point of pledging desistance from crime in the future. As such, the intersection of prison and motherhood, the subsequent pain of separation, and a pledge to stay away from things that would threaten, once again, to separate them from their children, were these incarcerated mothers' bedrock for desistance. Below are some of the remarks from whence this understanding was drawn by the researcher among the narratives:

I know I don't ever want to leave Skyler. It would probably hurt him more than it would me 'cause he's been with me all this time. [Layla]

Not really, I just don't wanna go back to what I was doin' before, but I look at him every day, and whenever I look at him, like, those thoughts 'n what not just go away (37 Interview- Final, Pos. 33)

And I'm a very quiet person, I keep to myself, you know. And I just want to do my time and go home. I don't want any problems in here. [Lucy]

I don't wanna be, I, my whole thing is, like, now, doin', bein' where I was, and then, like, now, I'm sober, 'n, you know, everything's cool- I have great relationships with my kids and my mom, you know, and my brothers, all my family, really. I don't even, I have no desire to even be around that partying life anymore or the people that I was hanging out with [Leah] 
So, it's like, 'Mommy's in big people's timeout'. You know, 'Mommy got in trouble. She did something wrong' ... and they don't know what but, 'Mommy did something wrong so now she has to stay here for a while'. But I let them know it's only two more birthdays and I'll be home. You know, we go by the birthdays, so you only have one a year, so it doesn't seem so long. [Claire]

\section{Summary of Findings}

After analysis, it is clear that women in this study face a host of challenges emanating from the intersection of prison and motherhood. Once incarcerated, staying connected with their children becomes difficult to which they respond by having to devise 'creative' ways of parenting like calling, writing letters, or entrusting their children to 'trusted caregivers.' All this is done, primarily, with the wellbeing of the child or children in mind. Unfortunately, this prisoninduced separation goes beyond only separating mother from child. By extension, siblings may also be separated as they may be split among various caregivers, which may lead to sibling estrangement as they end up growing with no sibling bond. Narratives of these mothers were emotion-filled as they blamed themselves, even ahead of their own childhood victimization and subsequent substance use, for the conspicuous absence from their children's lives. In all these challenges, mothers had to - for the sake of their children - survive. Against this backdrop, four themes - mothering, visitations, fears, and resilience - were the most recurring in the analysis. 


\section{CHAPTER V: DISCUSSION}

This research explored parenting experiences of women incarcerated in a Midwestern correctional center. The foundational pillars of this study were three objectives - participants' pre-incarceration parenting experiences, perceptions of quality of relationships with their child or children, and perceptions of the effects of incarceration on their child or children - from whence four themes were subsequently developed. These themes, in their order of appearance, are as follows: mothering, visitations, fears, and resilience. Remarkably, the themes intersected and overlapped in many respects which, ultimately, prompted the development of a flow chart (i.e., mind map) to help explain the interaction. Of note, findings from narratives of women in this study did confirm most of past literature's findings especially in two areas - the etiology of women offending, and the ensuing challenges experienced at the intersection of prison and motherhood. While the former area is tied to discrimination, past abuse and victimization, as well as drug dependence factors; the latter area sought to explain how women - especially mothers - resultantly, experience prison differently compared to their men counterparts.

However, on the other hand, not everything found in the data could be authoritatively confirmed by past research, at least, in terms of the literature identified for this study. Thus, a few novel issues emerged, or at least so it seemed. Nonetheless, due to the fact that the narratives confirmed findings from past literature, by extension, they also confirmed the three theories intersectionality, pathways, and attachment - which were closely linked to the said literature. It is against this backdrop (i.e., of both the old and new findings, as well as relevant theories), that gaps for research, limitations, and the subsequent calls for action were founded. Hence, this discussion chapter is organized as follows: overlaps with prior studies; emerging issues; relevance to theory; limitations; and, a call to action. 


\section{Overlaps with Prior Studies}

One of the main overlaps of the present study with prior literature is carceral collectivism. Several participants highlighted, one way or the other, how they would work together in order to survive the carceral ordeal. This collectivism included sharing vital information (e.g., about the family reunification program) to one another, teaching first time mothers parenting skills, praying for one another, carceral caregiving of other women's children while they attend - for instance - prison programs, and advising each other among several other things. This collectivism was not only limited to the carceral setting but would rather extend to the outside world in form of family support, whereby most of the alternative caregivers to the women's children outside prison were other women like mothers, grandmothers, and stepmoms. This ties into the "it takes a village to raise a child" or 'collective motherwork' notion (Gurusami, 2019) and 'survival via the collective value' (Garcia-Hallett, 2019b), thus encouraging them to remain resilient through discrimination, criminalization, and overall systematic oppression (O’Reilly, 2014) like the overbearing state surveillance.

Narratives in the current study pointed out situations in which justice-involved mothers had learned to anticipate and circumvent threats. This, for example, is captured vividly in Leah's following remark: "I had gotten into trouble, and I knew I was comin' to prison, so I, um, temporarily signed, or temporarily signed over guardianship of my kids to my mom.” Just like Leah's preemptive action of militating against anticipated state threats concerning recovering her post-incarceration mothering role, Gurusami (2019) refers to a similar situation as 'crisis motherwork.' The concept can be understood as the lengths and level of strife to which incarcerated (or formerly incarcerated) mothers can go, in confronting immediate threats that would either prevent reunification (Gurusami, 2019) or lead to 'loss of mothering opportunities' 
(Wismont, 2000). Overall, all these efforts fall under 'decarceral motherwork' which, according to Gurusami (2019) refers to, "context-specific strategies that women employ to anticipate, react to, and cope with state interventions that threaten their mothering (p. 128). Such a contextspecific strategy, as noted above, was employed by Leah when she anticipated the threat of losing her parental rights given the inevitability of her incarceration and reacted to the threat by preemptively signing-off temporal custody to a "trusted caregiver" - her mom. By so doing, she would not only have circumvented the threat of losing her child, but also the labor of 'recovering mothering' upon release.

Studies have noted that 'recovering mothering' might be a mammoth task (Williams et al, 2020) which, for many mothers, involves renegotiating their mothering role as the big and most challenging part of this process (Scott, 2019). Notably, though the process and its ensuing challenges may, arguably, be more pronounced in the 'mothering after prison' phase (Scott, 2019; Williams et al., 2020), in relation to the narratives of the current study, the process may have started long back during prison visitations. Typically, in the current study, mothers would battle with striking a balance between perceptions of own culpability (e.g., "but it's like who am I to tell him”) and re-exercising parental authority (e.g., “...I'm mom and what I say goes. I know I am not there but I ma still your mom..."). This is exacerbated by the grief and lack of autonomy that incarcerated women experience in relation to the correctional system (Wismont, 2000), which then ties into remarks of powerlessness (e.g., "Like, we don't have any control over what other people are doin', and what other people are pullin' for us") exhibited in the narratives of this study. Inclusive, the emotional (Wismont, 2000) and physical (Beichner \& Rabe-Hemp, 2014) distance between prisons and families, and the accompanying financial burdens and time constraints (Scott, 2019), affects - like in this study - the mother-child bond, 
leading to parent-child estrangement (e.g., "If I call home she don't want to talk to me on the phone she will say tell mom I said hi but she won't get on the phone and talk to me...").

Consistent with prior research, the researcher found that spirituality played a pivotal role in the lives of incarcerated mothers as a coping mechanism for dealing with carceral trauma, the pain of separation from their children, and anticipated threats (Rioux, 2007; Stringer, 2009; Wismont, 2000). Of note, while spirituality would help participants in this study to cope with their prison-induced stress, it was also a subtle confirmation of powerlessness or lack of autonomy (e.g., “...I don't know how that happened, I guess it was just God... ” or “...God willing..."), which knots with Stringer's (2009) "put it in the Lord's hands" or "keeping the faith" findings of his study. Perhaps, carceral spirituality in its entirety, can also be tied to the notion of resilience - a quest for survival that goes beyond a mere restoration to the pre-crisis state (Garcia-Hallett, 2019a; Williams et al., 2020) - as it is often emotion-oriented and inwardly directed, hence a "personal quest [for] answers to ultimate questions about life, meaning ... and relationships to the sacred" (Stringer, 2009, p. 327). This is consummate to the narratives of some women in the current study as they exhibited this quest to understand the meaning of life while separated from their children, and at the same time being powerless about it.

Another important finding that proves to be consistent with prior studies is the effects of incarceration on children. Previous research noted that these effects may include school failure, antisocial behavior, and intergenerational incarceration (Arditti, 2015), as well as unstable living arrangements (Beichner \& Rabe-Hemp, 2014; Rossiter et al., 2015). True, in response to questions about any behavioral changes they may have noticed on their children as a result of incarceration, women in this study emphasized issues like anger, withdrawal, rebellion, poor school performance, among other things. In terms of living arrangements, prior research had 
noted that children of justice-involved mothers are likely to have unstable living arrangements (Rossiter et al., 2015), as they likely end up living with relatives (Beichner \& Rabe-Hemp, 2014), and those children are likely to be those who had been vulnerable long before parental incarceration (Goodsell, 2017). Relating to the current study, most respondents reported to have been single or divorced, had an addiction, and were of low socioeconomic status. Upon their incarceration, most of them reported that their children were taken in by relatives as alternative caregivers which, apart from a host of other effects, sometimes led to sibling separation (e.g., "Well the biggest one with all of them is that they are all separated. They're not only separated from me, but now they're separated from each other. So that played a big impact."). This sibling separation, according to the women's narratives, would sometimes lead to sibling estrangement.

\section{Emerging Issues}

Even though there were a lot of overlays between findings of the current study and those of past research, there were, seemingly, some new issues arising from the narratives of these women, albeit a few. Such issues included the women's concern for the wellbeing of the child in terms of the age and gender of child upon separation. Women in this study would typically link the age of the child to the likelihood estrangement, with children who were old at the time of the prison-induced separation being reported to be more resentful towards their mothers. On the other hand, children who were younger at separation were reported to have a compromised mother-child attachment as they would be too young to recognize them as their mom (e.g., "No. No, 'cause he's my mama baby. Haha. So, I'm nobody to him it seem like, you know'). Also, the respondents believed that because of the age of their children's age vis-à-vis their conspicuous absence in their lives as mothers, they "matured too fast for their age, which was a cause for concern to them. The intersection of age, gender, and "maturity" was even a cause for more 
concern in regard to girl children, as mothers would report that they would talk "adult stuff" like dating with their children — some of whom were as young as 10 years of age.

Though past literature confirmed parent-child estrangement as mostly linked to the physical and emotional distancing brought about by incarceration, there was, however, a new twist to it in the narratives of the current study. Thus, in addition to the factor of emotional and physical distancing, the estrangement could also be engineered by estranged intimate partners as they would either withhold visits or influence the child or children to turn against their mother (i.e., badmouthing). Lastly, as far as striking a balance between parenthood and drug dependence was concerned, a couple of women in the current study would describe either their parents' or themselves as "functioning addicts," though - in most instances - their subsequent narratives would contradict the ethos of good parenting. This contradiction was not found in previous literature reviewed for this study.

\section{Relevance to Theory}

Several theories can be used to explain, analyze, or discuss parenting experiences of incarcerated mothers (or fathers). However, for this study, three theories - intersectionality, pathways, and attachment - were the most recurring in the reviewed literature, thus speaking to how relevant they may be to women caught at the intersection of prison and motherhood. Narratives from this study's participants seemed to vividly confirm the core tenets of these theories, with intersectionality highlighting the matrix of domination, pathways theory noting the trajectories these women followed into crime, and attachment theory pointing out the effects of prison-induced separation on children.

True, as noted by the Bangkok Rules that women are in prison as a result of direct or indirect intersectional layers of discrimination and deprivation (Penal Reform International, 
2013; UNDOC, 2015) coupled with victimization and subsequent drug dependence (Cobbina, 2021; Quinlan 2019), crimes committed by women in this study were nonviolent and closely linked to poverty (e.g., card fraud, retail theft, drug sale) and most of these women had a history of victimization and substance use. Both intersectionality and pathways theories are captured vividly in the following remarks: "Because my first daughter's dad...he just was not helping me at all. That's when the criminal activity started. I got desperate. I started trying to figure out ways to take care of myself and my daughter, and I did it illegally" [Audrey]; and, "Well I personally, I was sexually abused as a child by my cousin that lived with us, and I think we found out through the [drug treatment] program that that's the core of my addiction - that more than likely the reason why I became an addict like I did [Brooklyn].

According to attachment theory, it is typical for mammalian infants who have been separated from their parents to experience intense distress. This is usually seen through the extraordinary lengths (e.g., crying, clinging, and frantically searching) that these infants would go to prevent separation from their parents or to re-establish proximity to a missing parent (Bowlby, 1982; Fraley, 2021). Similarly, several women in this study described how their children would not want to leave or become sad when it is time to leave after prison visitations (e.g., “...she gets pretty upset when she has to go" or "they don't wanna leave”). In addition, some respondents noted how their children would cry (e.g., "she cries all the time") or have nightmares in the early days of the prison-induced separation (e.g., "He would wake up in the middle of the night, my mom said, screamin' for me for, like, six months, he would do that"). This ties into the extraordinary lengths like clinging and frantic searching mentioned above. 


\section{Strengths and Limitations}

Strengths: Concerning how the data was gathered for the initial study, the open interview method of data collection utilized provided the researcher an opportunity to clarify questioning while gaining a grander understanding of questions sought. Also, given that the interviews were transcribed verbatim, the coding and identification of themes in the current study will reflect the 'verbatim' parenting experiences of the participants. Concerning the present study, one of its strengths is the application of the principles and heuristic devices of Braun and Clarke's (2006) reflexive thematic analysis to ensure analytical rigor. In addition, this strategy enables unanticipated themes and avenues for inquiry to come to light.

Limitations: Even though the secondary data utilized for this study provides some compelling information on the experiences of incarcerated mothers, there are some methodological limitations to it, which may impact even the present research. Foremost, this study will be based on data collected from 46 convenient-sampled interviews conducted on incarcerated mothers participating in a prison family program. Given this, the findings of the present study will not be generalizable and, on that note, should be applied cautiously.

Second, though very rich in substance, data were gathered in an open interview setting. The nature of questioning sought extremely personal and private information about the lives of the participants. Given this, it is possible that some participants might have withheld certain information due to shame or discomfort in reporting. Hence, concerning accuracy and authenticity of the reporting mothers, the data could be questioned.

Lastly, the proportional sample size limitations would be an obvious challenge when it comes to analysis. The unequal numbering (i.e. 13 African American women, 31 Caucasian women, and 2 Asian women) may make it difficult in analysing data and identifying themes of 
similarity and difference. As such, due to smaller numbers in other races, the potential limitation on identifying other themes or patterns will be greater.

\begin{abstract}
A Call to Action
Recent research suggests that women are a fast-growing criminal justice population. A significant number of these women are mothers. In some of these instances they are entering pregnant and/or could be the primary caregiver. As mentioned earlier, available statistics indicate about $64 \%$ of female inmates in state prisons and $80 \%$ in federal prisons are mothers (see Arditti, 2015). According to the U.S. Department of Justice in 2004, 4\% of women in state prisons, 3\% of women in federal prisons, and 6\% of women in jails were pregnant (see Jbara, 2012). Also, most women in these groups (pregnant or primary caretaker) are single parents (see Arditti, 2015; Jbara, 2012; Ramirez, 2016). Conversely, less than one in five incarcerated men are single parents (see Jbara, 2012).
\end{abstract}

Borrowing from these statistics to justify the enormity of the problem at hand, this study sought to examine the parenting experiences of these incarcerated mothers. Also, the need to conduct this study was further exacerbated by the fact that, through social normalization, these women would have served as primary caretakers of children prior to entering prison. Notwithstanding that, almost half of those mothers were reportedly living in a single-parent household. Through an exploratory and secondary analysis approach, this study provided an indepth narrative of what it is or feels like to be 'mothering' from a distance, as well as what their prison-induced fears and perceived barriers are. It is against this backdrop that the analysis yielded four themes - mothering, visitations, fears, and resilience - which is an attempt to explain what these women and their children by extension, experience. At this juncture, the most 
pertinent question is 'what should we do then?' or rather 'what should be done then?' - a call to action. Though not a panacea, the ensuing paragraph offers some suggestions.

As the number of justice-involved women - most of whom are mothers - continue to rise, it is important to make sure their needs are met so they can successfully integrate into the community, which only keeps the public safe. Foremost, it is necessary to address women's unique needs via gender-responsive programming (Bloom, Owen, \& Covington, 2006). Genderresponsive programming acknowledges the following: (1) gender makes a difference; (2) fosters an environment based on safety, respect, and dignity; (3) promotes healthy connections to children, family, significant others, and the community; (4) addresses the web of appropriate social services; (5) address economic needs; and (6) improves coordination between community services (Bloom et al., 2006). Additionally, there is need to create opportunities for incarcerated women to stay involved with the caregiving of their children. When mothers of dependent children are incarcerated, especially those who served as the primary caregiver, it sets in motion a cascade of instability for the children. During imprisonment, mothers can be supported and trained in their parenting and co-parenting skills. Policymakers, prison staff, and management could facilitate this process by providing additional contact opportunities.

\section{Recommendations for Future Research}

Future studies may be conducted in various settings like urban, rural, or even across states, for both comparability of findings and for ensuring that some nuances that may be a result of these factors are captured. Further, future research may focus on interconnections between age/gender of child on prison-induced separation and parental perception of the severity of parent-child estrangement. Also, some research may pay attention to the heterogeneity of justiceinvolved mothers (i.e., race, class, and age of mothers) and the overall impact it has on family. 


\section{REFERENCES}

Abbott, L., Scott, T., Thomas, H., \& Weston, K. (2020). Pregnancy and childbirth in English prisons: institutional ignominy and the pains of imprisonment. Sociology of health \& illness, 42(3), 660-675. https://doi.org/10.1111/1467-9566.13052

AdoptUSKids. (2021). About the Children. https://www.adoptuskids.org/meet-thechildren/children-in-foster-care/about-the-children

Arditti, J. A., \& Few, A. L. (2008). 'Maternal Distress and Women's Reentry into Family and Community Life.' Family Process 47(3): 303-21. https://doi.org/10.1111/j.15455300.2008.00255.x

ARRWIP. (2021). US Prisons: Pregnancy Outcomes in US Prisons. https://arrwip.org/

Artz, L \& Rotmann, B. (2015). Taking “A Count” of Women in Prison. Agenda (Durban), 29(4), 3-13. https://doi.org/10.1080/10130950.2015.1129091

Audi, C. A. F, Santiago, S. M., Andrade, M. G. G \&Francisco, P. M. S. B (2016). Survey on the health conditions of incarcerated women. Saude debate, 40(109), 112-124. http://dx.doi.org/10.1590/0103-1104201610909

Barkauskas, V. H., Low, L. K., \& Pimlott, S. (2002). Health outcomes of incarcerated pregnant women and their infants in a community-based program. Journal of Midwifery \& Women's Health, 47(5), 371-379. https://doi.org/10.1016/S1526-9523(02)00279-9

Barzano, P. (2012). The Bangkok Rules: An international response to the needs of women offenders. Resource Material Series, 90, 81. https://unafei.or.jp/publications/pdf/RS_No90/No90_11VE_Barzano.pdf 
Bauer, S. (2019). American prison: a reporter's undercover journey into the business of punishment. Penguin Books.

Beichner, D \& Hagemann, O. (2016). Incarcerated Women: Their Situation, Their Needs and Measures for Sustainable Reintegration. In H. Kury, S. Redo \& E. Shea (Eds.). Women and Children as Victims and Offenders: Background, Prevention, Reintegration: Suggestions for Succeeding Generations (Volume 2) (pp. 85-116). Cham, Springer International Publishing. https://doi.org/10.1007/978-3-319-28424-8_4

Beichner, D \& Rabe-Hemp, C. (2014). “I Don't Want to Go Back to That Town:” Incarcerated Mothers and Their Return Home to Rural Communities. Critical Criminology (Richmond, B.C.), 22(4), 527-543. https://doi.org/10.1007/s10612-014-9253-4

Bennet, C. (2013, June 25). Low self-esteem: A disposition that can lead to addiction. Psychology Today. https://www.psychologytoday.com/intl/blog/heartachehope/201306/low-self-esteema-disposition-can-lead-addiction

Birgden, A., \& Perlin, M. L. (2009). "Where the home in the valley meets the damp dirty prison": A human rights perspective on therapeutic jurisprudence and the role of forensic psychologists in correctional settings. Aggression and Violent Behavior, 14(4), 256-263. https://doi.org/10.1016/j.avb.2009.04.002

Blackburn Center. (2020, February 26). Black Women and Domestic Violence. https://www.blackburncenter.org/post/2020/02/26/black-women-domestic-violence Bonczar, T. P \& Beck, A. J. (1997). Lifetime Likelihood of Going to State or Federal Prison. Bureau of Justice Statistics. https://bjs.ojp.gov/content/pub/pdf/Llgsfp.pdf 
Bowlby, J. (1982). Attachment and loss (Vol. 3). New York: Basic Books. https://doi.org/10.1177/000306518403200125

Braun, V., \& Clarke, V. (2006). Using thematic analysis in psychology. Qualitative Research in Psychology, 3(2), 77-101. https://doi.org/10.1191/1478088706qp063oa

Braun, V., \& Clarke, V. (2012). Thematic Analysis. In H. Cooper (Ed.), Handbook of research methods in psychology. (vol. 2: Research Designs: pp. 57-71) Washington, DC: APA Books.

Braun, V., \& Clarke, V. (2013). Successful qualitative research: A practical guide for beginners. London: SAGE.

Brennan, T., Breitenbach, M., Dieterich, W., Salisbury, E. J., \& Van Voorhis, P. (2012). Women's pathways to serious and habitual crime: A person-centered analysis incorporating gender responsive factors. Criminal Justice and Behavior, 39(11), 14811508. https://doi.org/10.1177/0093854812456777

Burch, M. (2017). (Re)entry from the Bottom Up: Case Study of a Critical Approach to Assisting Women Coming Home from Prison. Crit Crim 25, 357-374. https://doi.org/10.1007/s10612-016-9346-3

Bureau of Justice Statistics. (2010, March 30). Parents in Prison and Their Minor Children. https://www.bjs.gov/index.cfm?ty=pbdetail\&iid=823 
Burgess-Proctor, A., Huebner, B. M., \& Durso, J. M. (2016). Comparing the effects of maternal and paternal incarceration on adult daughters' and sons' criminal justice system involvement: A gendered pathways analysis. Criminal Justice and Behavior, 43(8), 10341055. https://doi.org/10.1177/0093854816643122

Byrne, C. F., \& Trew, K. J. (2008). Pathways through crime: The development of crime and desistance in the accounts of men and women offenders. The Howard Journal, 47, 238258. https://doi.org/10.1111/j.1468-2311.2008.00520.x

Byvelds, Christie, 1986-, (editor.) \& Jackson, Heather, 1982-, (editor.) (2019). Motherhood and social exclusion. Demeter Press, Bradford, Ontario

Carretero-Trigo, M., Carcedo, R., \& Fernández-Rouco, N. (2021). Correlates of a Positive Parenting Experience in Prison. International Journal of Environmental Research and Public Health, 18(2), 626-. https://doi.org/10.3390/ijerph18020626

Carson, E. A. (2020). Prisoners in 2019. Bureau of Justice Statistics. https://bjs.ojp.gov/content/pub/pdf/p19.pdf

Casey, S., Shlafer, R. J., \& Masten, A. S. (2015). Parental Incarceration as a Risk Factor for Children in Homeless Families. Family Relations, 64(4), 490-504. https://doi.org/10.1111/fare.12155

Cassidy, J., Poehlmann, J., \& Shaver, P. R. (2010). An attachment perspective on incarcerated parents and their children. Attachment \& Human Development, 12(4), 285-288. https://doi.org/10.1080/14616730903417110 
Celinska, K., \& Siegel, J. (2010). Mothers in Trouble: Coping with Actual or Pending Separation from Children due to Incarceration. The Prison Journal (Philadelphia, Pa.), 90(4), 447474. https://doi.org/10.1177/0032885510382218

Chambers, A.N. (2009) Impact of forced separation policy on incarcerated postpartum mothers. Policy, Politics, \& Nursing Practice, 10(3), 204-11. https://doi.org/10.1177/1527154409351592

Charles, P., Muentner, L., \& Kjellstrand, J. (2019). Parenting and Incarceration: Perspectives on Father-Child Involvement during Reentry from Prison. The Social Service Review (Chicago), 93(2), 218-261. https://doi.org/10.1086/703446

Charmaz, K. (2006). Constructing grounded theory: A practical guide through qualitative research. London: Sage.

Child Welfare League of America. (2021). Babies Behind Bars. https://www.cwla.org/babiesbehind-bars/

Chun Tie, Y., Birks, M., \& Francis, K. (2019). Grounded theory research: A design framework for novice researchers. SAGE open medicine, 7, 2050312118822927. https://doi.org/10.1177/2050312118822927

Clarke, Victoria [Victoria Clarke]. (2017, December 9). What is thematic analysis? [Video]. YouTube. https://www.youtube.com/watch?v=4voVhTiVydc\&t=1539s

Clarke, Victoria [Victoria Clarke]. (2019a, June 24). Thematic Analysis Part 1 - Braun, Clarke $\&$ Hayfield [Video]. YouTube. https://www.youtube.com/watch?v=Lor1A0kRIKU\&t=160s 
Clarke, Victoria [Victoria Clarke]. (2019b, June 24). Thematic Analysis Part 2 - Braun, Clarke $\&$ Hayfield [Video]. YouTube. https://www.youtube.com/watch?v=DzMgUGP15S0\&t=107s

Clarke, Victoria. [Victoria Clarke]. (2018, June 25). Thematic Analysis: An Introduction [Video]. YouTube. https://www.youtube.com/watch?v=5zFcC10vOVY

Coan, J. (2016). Towards a neuroscience of attachment. In J. Cassidy \& P. Shaver (Eds.), Handbook of attachment: Theory, research and clinical applications (3rd ed., pp. 242-272). New York: Guilford.

Cobbina, J. E. (2009). From Prison to Home: Women's Pathways In and Out of Crime. [Doctoral dissertation, University of Missouri]. https://www.ojp.gov/pdffiles1/nij/grants/226812.pdf

Cobbina, J. E. (2021, March 17). Feminist Approaches to Justice: Addressing Incarcerated and Reentering Women Worldwide [Webinar]. United Nations Commission on the Status of Women 65. https://ngocsw65forum.us2.pathable.com/meetings/virtual/tTFydYsoSGDnSpmNg

Collica, K. (2010). Surviving incarceration: Two prison-based peer programs build communities of support for female offenders. Deviant Behavior, 31(4), 314-347. https://doi.org/10.1080/01639620903004812

Covington, S. S. (1998). The relational theory of women's psychological development: Implications for the criminal justice system. In R. T. Zaplin (Ed.), Female offenders: Critical perspectives and effective interventions (pp. 135-164). Sudbury, MA: Jones and Bartlett. https://www.centerforgenderandjustice.org/assets/files/14.pdf 
Creswell, J. W., \& Poth, C.N. (2018). Five Qualitative Approaches to Inquiry. Qualitative Inquiry \& Research Design (4 ed., pp. 65-110): Sage.

Crewe, H. (2017). Can Therapeutic Jurisprudence Improve the Rights of Female Prisoners? In Therapeutic Jurisprudence and Overcoming Violence Against Women (pp. 248-263). IGI Global. https://doi.org/10.4018/978-1-5225-2472-4.ch015

Crewe, H. (2020). "No Babies in Prison?" -Norway's Exception Explained. The Cambridge Quarterly, 10.33774/coe-2020-g1f8w. https://www.researchgate.net/publication/344884025_No_Babies_in_Prison_Norway's_Exception_Explained

Cunha, M. I. (2018). Onstage and off: The shifting relevance of gender in women's prisons. In Female Crime and Delinquency in Portugal (pp. 57-74). Palgrave Macmillan, Cham. https://doi.org/10.1007/978-3-319-73534-4_4

Daly, K. (1992). Women's pathway to felony court: Feminist theories of law-breaking and problems of representation. Review of Law and Women's Studies, 2, 11-52.

DeHart, D. (2005). Pathways to Prison: Impact of Victimization in the Lives of Incarcerated Women. Washington, DC: U.S. Department of Justice, National Institute of Corrections. Retrieved from: https://www. ncjrs.gov/pdffiles1/nij/grants/208383.pdf

DeHart, D. (2018). Women's Pathways to Crime: A Heuristic Typology of Offenders. Criminal Justice and Behavior, 45(10), 1461-1482. https://doi.org/10.1177/0093854818782568 
Dodson, K., Cabage, L., \& McMillan, S. (2019). Mothering Behind Bars: Evaluating the Effectiveness of Prison Nursery Programs on Recidivism Reduction. The Prison Journal (Philadelphia, Pa.), 99(5), 572-592. https://doi.org/10.1177/0032885519875037

Dowell, C. M., Mejia., Preen, D. B \& Segal, L. (2018). Maternal incarceration, child protection, and infant mortality: a descriptive study of infant children of women prisoners in Western Australia. Health \& Justice, 6(1), 1-12. https://doi.org/10.1186/s40352-018-0060-y

Duffin, E. (2020). Imprisonment rate of sentenced prisoners in the United States under federal or state jurisdiction in 2019, by sex and ethnicity. Statista. https://www.statista.com/statistics/252871/imprisonment-rate-of-sentenced-prisoners-inthe-us-by-sex-and-ethnicity/

Easterling, B., Feldmeyer, B., \& Presser, L. (2019). Narrating Mother Identities from Prison. Feminist Criminology, 14(5), 519-539. https://doi.org/10.1177/1557085118773457

Eliason, A., Michele, J \& Arndt, S. (2004). Pregnant Inmates: A Growing Concern. Journal of Addictions Nursing, 15(4), 163-170. https://doi.org/10.1080/10884600490888358

Fochi, M., Melo, L., Mendes-Castillo, A., \& Lopes, M. (2020). Mothers' mothering in prison: an experience report of the nursing care project. Revista Brasileira de Enfermagem, 73(3). https://doi.org/10.1590/0034-7167-2018-0932

Foucault, M. (1977). Discipline \& punish: The birth of the prison. New York, NY: Vintage Books. https://www.jstor.org/stable/2737970?seq=1 
Fraley, R. C. (2021). Adult Attachment Theory and Research. University of Illinois at UrbanChampaign.

http://labs.psychology.illinois.edu/ rcfraley/attachment.htm\#: :text=The\%20theory\%20o f\%20attachment $\% 20$ was, been\%20separated\%20from\%20their\%20parents.

Fritz, S \& Whiteacre, A. (2016). Prison nurseries: Experiences of incarcerated women during pregnancy. Journal of Offender Rehabilitation, 55(1), 1-20. https://doi.org/10.1080/10509674.2015.1107001

Garcia, J. (2016). Understanding the Lives of Mothers after Incarceration: Moving Beyond Socially Constructed Definitions of Motherhood: Understanding the Lives of Mothers after Incarceration. Sociology Compass, 10(1), 3-11. https://doi.org/10.1111/soc4.12337

Garcia-Hallett, J. (2019a). Maternal Identities and Narratives of Motherhood: A Qualitative Exploration of Women's Pathways Into and Out of Offending. Feminist Criminology, 14(2), 214-240. https://doi.org/10.1177/1557085118769741

Garcia-Hallett, J. (2019b). "We're Being Released to a Jungle": The State of Prisoner Reentry and the Resilience of Women of Color. The Prison Journal, 99(4), 459-483. https://doi.org/10.1177/0032885519852089

Gardiner, A., Daniel, B., Burgess, C. \& Nolan, L. (2016). The Rose Project: Best for Babies Determining and Supporting the Best Interests and Wellbeing of Babies of Imprisoned Mothers in Scotland. Stirling: University of Stirling. https://www.stir.ac.uk/media/stirling/services/faculties/social-sciences/documents/therose-project-best-for-babies-report.pdf 
Gehring, K. S. (2018). A direct test of pathways theory. Feminist Criminology, 13(2), 115-137. https://doi.org/10.1177/1557085116646195

Gilfus, M. E. (1992). From victims to survivors to offenders: Women's routes of entry and immersion into street crime. Women \& Criminal Justice, 4, 63-89. https://doi.org/10.1300/J012v04n01_04

Gilligan, C. (1982). In a different voice: Psychological theory and women's development. Cambridge, MA: Harvard University Press. https://www.researchgate.net/publication/275714106_In_A_Different_Voice_Psychologi cal_Theory_and_Women's_Development

Glaser, B., \& Strauss, A. (1967). The discovery of grounded theory. London: Weidenfeld and Nicholson.

Glaze, L. E., \& Maruschak, L. M. (2010). Parents in prison and their minor children. Washington, DC: Bureau of Justice Statistics. https://www.bjs.gov/content/pub/pdf/pptmc.pdf

Goffman, A. (2014). On the Run: Fugitive life in an American city. University of Chicago Press.

Gunn, M. (2020). Promoting Recovery Identities Among Mothers with Histories of Addiction: Strategies of Family Engagement. Family Process, 59(1), 94-110. https://doi.org/10.1111/famp.12413

Gurusami, S. (2019). Motherwork Under the State: The Maternal Labor of Formerly Incarcerated Black Women. Social Problems (Berkeley, Calif.), 66(1), 128-143. https://doi.org/10.1093/socpro/spx045 
Haney, L. (2013). Motherhood as Punishment: The Case of Parenting in Prison. Signs, 39(1), 105-130. https://doi.org/10.1086/670815

Harris, M. (2017). Incarcerated Mothers: Trauma and Attachment Issues. Smith College Studies in Social Work, 87(1), 26-42. https://doi.org/10.1080/00377317.2017.1246796

Harris, Y.R., \& Harris, V. (2014). Pathways to Parenting Understanding Addiction Incarceration and Parenting: A Pilot Investigation. Journal of Psychology \& Clinical Psychiatry, 1.

Jbara, A. E. (2012). The price they pay: Protecting the mother-child relationship through the use of prison nurseries and residential parenting programs. Indiana Law Journal, 87(4), 1825-1846.

Johnson S.M. (2019). Attachment Theory. In: Lebow J.L., Chambers A.L., Breunlin D.C. (eds) Encyclopedia of Couple and Family Therapy. Springer, Cham. https://doi.org/10.1007/978-3-319-49425-8_215.

Johnson, A. (2021). The Benefits of Prison Nursery Programs: Spreading Awareness to Correctional Administrators Through Informative Conferences and Nursery Program Site Visits. Journal of the CAS Writing Program, Issue 11, 2018-2019. https://www.bu.edu/writingprogram/journal/past-issues/issue-9/johnson/

Kajstura, A. (2019, October 29). Women's Mass Incarceration: The Whole Pie 2019. Prison Policy Initiative. https://www.prisonpolicy.org/reports/pie2019women.html 
Kapua, P. (2021, March 17). Feminist Approaches to Justice: Addressing Incarcerated and Reentering Women Worldwide [Webinar]. United Nations Commission on the Status of Women 65. https://ngocsw65forum.us2.pathable.com/meetings/virtual/tTFydYsoSGDnSpmNg

Kennedy, S., Mennicke, A., \& Allen, C. (2020). "I took care of my kids": mothering while incarcerated. Health \& Justice, 8(1), 1-14. https://doi.org/10.1186/s40352-020-00109-3

Kimberle Crenshaw. (1991). Mapping the Margins: Intersectionality, Identity Politics, and Violence against Women of Color. Stanford Law Review, 43(6), 1241-1299. https://doi.org/10.2307/1229039

Kolb, A., \& Palys, T. (2018). Playing the part: Pseudo-families, wives, and the politics of relationships in women's prisons in California. The Prison Journal, 98(6), 678-699. https://doi.org/10.1177/0032885518811809

Kreager, D. A., Young, J. T., Haynie, D. L., Schaefer, D. R., Bouchard, M., \& Davidson, K. M. (2021). In the eye of the beholder: Meaning and structure of informal status in women's and men's prisons. Criminology, 59(1), 42-72. https://doi.org/10.1111/1745-9125.12260

Lee, M. Y. H. (2015, April 30). Does the United States really have 5 percent of the world's population and one quarter of the world's prisoners? The Washington Post. https://www.washingtonpost.com/news/fact-checker/wp/2015/04/30/does-the-unitedstates-really-have-five-percent-of-worlds-population-and-one-quarter-of-the-worldsprisoners/

Mariachiara Di Cesare. (2014). Women, marginalization, and vulnerability: Introduction. Genus, 70(2-3), 1-6. http://www.jstor.org/stable/genus.70.2-3.1 
McDermott, C. R. (2019). An intersectional examination of criminally involved women of color with mental illness [Master's thesis, Illinois State University]. Milner Library. https://ir.library.illinoisstate.edu/etd/1155

Mignon, S. (2016). Health issues of incarcerated women in the United States. Ciência \& Saude Coletiva, 21(7), 2051-2060. https://doi.org/10.1590/1413-81232015217.05302016

Miles, M.B., Huberman, A. M., \& Saldaña, J. (2014). Fundamentals of Qualitative Data Analysis. Qualitative data analysis: A methods sourcebook (pp. 1-22). Sage.

Morash, M., Kashy, D. A., Bohmert, M. N., Cobbina, J. E., \& Smith, S. W. (2017). Women at the nexus of correctional and social policies: Implications for recidivism risk. The British Journal of Criminology, 57(2), 441-462. https://doi.org/10.1093/bjc/azv124

Muentner, L., Holder, N., Burnson, C., Runion, H., Weymouth, L., \& Poehlmann-Tynan, J. (2018). Jailed Parents and their Young Children: Residential Instability, Homelessness, and Behavior Problems. Journal of Child and Family Studies, 28(2), 370-386. https://doi.org/10.1007/s10826-018-1265-3

Mukherjee, P. (2014). Mental Health Issues Among Pregnant Women in Correctional Facilities: A Systematic Review. Women \& Health, 54(8), 816-842. https://doi.org/10.1080/03630242.2014.932894

Murray, J., \& Murray, L. (2010). Parental incarceration, attachment and child psychopathology. Attachment \& Human Development, 12, 289-309. https://doi.org/10.1080/14751790903416889 
Nellis, A. (2016). The color of justice: Racial and ethnic disparity in state prisons. The Sentencing Project. https://dataspace.princeton.edu/bitstream/88435/dsp01bz60d032q/1/The-Color-ofJustice-Racial-and-Ethnic-Disparity-in-State-Prisons.pdf

Payne, B. K., Gainey, R. R., \& Carey, C. S. (2005). All in the family: Gender, family crimes, and later criminality. Women \& Criminal Justice, 16, 73-89.

Penal Reform International (PRI). (2013). Toolbox: UN Bangkok Rules on Women Offenders and Prisoners: Short Guide. https://cdn.penalreform.org/wpcontent/uploads/2013/07/PRI-Short-Guide-Bangkok-Rules-2013-Web-Final.pdf

Poehlmann, J. (2005). Representations of Attachment Relationships in Children of Incarcerated Mothers. Child Development, 76(3), 679-696. https://doi.org/10.1111/j.14678624.2005.00871.x

Prison Fellowship. (2021). FAQS About Children of Prisoners: Gain insight into the problems children face when a parent goes to prison. https://www.prisonfellowship.org/resources/training-resources/family/ministrybasics/faqs-about-children-of-prisoners/

Quinlan, C. (2019). Motherhood and Social Exclusion: Narratives of Women in Prison in Ireland. Motherhood and Social Exclusion.

Ramirez, R. (2016). Reentry consideration for justice-involved women. Center for Effective Public Policy. https://www.ojp.gov/library/publications/reentry-considerations-justiceinvolved-women 
Ranjit, Y.S., Azbel, L., Krishnan, A., Altice, F.L \& Meyer, J. P. (2019). Evaluation of HIV risk and outcomes in a nationally representative sample of incarcerated women in Azerbaijan, Kyrgyzstan, and Ukraine. AIDS Care, 31(7), 793-797.

https://doi.org/10.1080/09540121.2019.1573969

Reuters. (2016, October 4). 'Film '13th' traces path from slavery to U.S. mass incarceration.' Reuters, New York. https://www.reuters.com/article/us-film-13th-avaduvernay/film13th-traces-path-from-slavery-to-u-s-mass-incarceration-idUSKCN1241RF

Richie, B. (2001). Challenges incarcerated women face as they return to their communities: Findings from life history reviews. Crime \& Delinquency, 47, 368-389. https://doi.org/10.1177/0011128701047003005

Rioux, P. (2007, January 28). A Chance for a Fresh Start. Times Picayune.

Rippey, S. (2020). Incarcerated Parents and Child Welfare in Washington. Wash. L. Rev., 95, 531. https://digitalcommons.law.uw.edu/wlr/vol95/iss1/15

Rodda, J., \& Beichner, D. (2017). Identifying programming needs of women detainees in a jail environment. Journal of Offender Rehabilitation, 56(6), 373-393. https://doi.org/10.1080/10509674.2017.1339161

Roscigno, V. J., \& Bobbitt-Zeher, D. (2007). Sex discrimination in employment. In V. J. Roscigno (Ed.), The face of discrimination (pp. 57-72). Lanham, MD: Rowman \& Littlefield. 
Rose, S., \& LeBel, T. P. (2017). Incarcerated Mothers of Minor Children: Physical Health, Substance Use, and Mental Health Needs. Women \& Criminal Justice, 27(3), 170-190. https://doi.org/10.1080/08974454.2016.1247772

Rossiter, C., Power, T., Fowler, C., Jackson, D., Hyslop D \& Dawson, A. (2015) Mothering at a Distance: what incarcerated mothers' value about a parenting programme. Contemporary Nurse, 50 (2-3), 238-255. http://dx.doi.org/10.1080/10376178.2015.1105108

Roy, D. (2005). Gatekeeping in Context: Babymama Drama and the Involvement of Incarcerated Fathers. Fathering (Harriman, Tenn.), 3(3), 289-310. https://doi.org/10.3149/fth.0303.289

Saldaña, J. (2016). The coding manual for qualitative researchers. (Sage.2016). The coding manual for qualitative researchers. Sage.

Schlager, M. D. (2018). Through the looking glass: Taking stock of offender reentry. Journal of Contemporary Criminal Justice, 34(1), 69-80.

Severson, M., Postmus, J., \& Berry, M. (2005). Incarcerated women: Consequences and contributions of victimization and intervention. International Journal of Prisoner Health, 1, 223-240. https://doi.org/10.1080/17449200600554611

Shared Justice. (2017). Aging out of the foster care: 18 and on your own. http://www. sharedjustice.org/most-recent/2017/3/30/aging-out-of-foster-care-18-and-onyour-own

Shlafer, R., Duwe, G., \& Hindt, L. (2019). Parents in prison and their minor children: Comparisons between state and national estimates. The Prison Journal, 99(3), 310-328. https://doi.org/10.1177/0032885519836996 
Shoemaker, J. (2017). Development and Implementation of the Health Education and Promotion Module for Incarcerated Mothers: Knowledge Gains and Future Implications. SAGE Open Nursing, 3, 237796081769962-. https://doi.org/10.1177/2377960817699623

Siegel, J. A. 2011. Disrupted Childhoods: Children of Women in Prison. New Brunswick, NJ: Rutgers University Press. https://muse.jhu.edu/book/13869

Silverman, D. (2011). Interpreting qualitative data: A guide to the principles of qualitative research. Los Angeles, CA: Sage

Snyder, H.N., Durose, M.R., Cooper, A. \& Mulako-Wangota, J. (2016). Recidivism Rates of Prisoners with Selected Characteristics Released from Prisons in 30 States in 2005 Female and Male. Generated using the Prisoner Recidivism Analysis Tool - 2005 (PRAT2005). Bureau of Justice Statistics. https://www.bjs.gov/recidivism_2005_arrest/

St. Joseph Institute for Addiction. (2018, June 18). Understanding the relationship between poverty and addiction. https://stjosephinstitute.com/understanding-the-relationshipbetween-poverty-and-addiction/

Stalans, L \& Lurigio, A. J. (2015). Parenting and Intimate Relationship Effects on Women Offenders' Recidivism and Noncompliance with Probation. Women \& Criminal Justice, 25(3), 152-168. https://doi.org/10.1080/08974454.2014.909764

Stringer, E. C. (2009). "Keeping the Faith": How Incarcerated African American Mothers Use Religion and Spirituality to Cope with Imprisonment. Journal of African American Studies (New Brunswick, N.J.), 13(3), 325-347. https://doi.org/10.1007/s12111-0099096-3 
Sufrin, C. (2019). When the Punishment is Pregnancy: Carceral Restriction of Abortion in the United States. Cultural Anthropology, 34(1), 34-40. https://doi.org/10.14506/ca34.1.06

Todd, C \& Frost, N. A. (2014). The Punishment Imperative: The Rise and Failure of Mass Incarceration in America. New York: New York University Press. 71- 158.

Turney, K., \& Goodsell, R. (2018). Parental Incarceration and Children's Wellbeing. The Future of Children, 28(1), 147-164. https://doi.org/10.1353/foc.2018.0007

U.S. Census Bureau. (2020). Quick Facts: United States. https://www.census.gov/quickfacts/fact/table/US/PST045219

United Nations Office on Drugs and Crime (UNODC). (2015). The Bangkok Rules: United Nations Rules for the Treatment of Women Prisoners and Non-custodial Measures for Women Offenders with their Commentary. UNODC. https://www.unodc.org/documents/justice-and-prisonreform/Bangkok_Rules_ENG_22032015.pdf

United States Sentencing Commission. (2013). Quick Facts: Women in the Federal Offender Population. https://www.ussc.gov/sites/default/files/pdf/research-and-publications/quickfacts/Quick_Facts_Female_Offenders.pdf

Vera Institute of Justice. (2004). Hard Data on Hard Times: An Empirical Analysis of Maternal Incarceration, Foster Care, and Visitation. Report, Vera Institute of Justice, New York. http://repositories2.lib.utexas.edu/bitstream/handle/2152/15169/HardData_HardTimes_V era.pdf? sequence 52 
Verona, E., Murphy, B., \& Javdani, S. (2015). Gendered Pathways: Violent Childhood Maltreatment, Sex Exchange, and Drug Use. Psychology of violence, 2015, a0039126. https://doi.org/10.1037/a0039126

Villa, M. (2017). The Mental Health Crisis Facing Women in Prison. The Marshall Project. https://www.themarshallproject.org/2017/06/22/the-mental-health-crisis-facing-womenin-prison

Wacquant, L. (2009). Punishing the poor: The neoliberal government of social insecurity. Durham, NC: Duke University Press. http://www.jstor.org/stable/j.ctv11smrv3.2

Warner, J. (2015). Infants in Orange: An International Model-Based Approach Prison Nurseries. Hastings Women's Law Journal, 26

(1). https://repository.uchastings.edu/hwlj/vol26/iss 1/5

Williams, J. M., Spencer, Z., \& Wilson, S. K. (2020). I am Not Your Felon: Decoding the Trauma, Resilience, and Recovering Mothering of Formerly Incarcerated Black Women. Crime \& Delinquency. https://doi.org/10.1177/0011128720974316

Wismont, J. (2000). The lived pregnancy experience of women in prison. Journal of Midwifery \& Women's Health, 45(4), 292-300. https://doi.org/10.1016/S1526-9523(00)00034-9

World Health Organization. (2013). Global and regional estimates of violence against women: prevalence and health effects of intimate partner violence and non-partner sexual violence. WHO Geneva, 47. https://www.who.int/publications/i/item/9789241564625

World Health Organization. (2020). Global mental health: How are we doing? World Health Organization. https://www.mhinnovation.net/global-mental-health-how-are-we-doing 
World Prison Brief. (2021). United States of America: Female Prison Population Trend. Institute for Crime \& Justice Policy Research. https://www.prisonstudies.org/country/unitedstates-america

Zaitzow, B. H. (2003). Doing gender in a women's prison: Women in prison. Gender and social control, 21-38. https://www.rienner.com/title/Women_in_Prison_Gender_and_Social_Control

Zhao, Q., Cepeda, A., Chou, C.-P., \& Valdez, A. (2020). Incarceration Trajectories of Women Who Are Mothers: A Nationally Representative Study of State and Federal Prisoners. Crime \& Delinquency. https://doi.org/10.1177/0011128720974315 


\section{APPENDIX: ORIGINAL RESEARCH QUESTIONS FROM DR. BEICHNER'S}

\section{STUDY}

[1] explore participants' parenting experiences pre-incarceration (i.e., Were the children residing with participant? Was she the primary care provider? What was the nature of her relationship with the child(ren)?)

[2] examine participants' motivations for enrolling in the parenting program (i.e., Does she feel that her experiences with her parents did/did not prepare her to become a parent? Is she participating as a means to address past parenting issues she confronted prior to her incarceration?)

[3] establish the nature (i.e., telephone, mail correspondence, face-to-face supervised visitation, overnight visitation) and frequency (i.e., daily, weekly, bi-monthly, monthly, bi-annually, annually) of communication between participant and child(ren)

[4] develop an understanding of respondents' perceptions of the quality of the relationships with their child(ren) (i.e., Does the respondent believe that the relationship is one in which she can engage in meaningful parenting or does her confinement preclude her from having such a relationship with her child(ren)?)

[5] understand the respondents' perceptions of the effects of incarceration on their child(ren) (i.e., Has the respondent observed any behavioral changes in her child(ren) since she has become incarcerated? What related concerns does she have with the child(ren)'s wellbeing during this period of confinement?)

[6] document the respondents' evaluations of the parenting programs in meeting their needs and those of their substitute caregivers and child(ren) (i.e., If the respondent had dysfunction in her own family unit, does the program provide any curricular components to address these issues? 
Similarly, if there were issues with domestic violence or child abuse in her past, does the program address these problems? Does the program provide the mother and child(ren) the necessary resources to establish and maintain bonds/attachments? Are there any suggestions for improvement or any unmet needs?) Also establish who the primary caregiver has been in her absence.

[7] determine participants' plans for reunification post-release from the correctional center (i.e., Will the respondent act as the primary care provider for her child(ren) following her release? What kinds of support will her family provide for her in making this transition?) [8] establish what other programming she was involved in while incarcerated at DCC (i.e., employment, educational programs, seeking safety course, etc.) 